\title{
PALEOCEANOGRAPHY OF THE ATLANTIC- MEDITERRANEAN EXCHANGE: OVERVIEW AND FIRST QUANTITATIVE ASSESSMENT OF CLIMATIC FORCING
}

\author{
M. Rogerson, ${ }^{1}$ E. J. Rohling, ${ }^{2}$ G. R. Bigg, ${ }^{3}$ and J. Ramirez ${ }^{1}$ \\ Received 2 October 2011; revised 10 March 2012; accepted 18 March 2012; published 9 May 2012.
}

[1] The Mediterranean Sea provides a major route for heat and freshwater loss from the North Atlantic and thus is an important cause of the high density of Atlantic waters. In addition to the traditional view that loss of fresh water via the Mediterranean enhances the general salinity of the North Atlantic, and the interior of the eastern North Atlantic in particular, it should be noted that Mediterranean water outflowing at Gibraltar is in fact cooler than compensating inflowing water. The consequence is that the Mediterranean is also a region of heat loss from the Atlantic and contributes to its large-scale cooling. Uniquely, this system can be understood physically via the constraints placed on it by a single hydraulic structure: the Gibraltar exchange. Here we review the existing knowledge about the physical structure of the Gibraltar exchange today and the evidential basis for arguments that it has been different in the past. Using a series of quantitative experiments, we then test prevailing concepts regarding the potential causes of these past changes. We find that (1) changes in the vertical position of the plume of Mediterranean water in the Atlantic are controlled by the vertical density structure of the Atlantic; (2) a prominent Early Holocene "contourite gap" within the Gulf of Cadiz is a response to reduced buoyancy loss in the eastern Mediterranean during the time of "sapropel 1" deposition; (3) changes in buoyancy loss from the Mediterranean during MIS3 caused changes in the bottom velocity field in the Gulf of Cadiz, but we note that the likely cause is reduced freshwater loss and not enhanced heat loss; and (4) strong exchange at Gibraltar during Atlantic freshening phases implies that the Gibraltar exchange provides a strong negative feedback to reduced Atlantic meridional overturning. Given the very counterintuitive way in which the Strait of Gibraltar system behaves, we recommend that without quantitative supporting work, qualitative interpretations of how the system has responded to past external forcing are unlikely to be robust.

Citation: Rogerson, M., E. J. Rohling, G. R. Bigg, and J. Ramirez (2012), Paleoceanography of the AtlanticMediterranean exchange: Overview and first quantitative assessment of climatic forcing, Rev. Geophys., 50, RG2003, doi:10.1029/2011RG000376.

\section{INTRODUCTION}

[2] Exchange of water between the Mediterranean Sea and Atlantic Ocean through the Strait of Gibraltar exerts a major control on circulation in the Mediterranean [Bryden and Stommel, 1984], and also significantly influences the hydrography of the eastern North Atlantic [Johnson and Stevens,

\footnotetext{
${ }^{1}$ Geography Department, University of Hull, Hull, UK.

${ }^{2}$ School of Ocean and Earth Science, University of Southampton, National Oceanography Centre, Southampton, UK.

${ }^{3}$ Department of Geography, University of Sheffield, Sheffield, UK.

Corresponding author: M. Rogerson, Geography Department, University of Hull, Cottingham Road, Hull HU6 7RX, UK. (m.rogerson@hull.ac.uk)
}

2000]. Beyond the immediate impact of the plume of warm and saline water formed by the Mediterranean Outflow, which is a prominent feature between $20^{\circ} \mathrm{N}$ and $50^{\circ} \mathrm{N}$ as far west as $30^{\circ} \mathrm{W}$ [Iorga and Lozier, 1999], water mass transformation in the Gulf of Cadiz drives the formation of the Azores frontal system [Jia, 2000; Özgökmen et al., 2001]. This effectively traps a warm and saline pool of water, the "Madeira Mode" water, south of $35^{\circ} \mathrm{N}$ [Pollard and Pu, 1985] (Figure 1). Moreover, as surface water flowing into the Mediterranean is both warmer $\left(16.6^{\circ} \mathrm{C}-22.6^{\circ} \mathrm{C}\right.$, varying seasonally) and less saline $\left(\sim 36.5 \mathrm{~S}_{\mathrm{p}}\right)$ than the subsurface outflowing water $\left(\sim 12.9^{\circ} \mathrm{C}\right.$ and $\left.\sim 38.5 \mathrm{~S}_{\mathrm{p}}\right)$ [MEDAR Group, 2002], the action of the Gibraltar exchange enhances North Atlantic density, which helps to precondition the North Atlantic for deep convection [Bigg et al., 2003]. 


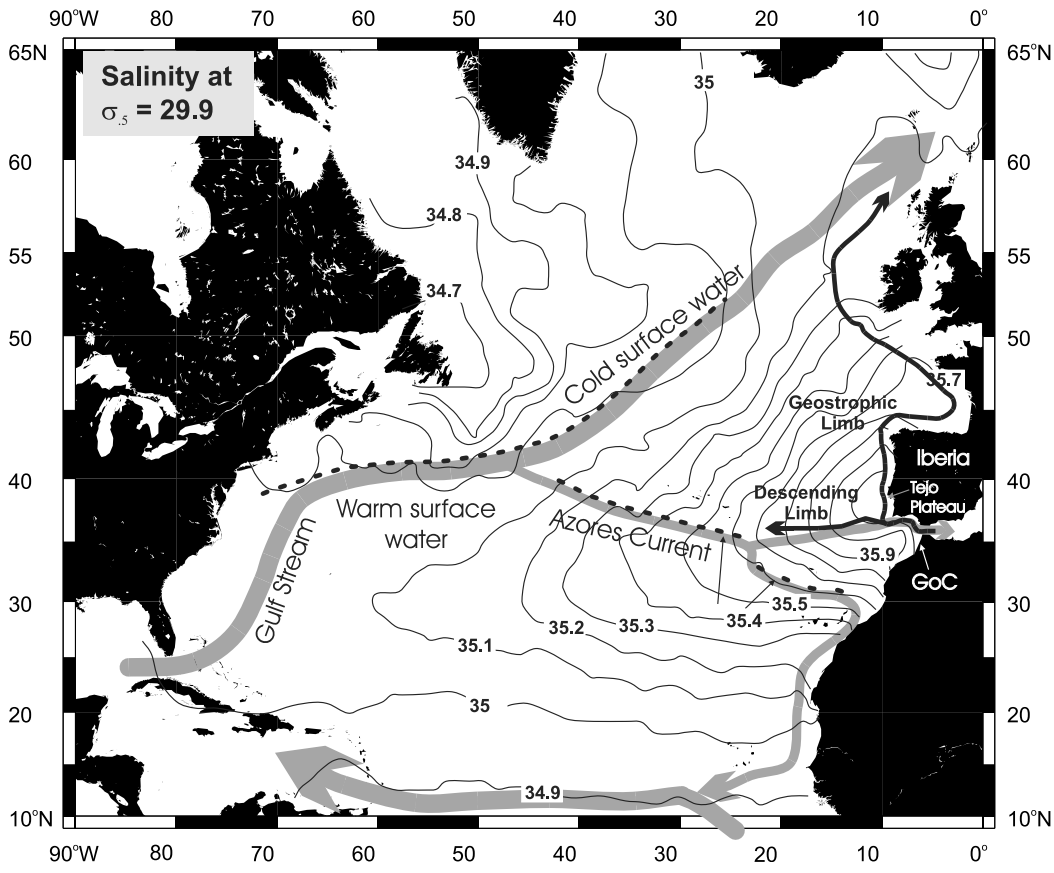

Figure 1. Schematic surface circulation (gray lines with arrows) and pathway (black lines with arrows) of the Mediterranean Outflow Water in the North Atlantic. Dashed lines show major fronts. Contours show salinity at the mid-depth isopycnal typical of the modern Mediterranean Outflow derived from the mean climatology of Iorga and Lozier [1999]. GoC is Gulf of Cadiz.

[3] Considering its role in net freshwater export alone, the Mediterranean is a significant player in North Atlantic density enhancement. Of the $\sim 0.18 \mathrm{~Sv}\left(1 \mathrm{~Sv}=10^{6} \mathrm{~m}^{3} \mathrm{~s}^{-1}\right)$ of net freshwater loss experienced by the North Atlantic system [Broecker, 1991], around 0.05 Sv is lost via net evaporation from the Mediterranean [Bethoux, 1979]. It remains controversial whether the Mediterranean Outflow Water directly penetrates the Nordic Seas [Reid, 1979], with several authors providing evidence against this notion [Hill and MitchelsonJacob, 1993; New et al., 2001]. However, recent reanalysis of regional climatology data indicates that Mediterranean water does indeed pass directly into the Nordic Seas, albeit only under high-index conditions of the North Atlantic Oscillation [Lozier and Stewart, 2008]. The remaining Mediterranean water that fails to penetrate northward of the GreenlandScotland ridge is thought to be mixed to the surface during deep winter convection to the west of Ireland, within the path of the North Atlantic Drift [New et al., 2001]. Consequently, it now seems beyond question that the North Atlantic density enhancement driven by the Gibraltar exchange is transferred to key sites of NADW formation or modification, either directly (high NAO) or indirectly (low NAO).

[4] Although circulation modeling generally suggests a small impact from altering conditions at Gibraltar [Rahmstorf, 1998], some impact is a robust feature of these models [Bigg et al., 2003]. Recent investigation of this impact, using a coupled model and a Mediterranean Outflow parameterization that follows the marginal sea boundary condition approach [Price and Yang, 1998], showed that without connection at Gibraltar, meridional overturning in the Atlantic would be slowed by about $15 \%$, while sea surface temperature in the
North Atlantic would be reduced by up to $1^{\circ} \mathrm{C}[W u$ et al., 2007]. Although it may not be the dominant control on deep convection in the Atlantic, the modern Gibraltar exchange therefore is undoubtedly capable of altering it. As a consequence, it is essential that the behavior of the Gibraltar exchange is constrained in order to understand the Atlantic Meridional Overturning Circulation under states that were different to that of today. Fortunately, the oceanic areas adjacent to the strait, both to the east (Alboran Sea) and to the west (Gulf of Cadiz; Figure 2a), have thick deposits of sediment from which records of the past exchange can be extracted.

[5] On millennial timescales, the Gibraltar exchange can be considered a mechanism of enhancing Atlantic density which is controlled by temperature and humidity of air over the Mediterranean basin, runoff from North Africa and southern Europe and the properties of the part of the eastern North Atlantic abutting the Iberian and Moroccan margins. Climatically driven changes in highly diverse parts of the Earth system are therefore integrated by the Mediterranean, transferred to the North Atlantic as a change in its density budget and ultimately transmitted to the Atlantic Meridional Overturning Circulation as the primary means to balance these changes in the density budget. Southern high latitude correlates with reduced sea level (cf. higher coherence of sea level records with Antarctic temperature than Greenland temperature [Rohling et al., 2009]) and consequently with reduced Gibraltar exchange flux (higher density, deeper settling in the open Atlantic). This will tend to weaken the degree to which Mediterranean-derived water can affect the properties of surface water in the North Atlantic. Given the remarkable 


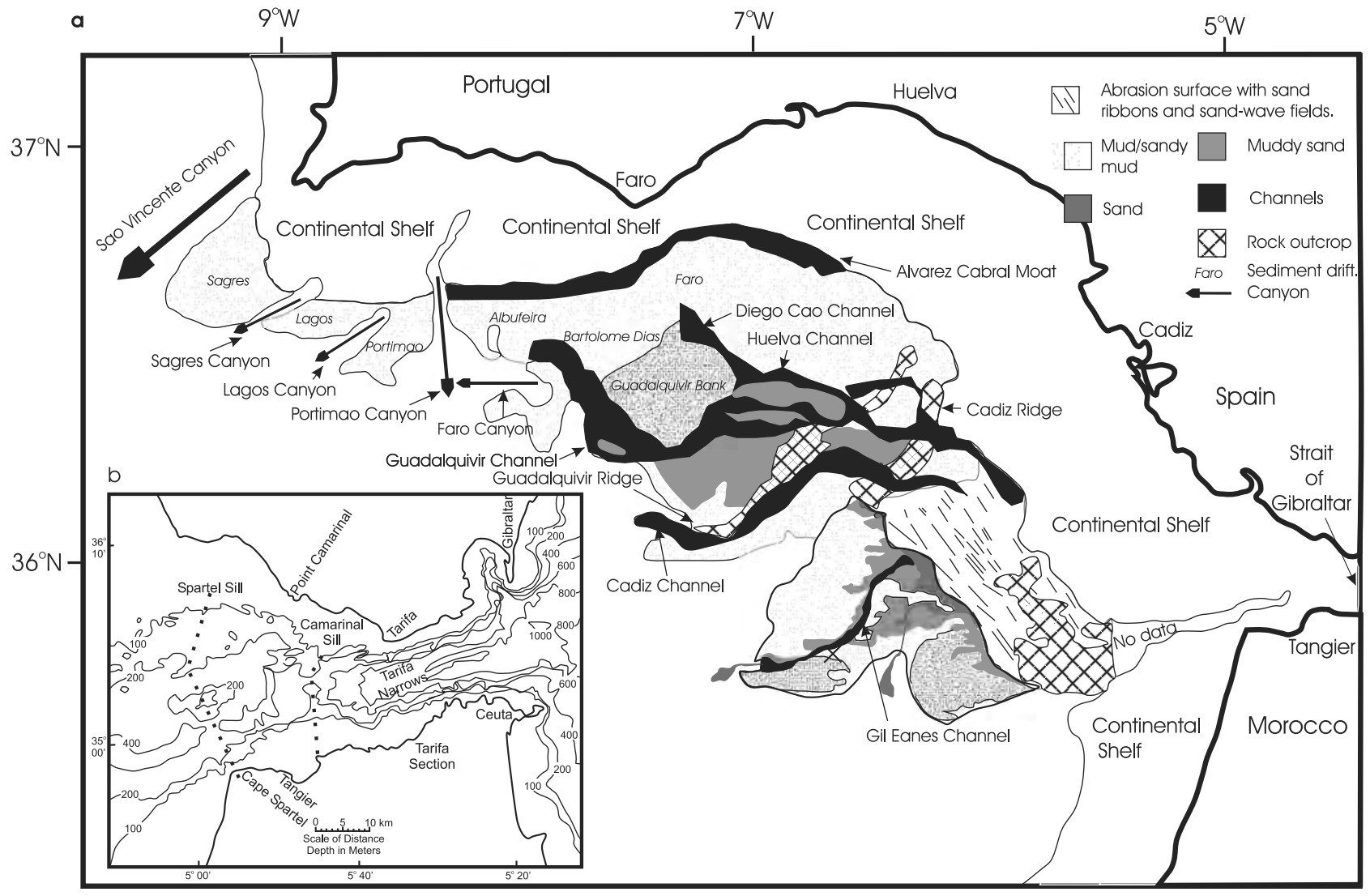

Figure 2. (a) Surface sediment in the Gulf of Cadiz showing the flowpath of the Mediterranean Outflow (modified from Hernández-Molina et al. [2003] and Rogerson et al. [2005]). (b) Topography of the Strait of Gibraltar, from Lacombe and Richez [1982].

coherence between Mediterranean and Greenland temperatures [Cacho et al., 1999], northern high-latitude cooling will enhance temperature loss from Mediterranean water (enhancing buoyancy loss) but also reduce evaporation (reducing buoyancy loss) and so plays an ambiguous role in regulating the role of the Gibraltar exchange in controlling North Atlantic water masses. Low-latitude changes in atmospheric circulation and the latent heat pump alter the latitude and magnitude of the African summer monsoon [Gasse and van Campo, 1994], with the consequence that the Nile and other North African rivers considerably alter the flux of runoff water to the eastern Mediterranean basin [Revel et al., 2010]. More northerly and higher-magnitude monsoon rainfall would be expected to reduce the Gibraltar exchange, reducing buoyancy loss from the North Atlantic. Conversely, freshening of the Atlantic arising from a collapse in meridional overturning must have the consequence of considerably enhancing flow through Gibraltar [Rogerson et al., 2010]; under these circumstances the Mediterranean conceptually becomes a capacitor for salt and the Gibraltar exchange becomes an important means of competing with Arctic freshening and maintaining the overturning circulation.

[6] Here we assess the state of knowledge derived from sediment records and consider to what extent this knowledge can be used to constrain the past hydraulics of the Gibraltar exchange, and therefore the degree to which the Mediterranean circulation acts in concert or inversely with
North Atlantic circulation. We first review the physical knowledge of hydraulic structures associated with the Gibraltar exchange today, and then the paleoceanographic knowledge of the exchange in the past (qualitatively and quantitatively). Finally, we provide an overview of outstanding problems that paleoceanographers and dynamicists face in determining the range of possible behaviors of the Gibraltar exchange.

\section{THEORETICAL CONSTRAINTS ON THE GIBRALTAR EXCHANGE}

\subsection{The Exchange as a 2-Layer System}

[7] Exchange of water through the Strait of Gibraltar occurs because the Mediterranean basin has a high net evaporation, ( 0.5 to $\left.0.8 \mathrm{~m} \mathrm{yr}^{-1}\right)$, which results in a net export of atmospheric water out of the basin [Bethoux, 1979; Bethoux and Gentili, 1999; Bryden and Kinder, 1991; Garrett et al., 1990; Millot et al., 2006]. This freshwater export combined with strong cooling in the northern sectors of the Mediterranean Sea results in the formation of substantially higher density waters within the Mediterranean $\left(\sigma_{\theta} \approx\right.$ $\left.1029.2 \mathrm{~kg} \mathrm{~m}^{-3}\right)$ compared to surface water in the adjacent Atlantic $\left(\sigma_{\theta} \approx 1026.78 \mathrm{~kg} \mathrm{~m}^{-3}\right)$ (see Table 1). The thermohaline parts of the circulation within the Mediterranean, and the impact of Mediterranean Outflow Water on the thermohaline circulation within the North Atlantic, are both 


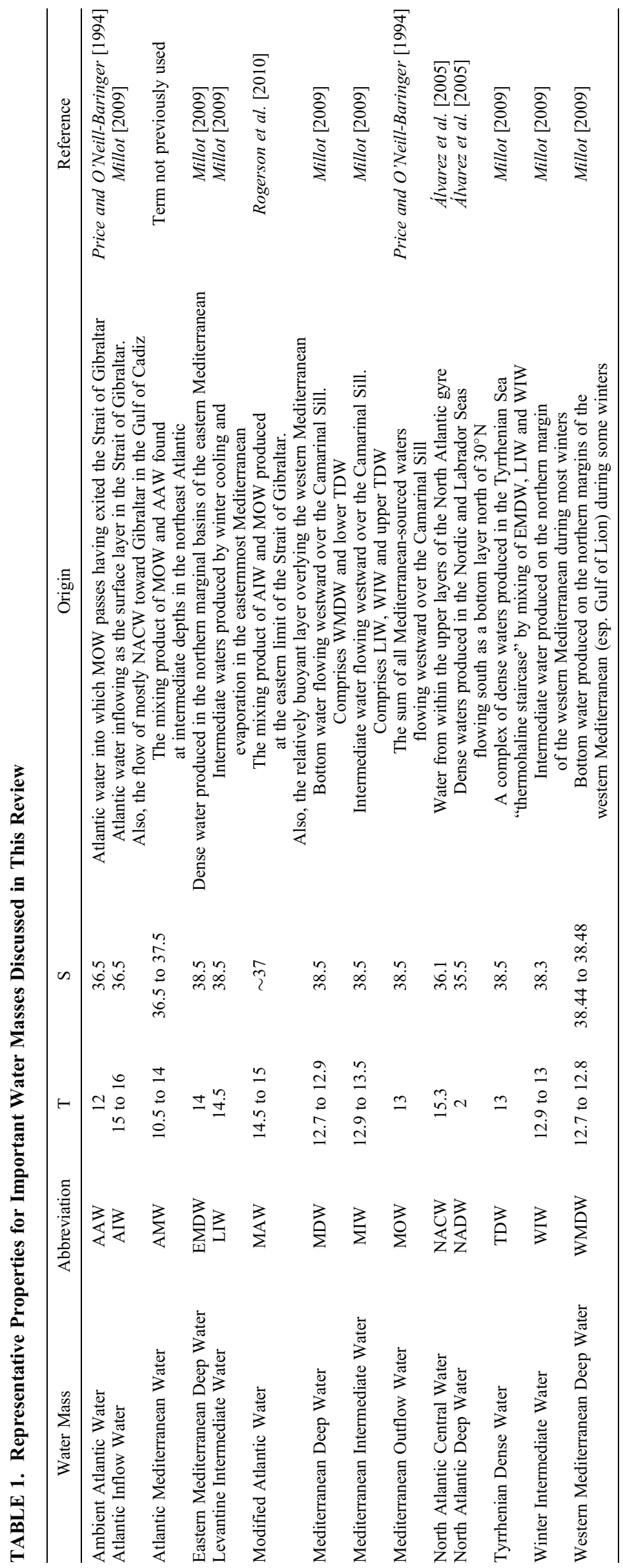

4 of 32 

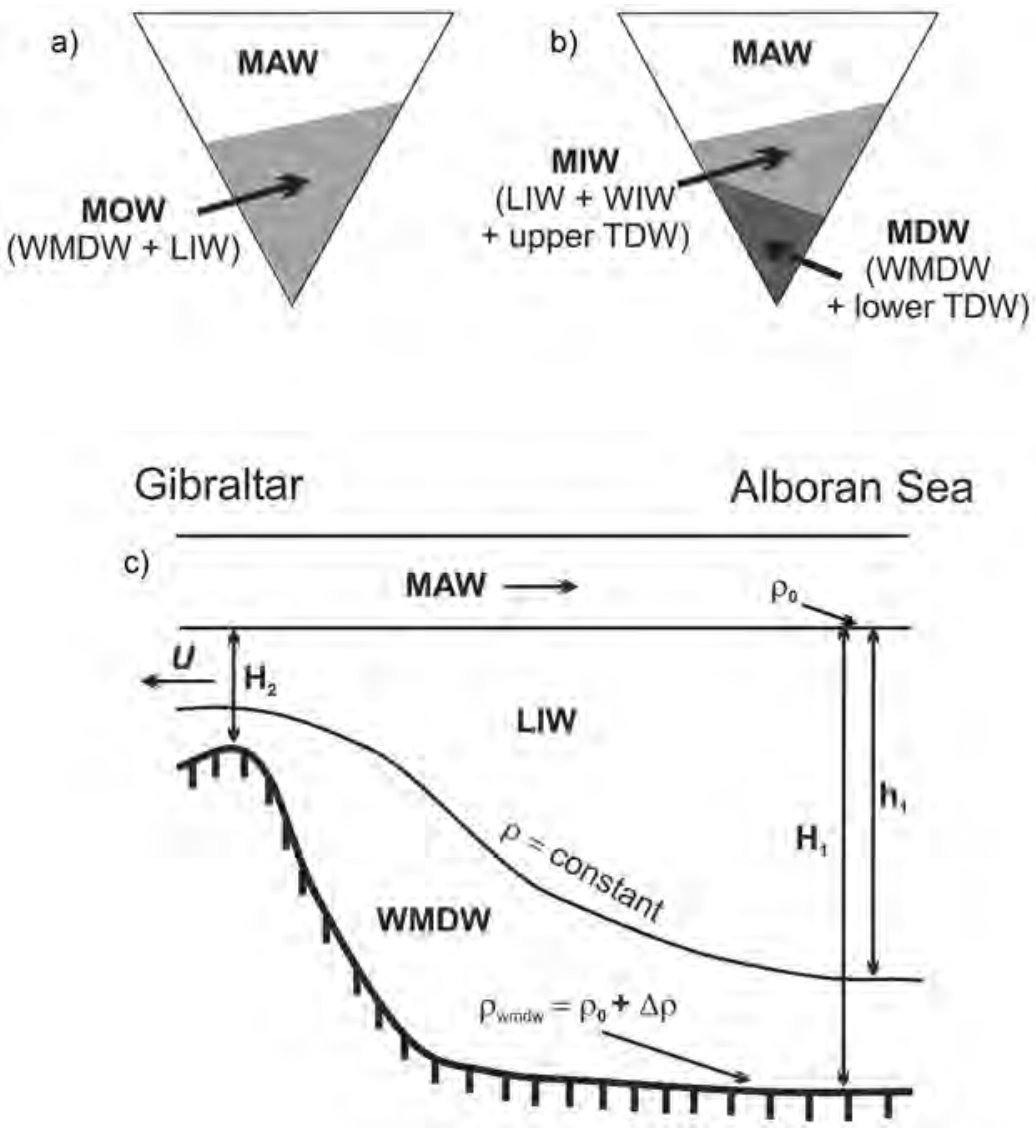

Figure 3. (a) Two-layer formulation of the Gibraltar exchange [Bryden et al., 1994]. (b) Three-layer formulation of the Gibraltar exchange [Millot, 2009]. MAW, Modified Atlantic Water; MOW, Mediterranean Outflow Water; WMDW, Western Mediterranean Deep Water; LIW, Levantine Intermediate Water; TDW, Tyrrhenian Dense Water; WIW, Winter Intermediate Water; MDW, Mediterranean Deep Water; MIW, Mediterranean Intermediate Water. (c) Schematic diagram showing aspiration of MDW from the Gulf of Lion; $\rho_{\text {WMDW }}$ is density of WMDW, $\rho_{0}$ is the density of surface water, $H_{1}$ is the depth of the Alboran Sea, $H_{2}$ is the depth at the Camarinal Sill, $h_{1}$ is the lowest depth from which water can be aspirated over the Camarinal Sill, $U$ is the maximum velocity of outflowing water at the Camarinal Sill, and $\Delta \rho$ is the density difference between surface and bottom water in the Alboran Sea.

expressions of the ocean system adjusting to this buoyancy loss [Bryden and Stommel, 1984].

[8] The Gibraltar exchange itself is regulated by the hydraulics of the specific configuration of the $60-\mathrm{km}$-long sill-and-narrows system of the Gibraltar Strait [Armi and Farmer, 1986; Farmer and Armi, 1986]. Direct control on the inflow is exerted by the width of the narrowest section, the Tarifa Narrows (Figure 2b), which is a 12-km-wide section within the generally $\sim 15-\mathrm{km}$-wide strait. In addition, the inflow primarily balances mass loss via net evaporation and outflow, and thus is indirectly regulated by the depth of the shallowest sill [Bryden et al., 1988, 1994]. The lateral expansion of this layer to the east of the Tarifa Narrows combined with frictional forcing from the counterflowing water below means that some upwelling occurs within the strait, converting pure Atlantic water into a cooler and more saline water mass, the Modified Atlantic Water $(M A W)$. (Italicized terms are defined in the glossary, after the main text.) The Strait of Gibraltar has two significant sills. The Camarinal Sill has a maximum depth of $284 \mathrm{~m}$ and extends from Point Paloma (Spain) to Point Altares (Morocco) and is the critical sill in regulating the exchange. The Spartel Sill lies to the west of the Camarinal Sill, and together these sills delimit the relatively deep Tangier Basin (depth $450 \mathrm{~m}$ ). Though it has little effect on the flow through the Straits, the Spartel Sill has a profound effect on variability in the flux of Mediterranean water as it enters the Atlantic [Thorpe, 1976].

[9] For true hydraulic control on the Gibraltar exchange to be assumed, it must be shown that the two-layer flow across the Camarinal Sill (Figure 3a) passes through at least one hydraulic jump, which is a point at which the flow becomes nonturbulent [Kinder et al., 1988]. Under these conditions, the flow is termed critical, and the exchange is termed maximal [Armi and Farmer, 1986, 1988; Farmer and Armi, 1986, 1988]. Measurements of the exchange indicate that the flow over the sill becomes supercritical (i.e., the water itself is moving faster than Rayleigh waves within it are able to travel) during almost every tidal cycle, and that approximately half of the outflow flux is achieved under critical flow during the falling tide [Bryden et al., 1988]. The Gibraltar 


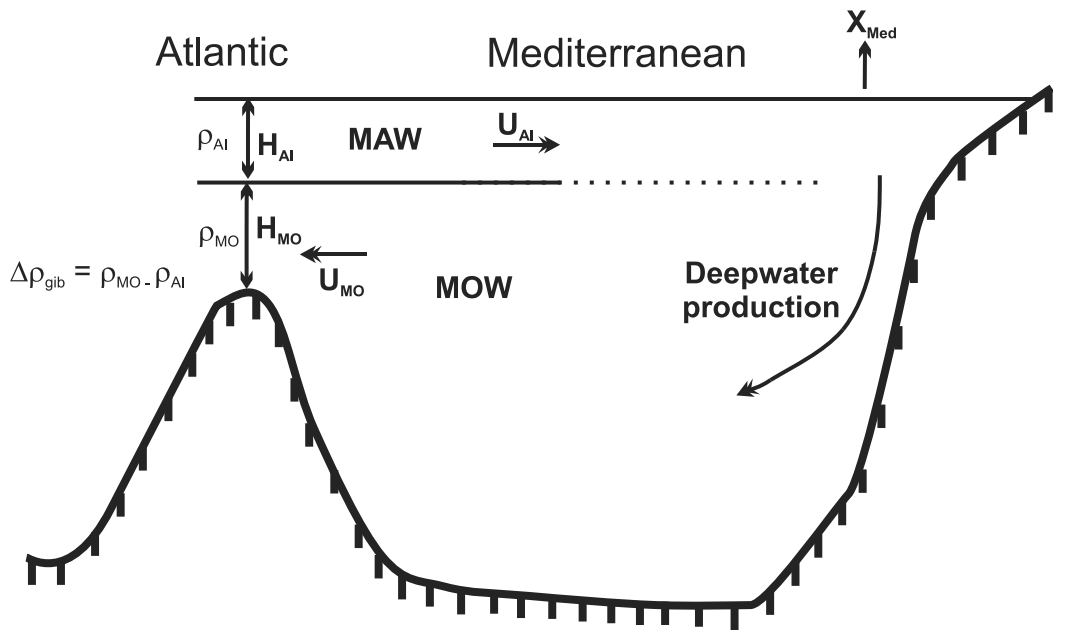

Figure 4. Schematic representation of the budgets of the Mediterranean Sea. MOW, Mediterranean Outflow Water. MAW, Modified Atlantic Water. $\Delta \rho_{\text {gib }}$ is the density difference between inflowing and outflowing water at Gibraltar; $\rho_{\mathrm{MO}}$ and $\rho_{\mathrm{AI}}$ are the densities of outflowing Mediterranean and inflowing Atlantic waters, respectively. $H_{\mathrm{AI}}$ and $H_{\mathrm{MO}}$ are the heights of the inflowing and outflowing layers at the Camarinal Sill, and $U_{\mathrm{AI}}$ and $U_{\mathrm{MO}}$ are the velocities of these layers, respectively. $X_{\mathrm{med}}$ is the net evaporative flux from the Mediterranean.

exchange may thus practically be assumed to be very near maximal [Bryden et al., 1988; Bryden and Kinder, 1991]. This permits analysis of the exchange as maximal at times in the past when it is at least as restricted as today, though this may not be appropriate when exchange conditions are relaxed [Matthiesen and Haines, 2003; Rohling and Bryden, 1994]. The most likely times to expect submaximal exchange would be during periods of significantly higher sea level, which have not occurred since the Pliocene [Lisiecki and Raymo, 2005]. During such times it should be borne in mind that the conditions below would not be met, significantly reducing the capacity of the Mediterranean to develop waters substantially more dense than the Atlantic.

[10] For the flow to be considered supercritical, the twolayer Froude number $\left(G^{2}\right)$ must exceed 1:

$$
G^{2}=\left(u_{\mathrm{AI}}^{2} / g^{\prime} H_{\mathrm{AI}}\right)+\left(u_{\mathrm{MO}}^{2} / g^{\prime} H_{\mathrm{MO}}\right) \geq 1
$$

where $u_{\mathrm{AI}}$ and $u_{\mathrm{MO}}$ are the velocities of the upper and lower layer, respectively (Figure 4$), H_{\mathrm{AI}}$ and $H_{\mathrm{MO}}$ are the thicknesses of the upper and lower layers, respectively, and $g^{\prime}=$ $g \beta\left(S_{\mathrm{MO}}-S_{\mathrm{AI}}\right) / \rho_{2}$ where $\beta$ is the coefficient for saline contraction $\left(0.77 \mathrm{~kg} \mathrm{~m}^{-3} \mathrm{~S}_{\mathrm{p}}^{-1}\right), g$ is the acceleration due to gravity and $S_{\mathrm{AI}}$ and $S_{\mathrm{MO}}$ are the salinities of the inflowing and outflowing layers, respectively (a full list of parameters is shown in Table 2). Assuming that the exchange is maximal and that the Camarinal Sill is triangular in cross section, the fluxes of the Mediterranean Outflow $(M O)$ and Atlantic Inflow $(A I)$ can be estimated by a simple geometric relationship [Bryden and Kinder, 1991]:

$$
Q_{A I}-Q_{M O}=C \frac{D_{s} b_{s}}{2} \sqrt{g^{\prime} D_{s}}
$$

Here $Q_{\mathrm{AI}}$ is the flux of inflowing Atlantic water, $Q_{\mathrm{MO}}$ is the flux of $\mathrm{MO}$ (and is a negative value), $b_{s}$ is sill width,
$D_{s}$ is water depth at the sill and $C$ is a constant that depends on the physical configuration of the strait $(\sim 0.28$ in this case) [Bryden, 1993]. Lowering sea level (as has occurred repeatedly in the past) will therefore reduce the exchange through the Strait of Gibraltar by reducing both $D_{s}$ and $b_{s}$. Combining equation (2) with a statement of mass conservation, it is possible to show that the salinity contrast between the Mediterranean and Atlantic at Gibraltar is essentially determined by the maximal exchange and the net evaporation in the Mediterranean [Bryden and Kinder, 1991]:

$$
Q_{A I}-Q_{M O}=\frac{2 S_{A l}+\Delta S_{g i b}}{\Delta S_{g i b}} X_{M e d}
$$

Here $X_{\text {med }}$ is net evaporation from the Mediterranean basin and $\Delta S_{\text {gib }}$ is the salinity contrast between the inflow and outflow at Gibraltar. This simple relationship means that low fluxes at Gibraltar will result in high salinities in the Mediterranean, giving the system a strong dependence on sea level.

[11] Modern estimates of the exchanged fluxes are generally based on measurements taken during the Gibraltar Experiment of the 1980s, which suggested an outflow value of $0.68 \times 10^{6} \mathrm{~m}^{3} \mathrm{~s}^{-1}$, with a corresponding inflow flux estimate of $0.72 \times 10^{6} \mathrm{~m}^{3} \mathrm{~s}^{-1}$ [Bryden et al., 1994]. Subsequent analysis, combined with higher-resolution hydrography, provided estimates of transport through Gibraltar of $0.57 \pm$ $0.26 \mathrm{~Sv}$ for the outflow and $0.66 \pm 0.47 \mathrm{~Sv}$ for the inflow [Tsimplis and Bryden, 2000]. Although these values are lower than traditional estimates [Lacombe and Richez, 1982], they are consistent with estimates derived from the steady state hydraulic model outlined in equations (1)-(3) [Bryden and Kinder, 1991]. However, the exchange can be quite variable, and during part of their survey, Tsimplis and Bryden [2000] observed a net inflow of only $0.156 \pm 0.018 \mathrm{~Sv}$. More 
TABLE 2. List of Parameters Used in This Study

\begin{tabular}{|c|c|c|c|}
\hline Symbol & Parameter & $\begin{array}{c}\text { Value } \\
\text { (if Constant) }\end{array}$ & Units \\
\hline$\Phi$ & Mixing coefficient & & \\
\hline$B_{\text {geo }}$ & Geostrophic buoyancy flux & & $\mathrm{m}^{3} \mathrm{~s}^{-3}$ \\
\hline$U_{\text {geo }}^{500}$ & Geostrophic velocity & & $\mathrm{m} \mathrm{s}^{-1}$ \\
\hline$g^{\prime}$ & Reduced gravity & & \\
\hline$\pi$ & Bottom gradient & & o \\
\hline$f$ & Coriolis parameter & 0.000084 & \\
\hline$H_{\text {src }}$ & Height of MOW plume at source & & $\mathrm{m}$ \\
\hline$K_{\text {geo }}$ & Geostrophic Ekman number & & \\
\hline$x$ & $\begin{array}{l}\text { Distance from source of } \\
\text { entrainment "event" }\end{array}$ & 100,000 & $\mathrm{~m}$ \\
\hline$W_{\text {src }}$ & Width of MOW plume at source & & $\mathrm{m}$ \\
\hline$g$ & Acceleration due to gravity & 9.81 & $\mathrm{~m} \mathrm{~s}^{-2}$ \\
\hline$\rho_{\mathrm{MO}}$ & Density of Mediterranean water & & $\mathrm{kg} \mathrm{m}^{-3}$ \\
\hline$\rho_{\mathrm{ATL}}$ & Density of inflowing Atlantic water & & $\mathrm{kg} \mathrm{m}^{-3}$ \\
\hline$D_{\text {settling }}$ & Mean settling depth of AMW & & $\mathrm{m}$ \\
\hline$\Delta \rho_{\mathrm{MO}}$ & $\begin{array}{l}\text { Density difference of } \\
\text { Mediterranean and Atlantic water }\end{array}$ & & $\mathrm{kg} \mathrm{m}^{-3}$ \\
\hline$D_{s}$ & Depth of water at the Camarinal Sill & & $\mathrm{m}$ \\
\hline$h^{\prime}$ & Global sea level change & & $\mathrm{m}$ \\
\hline$\partial \rho / \partial z$ & Atlantic vertical density gradient & & $\mathrm{kg} \mathrm{m}^{-4}$ \\
\hline$Q_{\mathrm{MO}}$ & Flux of MOW & & Sv \\
\hline$\Delta S_{\text {gib }}$ & $\begin{array}{c}\text { Salinity difference between Atlantic } \\
\text { and Mediterranean water }\end{array}$ & & $\mathrm{S}_{\mathrm{p}}$ \\
\hline$S_{\text {atl }}$ & Salinity of inflowing Atlantic water & & $\mathrm{S}_{\mathrm{p}}$ \\
\hline$X_{\text {med }}$ & $\begin{array}{l}\text { Mediterranean net freshwater } \\
\text { export flux }\end{array}$ & & Sv \\
\hline$C$ & $\begin{array}{l}\text { Geometric coefficient for } \\
\text { Strait of Gibraltar }\end{array}$ & 0.283 & \\
\hline $\begin{array}{l}Q_{\text {total }} \\
B\end{array}$ & $\begin{array}{l}\text { Total, two-layer export at Gibraltar } \\
\text { Coefficient of saline contraction }\end{array}$ & 0.00077 & $\mathrm{~kg} \mathrm{~m}^{-3} \mathrm{~S}_{\mathrm{p}}^{-1}$ \\
\hline$A$ & Coefficient of thermal expansion & 0.0002 & $\mathrm{~kg} \mathrm{~m}^{-3}{ }^{\circ} \mathrm{C}^{-1}$ \\
\hline$\Delta T_{\text {gib }}$ & $\begin{array}{l}\text { Temperature difference between } \\
\text { Atlantic and Mediterranean water }\end{array}$ & & ${ }^{\circ} \mathrm{C}$ \\
\hline $\begin{array}{l}q_{s} \\
X 1 \\
X 2\end{array}$ & $\begin{array}{l}\text { Sediment flux } \\
\text { First entrainment coefficient } \\
\text { Second entrainment coefficient }\end{array}$ & & $\mathrm{kg} \mathrm{s}^{-1}$ \\
\hline $\mathrm{S}_{\mathrm{d}}$ & Sediment density & 2.65 & $\mathrm{~g} \mathrm{~cm}^{-3}$ \\
\hline$D_{50}$ & median grain size of sediment & 2.4 & $\mu \mathrm{m}$ \\
\hline$U^{*}$ & Shear velocity & & $\mathrm{m} \mathrm{s}^{-1}$ \\
\hline$U_{\text {crit }}^{*}$ & Critical shear velocity & 2.4 & $\mathrm{~m} \mathrm{~s}^{-1}$ \\
\hline
\end{tabular}

extreme variability is shown by García Lafuente et al. [2002], who found an outflow of $0.018 \pm 0.502 \mathrm{~Sv}$ in the surface layer in part of their analysis period. It is therefore necessary to consider what secondary influences affect the exchange, and under what conditions the Bryden and Kinder [1991] formulation can be considered valid.

[12] Within the Strait of Gibraltar section, the exchange shows significant cyclicity on annual, subannual and diurnal timescales, with the barotropic (i.e., tidal and atmospherically forced) mode of the exchange contributing around $80 \%$ of the total transport [Gomis et al., 2006]. These forcings result in a seasonal cycle in the fluxes that is estimated for the inflow at $\pm 0.1 \mathrm{~Sv}$ with a maximum in September, and for the outflow at $\pm 0.03 \mathrm{~Sv}$ with a maximum in January [Garcia Lafuente et al., 2007]. A 6-month-long record of Camarinal Sill transports is shown in Figure 5 [Vargas et al., 2006]. The largest single factor is the tidally driven diurnal cycle, which causes full reversal of both the inflowing and outflowing layers at the Camarinal Sill during most tidal cycles [Bryden et al., 1994; Vargas et al., 2006]. The diurnal change in transport at the Camarinal Sill means that the height of the reservoir in the Tangier Basin is also variable, but despite this the flow out of the Tangier Basin over the Spartel Sill is almost constant throughout the tidal cycle [Bryden et al., 1988; García-Lafuente et al., 2009]. As it is this sill that partitions the Tangier Basin from the Atlantic, this means that the Mediterranean water in the Gulf of Cadiz and beyond has hardly any short-term variability [Armi and Farmer, 1988; Farmer and Armi, 1988; Thorpe, 1976]. If flow within the Mediterranean Outflow in the Atlantic is the target of analysis, this smoothing of the outflow properties makes steady state treatment of the outflow valid on barotropic (i.e., tidal or weather-related) timescales even though it may not be valid upstream. Nevertheless, significant seasonal variability persists downstream of the Tangier Basin, and the annual variability in the outflow at Spartel Sill may be as much as $15 \%$ of the total flux [GarcíaLafuente et al., 2009; Millot, 2008]. Steady state models of the exchange are therefore not valid on timescales between days and years. On these timescales, the density of outflowing Mediterranean waters shows variability that cannot be accounted for in the Bryden and Kinder [1991] formulation, with temperature (salinity) reaching a minimum (maximum) in winter [Garcia-Lafuente et al., 2009]. However, as these effects tend to negate each other through several annual cycles [Gomis et al., 2006], a steady state model of the mean fluxes on timescales of at least 1 decade remains a reasonable approximation. For example, net barotropic flow in the exchange in the last 40 years is anticipated to be of the order of $10^{-4}$ to $10^{-5} \mathrm{~Sv}$ [Gomis et al., 2006].

[13] In paleoceanographic terms, the Bryden and Kinder [1991] approach therefore remains the most appropriate formulation for estimating past conditions of the Gibraltar exchange, although we recommend caution when it is applied at very high (subdecadal to seasonal) time resolution.

\subsection{The Exchange as a Three-Layer System}

[14] The $12.9^{\circ} \mathrm{C}$ isotherm, defined as being coincident with the top of the Western Mediterranean Deep Water $(W M D W)$, lies at $700 \mathrm{~m}$ depth in the Alboran Sea [Pettigrew, 1989; Stommel et al., 1973] and shoals to less than $400 \mathrm{~m}$ at the eastern entrance of the strait [Bryden and Stommel, 1982]. This shoaling represents a process of Bernoulli aspiration or "suction," and it is this process that permits WMDW to pass over the Camarinal Sill and contribute to the Mediterranean water in the Atlantic [Kinder and Parrilla, 1987; Millot, 1999, 2009; Stommel et al., 1973] (Figure 3c). Bernoulli suction is a frictional process that depends on the transfer of momentum into the WMDW layer from the motion of overlying water layers, typically the Levantine Intermediate Water $(L I W)$ [Millot, 1999, 2009]. Inevitably, there will be some level within the WMDW layer below which the aspiration force is insufficient to lift the water to sill depth, and we follow previous authors in calling this the "stagnation depth" [Kinder and Bryden, 1990; Seim and Gregg, 1997; Stommel et al., 1973]. A simple formulation for estimating this stagnation depth $\left(d^{\prime}\right)$ is provided by Seim and Gregg [1997]:

$$
\mathrm{d}^{*}=0.5 \mathrm{H}_{2}+\left(\frac{0.25 \mathrm{H}_{2}^{2}+u_{\mathrm{MO}}{ }^{2}}{\mathrm{~g} \Delta \rho / \rho_{0} \mathrm{H}_{1}}\right)^{0.5}
$$


a
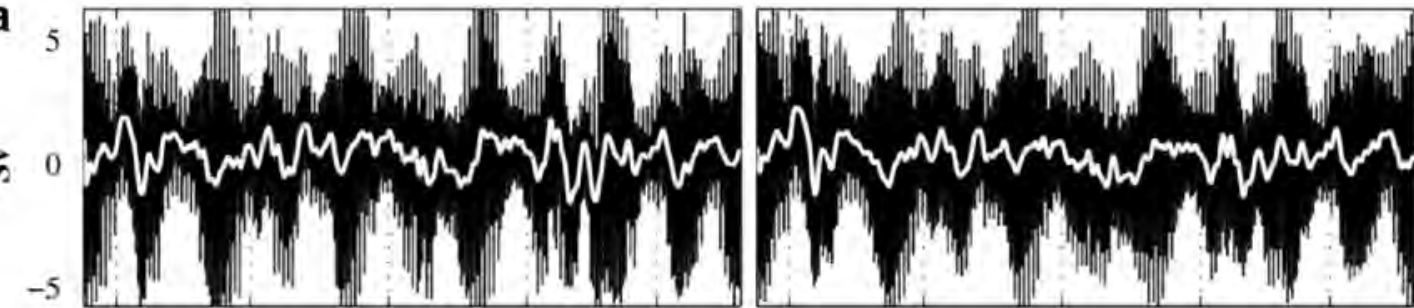

b
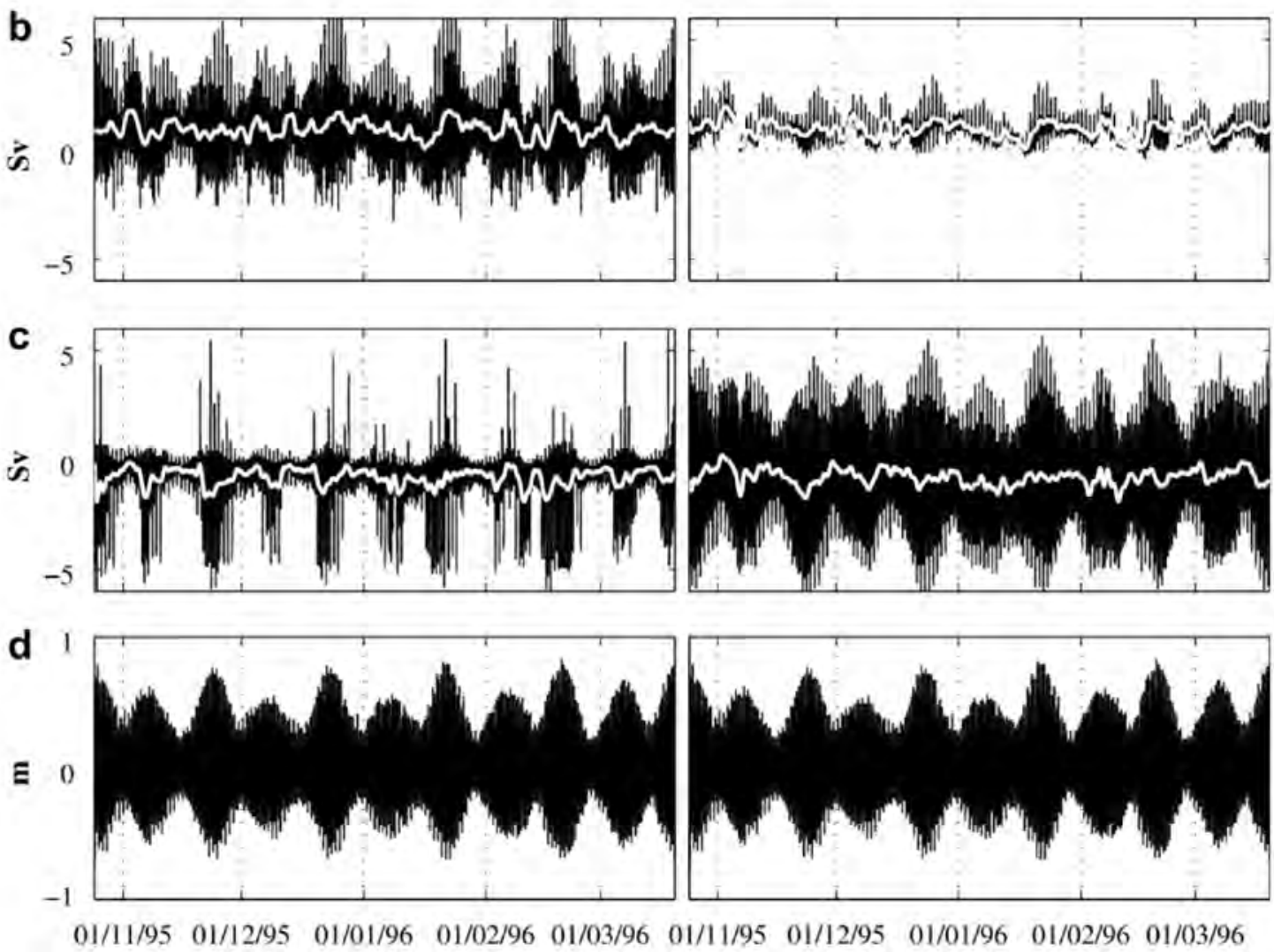

Figure 5. Estimated instantaneous (black) and subinertial (white) transports at (left) Camarinal Sill and (right) Spartel Sill: (a) Net transport $Q_{0}$, (b) upper layer transport $Q_{1}$, and (c) lower layer transport $Q_{2}$. (d) Tidal signal of the sea level at Tarifa. Reproduced from Vargas et al. [2006] with permission.

where depth terms $H_{1}$ and $H_{2}$ are the modern depths of the Alboran Sea $(\sim 2000 \mathrm{~m})$ and the Camarinal Sill $(284 \mathrm{~m})$, respectively, $\Delta \rho$ is the density difference between surface and bottom waters in the Alboran Sea, and $\rho_{0}$ is the density of the surface layer. Today, this "stagnation depth" lies at about $800 \mathrm{~m}$ [Rogerson et al., 2008], which explains why a persistent reservoir of WMDW exists in the Alboran Sea below this depth in modern hydrographies [MEDAR Group, 2002]. A critically important aspect of the hydraulics of this system is that changes in the rate of creation of new WMDW may only force changes in western Mediterranean bottom stagnation or MO activity at Gibraltar if activity in the LIW is constant or changes in harmony with WMDW [Rogerson et al., 2008]. The widespread assumption in the paleoceanographic literature that ventilation in the deep western Mediterranean and the velocity of the Mediterranean Outflow in the Gulf of Cadiz are linked [Cacho et al., 2000; Khélifi et al., 2009; Llave et al., 2006; Toucanne et al., 2007; Voelker et al., 2006] is therefore problematic. Before inferences that climatic conditions in southwest Europe have impacted on $M O W$ properties can be accepted, it needs to be demonstrated that transmission of the strong cooling typical of this region [Kuhlemann et al., 2008] can significantly alter flow west of Gibraltar.

[15] Due to Bernoulli suction, WMDW (i.e., water cooler than $12.9^{\circ} \mathrm{C}$ ) has been found to be passing over the deepest part of the Camarinal Sill during nearly two thirds of the Gibraltar Experiment period [Pettigrew, 1989]. This aspiration of deep water was originally thought to contribute less than $10 \%$ of the total flux [Bryden, 1993], but recent estimates are as high as $30 \%$ annually and up to $50 \%$ in the winter [Garcia Lafuente et al., 2007]. The export flux of WMDW $\left(Q_{\mathrm{WMDW}}\right)$ is thus around $0.1 \mathrm{~Sv}$ [Garcia Lafuente et al., 2007], approximately accounting for one third of its total production [Millot, 1999]. However, it has recently been shown that virtually no water colder than $13^{\circ} \mathrm{C}$ passed over the Camarinal Sill during 2003-2004 [Millot, 2009], meaning that $Q_{\text {WMDW }}$ during this period was $\sim 0$. During 
this period, the dense lower part of the outflowing water comprised mostly Tyrrhenian Dense Water [Millot, 2009]. This finding is significant because it confirms that, although the individual source-water contributions to the total water outflowing at Gibraltar may depend on the severity of winter in the northwest Mediterranean, this does not need to substantively change the overall flux and density of MO as it exits into the North Atlantic.

[16] In highlighting changes in the source-water composition of the MO, Millot [2009] recommends that the Gibraltar exchange be considered as a three-layered process (Figure 3b), with AI in the north overlying "Mediterranean Intermediate Water" (MIW; comprising mainly LIW with minor Winter Intermediate Water generated in the western Mediterranean) and in the south overlying "Mediterranean Dense Water" ( $M D W$; mainly comprising either WMDW or Tyrrhenian Deep Water $(T D W)$ ). On the basis of hydrographic surveys, Millot [2009] suggests that the two bottom layers should be considered as stacked horizontally rather than vertically. Curiously, a different type of three-layer exchange was suggested by the first successful attempts to numerically simulate the exchange with high spatial resolution [Sannino et al., 2007, 2009]. In these simulations, the water mass layering is essentially vertical with an intermediate layer generated by mixing of Mediterranean and Atlantic waters, but nevertheless this third layer is "active" and modifies the exchange.

[17] Such three-layer formulations of the exchange challenge the salinity-controlled two-layer formulations employed in equations (1)-(3). However, the core issue, especially in Millot's [2009] formulation of the problem, is the role of temperature forcing derived from the western Mediterranean basin. The advantage to paleoceanographers of the threelayer formulation therefore is that strong hydrographic differences between the basins, which lead to enhanced buoyancy loss in the western basin relative to the eastern basin (for example, from strong thermal forcing from the European landmass [Kuhlemann et al., 2008]), might be explicitly considered. This allows some degree of assessment of the impact of thermal forcing to be incorporated within estimates of the net Mediterranean buoyancy budget.

[18] As an alternative to more complete three-layer modeling, thermal forcing can also be incorporated within the Bryden and Kinder [1991] theory by modifying the formulation of the reduced gravity of the outflowing Mediterranean water $\left(\mathrm{g}^{\prime}\right)$ to account for both salinity and temperature:

$$
g^{\prime}=g\left(\left(\alpha \Delta T_{\text {gib }}\right)+\left(\beta \Delta S_{\text {gib }}\right)\right) / \rho_{\text {MO }}
$$

where $\alpha$ is the coefficient of thermal expansion $\left(-0.2 \mathrm{~kg} \mathrm{~m}^{-3}\right.$ $\mathrm{K}^{-1}$ ), and $\Delta T_{\text {gib }}$ is the mean temperature difference between the Mediterranean and Atlantic layers. The density difference between the outflowing and inflowing layers at Gibraltar is $\sim 2.2 \mathrm{~kg} \mathrm{~m}^{-3}$, of which $\sim 0.66 \mathrm{~kg} \mathrm{~m}^{-3}$ can be ascribed to the temperature difference and $\sim 1.54 \mathrm{~kg} \mathrm{~m}^{-3}$ to the salinity difference. Incorporating the density enhancement by temperature within the Bryden and Kinder [1991] model increases the net Gibraltar exchange $\left(Q_{\mathrm{AI}}-Q_{\mathrm{MO}}\right.$; also termed $\left.Q_{\text {net }}\right)$ by $<20 \%$, and this remains well within the range of estimates within the literature (0.5-1 Sv [Millot, 2009]).

\subsection{The Role of Mediterranean Source-Water Contributions to Atlantic-Mediterranean Buoyancy Flux}

[19] Today, the density difference between the MIW and MDW layers (in the sense of Millot [2009]) is $\sim 0.003 \mathrm{~kg} \mathrm{~m}^{-3}$, which implies that the behavior of the MO in the Atlantic is largely independent of the relative contributions of the different Mediterranean source waters. The balance of buoyancy fluxes between the two outflowing layers today is therefore controlled only by their relative volumetric fluxes, so that about $70 \%$ of the buoyancy flux occurs within the MIW layer. Changes in the density difference between the layers would alter this balance and also make the Gibraltar buoyancy flux sensitive to changes in the relative proportions of MIW and MDW within the outflow. We again emphasize that increases in the production of WMDW would therefore not change $\mathrm{MO}$ velocity, although changes in the properties of WMDW may do so.

[20] As the best estimate of outflow flux of MO today is around $0.57 \pm 0.26 \mathrm{~Sv}$ [Tsimplis and Bryden, 2000], the net buoyancy export flux from the Atlantic is approximately $1.28 \pm 0.58 \times 10^{6} \mathrm{~kg} \mathrm{~s}^{-1}$, which then must be compensated for by the internal Atlantic density budget. Assuming a simple 2:1 balance of an easterly sourced MIW with $\theta=$ $13.1^{\circ} \mathrm{C}$ and $S=38.5$ and a westerly sourced MDW with $\theta=12.8^{\circ} \mathrm{C}$ and $S=38.4$, the relative contributions of fresh water and heat change within the two sub-basins of the Mediterranean to MO buoyancy flux can be estimated from the relative contributions of these terms to the density of MOW. Buoyancy fluxes due to temperature and freshwater loss from the western Mediterranean are estimated at $-1.87 \times 10^{5} \mathrm{~kg} \mathrm{~s}^{-1}$ and $-2.40 \times 10^{5} \mathrm{~kg} \mathrm{~s}^{-1}$, respectively. For the eastern basin, density loss via Gibraltar occurs due to LIW export but also due to admixture of Eastern Mediterranean Deep Water into Tyrrhenian Deep Water. This admixture occurs within the Tyrrhenian "thermohaline staircase," in which waters of a variety of densities and origins interact and mix within the semienclosed Tyrrhenian Sea [Zodiatis and Gasparini, 1996]. This system is extremely complex, making analysis of internal density fluxes challenging. However, compared to the buoyancy loss due to LIW export the buoyancy loss via TDW is likely to be small, and we do not venture a value for this here. Buoyancy losses via LIW outflow at Gibraltar are estimated at $-3.21 \times$ $10^{5} \mathrm{~kg} \mathrm{~s}^{-1}$ and $-5.32 \times 10^{5} \mathrm{~kg} \mathrm{~s}^{-1}$ for temperature and salinity, respectively.

\section{REGIONAL IMPACT OF THE GIBRALTAR EXCHANGE}

\subsection{Impact of the Gibraltar Exchange on the Western Mediterranean}

[21] The Gibraltar exchange controls the hydrography of the western Mediterranean at all levels. Its direct impact on bottom water in the western basin has been considered above 
(section 2.2). Within the intermediate layer the most striking effect is the net westward flow of water from the Strait of Sicily and Tyrrhenian Sea toward the Atlantic, though this tends to occur within eddies rather than as continuous streams [Millot, 1999]. Within the surface layer, the exchange causes the formation of the Atlantic Inflow Water $(A I W)$, which flows from west to east along the Algerian margin [Millot, 1999]. In the westernmost Alboran Sea, the surface water that enters from the Atlantic through the Strait of Gibraltar is subjected to a substantial decrease in temperature and increase in salinity, which reflects an approximately $42 \pm 8 \%$ admixture of outflowing water (MO) on the eastward side of the Camarinal Sill due to upwelling [Folkard et al., 1997; Rogerson et al., 2010]. The product water is termed "Modified Atlantic Water" (MAW).

[22] The jet-like flow of MAW through the Alboran Sea causes the formation of two gyres: the eastern and western. Recently, it has been noted that the activity of the Western Alboran Gyre influences the Gibraltar exchange; when it is active the MO is colder, reflecting increased admixture of WMDW [Garcia-Lafuente et al., 2009]. This link is due to the position of the WMDW along the southern margin of the Alboran Sea, which is highly analogous to a classic boundary current [Millot, 1999]. The southern limb of the western gyre flows westward, so that-when momentum is transferred downward through friction-it accelerates the WMDW, which enhances its ability to be lifted over the Camarinal Sill [Garcia-Lafuente et al., 2009]. The Alboran gyres therefore are integral to the Gibraltar exchange, as they are both generated by it and reinforce it.

\subsection{Impact on Gulf of Cadiz}

[23] The subsurface Mediterranean water that exits through the Strait of Gibraltar (the MO) cascades down the slope of the Gulf of Cadiz, dominating the hydraulic structure of the region at all levels [Johnson and Stevens, 2000]. The MO entrains ambient water as it passes into the Gulf of Cadiz $(G o C)$, increasing in volume by a factor of 3 to 4 within the first $100 \mathrm{~km}$ of leaving the Strait of Gibraltar [O'NeillBaringer and Price, 1999]. This reduces the density of the plume and erodes its velocity (Figure 6a). The final depth of settling of the MO plume is controlled by the final density of the MO product water, which we will refer to here as the Atlantic Mediterranean Water $(A M W)$ to distinguish it from the pure "Mediterranean Outflow Water" it is derived from. The density of AMW is controlled by $g^{\prime}$ (which can be derived from analysis of the Gibraltar exchange itself; see section 2.1) and $\Phi$, which is the proportion of Atlantic Ambient Water contributing to AMW (today $\approx 0.66$ to 0.75 ). Over timescales much longer than the overturning timescale of the Mediterranean ( $>100$ years), the effects of variations in the Atlantic water mass properties adjacent to the Strait of Gibraltar will be reflected (through inflow and water mass transformation within the Mediterranean) in the properties of $\mathrm{MO}$ and will not materially influence $g^{\prime}$ [Rogerson et al., 2005]. We can therefore assume a common "reference" density which roughly represents conditions in the Atlantic water masses that interact with the Gibraltar exchange. To a first approximation, the settling depth $(h)$ of $\mathrm{MOW}$ is therefore given by

$$
h=\frac{(1-\Phi) \Delta \rho_{g i b}}{\partial \rho / \partial z}
$$

where $\partial \rho / \partial z$ is the vertical density gradient in the eastern North Atlantic (today $\sim 9 \times 10^{-7} \mathrm{~kg} \mathrm{~m}^{-4}$ ) and $\Delta \rho_{\text {gib }}$ is the density contrast between the cores of inflow and outflow within the Strait of Gibraltar (Figure 6b).

[24] However, things are not this simple. The AMW occurs in several layers within the North Atlantic, with two major cores (upper and lower AMW) that present slightly different salinities $(S=36.5-37.0$ and $\mathrm{S}=36.5-37.5$, respectively), and temperatures $\left(13.0-14.0^{\circ} \mathrm{C}\right.$ and $10.5-11.5^{\circ} \mathrm{C}$, respectively) [O'Neill-Baringer and Price, 1999]. A difference in settling depths is observed (300-800 m and 1100-1400 m, respectively), which is a logical consequence of the higher density of lower AMW [Ambar and Howe, 1979]. It is generally assumed that the separation into two cores arises from differences in mixing, frictional influence and topographic steering [Borenäs et al., 2002]. However, it has recently been suggested that the splitting behavior may, in part, reflect slight differences in the hydrography of the MO at Gibraltar [Millot, 2009; Sannino et al., 2007], although that idea itself is not new [Zenk, 1975]. A three-layer formulation for the Gibraltar exchange, which permits the outflow to be incompletely mixed within the strait [Millot, 2009], will definitely allow the existence of initial density differences within the plume, which may then be amplified by mixing processes within the Gulf of Cadiz.

[25] The $1.5^{\circ} \mathrm{C}-3.5^{\circ} \mathrm{C}$ temperature difference between the lower and upper AMW limbs, with only a small difference in salinity, indicates that the lower limb mixes with deeper, colder Atlantic water than the upper limb [O'Neill-Baringer and Price, 1999]. Entrainment of Atlantic water into the MO plume thus appears to be gradual, and mixing occurs in the outermost (uppermost and probably MIW) part of the plume before it penetrates the (largely MDW) flow core [O'NeillBaringer and Price, 1997]. The unmixed inner flow core will therefore retain a higher $g^{\prime}$ and move more rapidly than the sheath of AMW product water surrounding it [Johnson et al., 1994a]. On average, the height of the unmixed layer $\left(H_{\mathrm{AMw}}\right)$ is less than half of that of the height of frictional influence (Ekman layer, $D_{E}=\pi(2 A / f)^{1 / 2}$ where $A$ is the eddy viscosity coefficient) from the bottom [Johnson et al., 1994b]. This causes "Ekman veering" [Gammelsrød, 1975], forcing the unmixed water to flow downslope at a different (steeper) angle than the product water. Consequently, by the time the inner layer has the opportunity to interact with ambient water it has already been injected to greater depth. It is therefore more correct to consider the two major AMW limbs in the GoC as being the "geostrophic" and "descending" parts of the AMW plume, respectively. The final splitting of these limbs relates primarily to the impact of local topography, and realistic splitting has been simulated in simple stream tube models with scaled bottom elevation [Borenäs et al., 2002]. 
a)

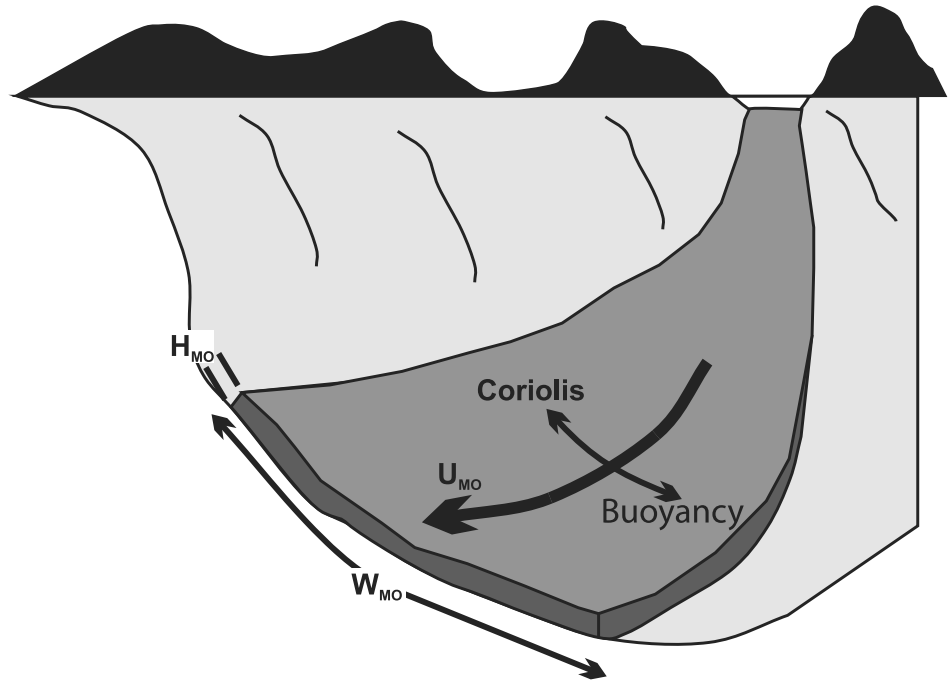

b)

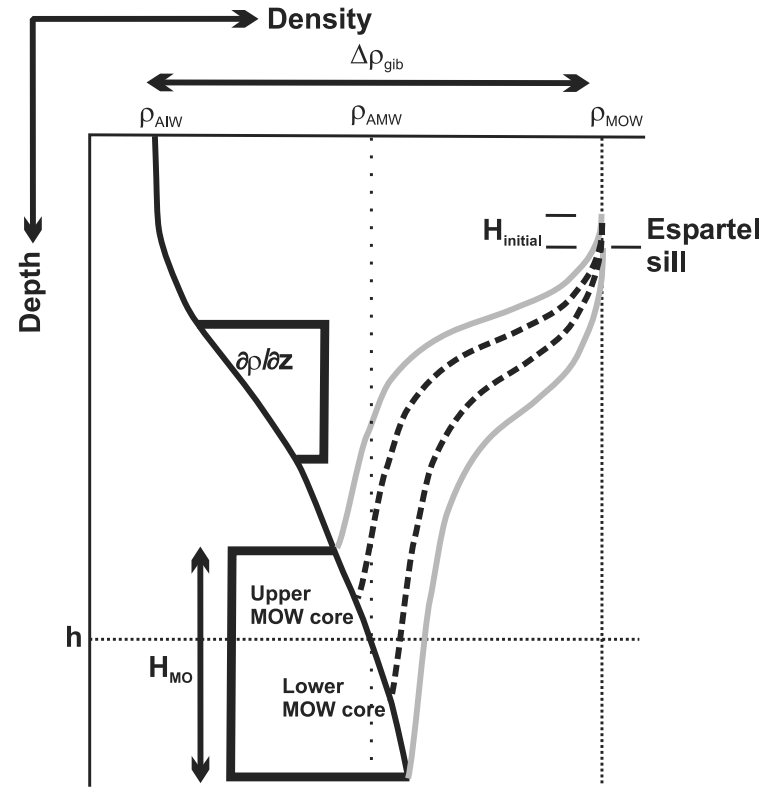

$$
\rho_{\text {AMW }}=\rho_{\text {MOW }}-\left(\rho_{\text {MOW }}-\rho_{\text {AIW }}\right) \Phi
$$

Figure 6. (a) Schematic showing the settling and spreading of Mediterranean water in the Gulf of Cadiz (redrawn from Price and O'Neill-Baringer [1994]). (b) Mixing and settling of Mediterranean water into ambient Atlantic water and the creation of Atlantic Mediterranean Water (AMW). MOW is the Mediterranean Outflow Water. $U_{\mathrm{MO}}, W_{\mathrm{MO}}, H_{\mathrm{MO}}$ and $\rho_{\mathrm{MO}}$ are the velocity, width, height and density of Mediterranean Outflow Water, respectively. $H_{\text {initial }}$ is the height of Mediterranean Outflow Water at the Camarinal Sill; $\rho_{\mathrm{AMW}}$ and $\rho_{\mathrm{AIW}}$ are the densities of AMW and Atlantic Inflow Water, respectively, $\varphi$ is the proportion of MOW in AMW, $\Delta \rho_{\text {gib }}$ is the density difference between inflowing and outflowing layers at Gibraltar, $\partial \rho / \partial z$ is the vertical density gradient in the North Atlantic adjacent to the Gulf of Cadiz, and $h^{\prime}$ is the settling depth of AMW within the open North Atlantic.

\subsubsection{Pathways of AMW in the North Atlantic}

[26] Within the Atlantic water mass outside the Gulf of Cadiz, AMW presents three dominant pathways. The geostrophic limb flows along the Iberian continental slope between 300 and $800 \mathrm{~m}$ depth, into the Bay of Biscay and onto the Irish continental slope [Iorga and Lozier, 1999]. There, the isopycnal it lies upon shoals to intersect with the surface [New et al., 2001], or penetrates directly into the Nordic Seas, depending on the NAO state [Lozier and Stewart, 2008]. The descending limb of AMW splits at Cape St. Vincent's Gateway (between the cape itself and the Gettysburg Bank [Iorga and Lozier, 1999; Zenk and Armi, 1990]) to either follow the geostrophic limb along the Portuguese margin or to flow westward into the Atlantic 
where it forms a "reservoir" of AMW as an intermediate layer [Daniault et al., 1994; Iorga and Lozier, 1999]. This reservoir appears prominently in the hydrography of the eastern North Atlantic subsurface [Daniault et al., 1994], but beyond $20^{\circ} \mathrm{W}$ continued westward transport of salt is essentially by diffusion [Iorga and Lozier, 1999]. Finally, high vorticity in the AMW plume generates mesoscale eddies ("Meddies") which remain coherent well out into the Atlantic [Aleinik, 1998; Peliz et al., 2007], and can be found as far west as the Bahamas [Armi and Bray, 1982]. Only a minority of AMW is transported westward, however, with the majority following the northward pathway [Daniault et al., 1994; Iorga and Lozier, 1999].

\subsubsection{Mixing and Generation of Atlantic Mediterranean Water Product Waters}

[27] Significant progress has been made in improving the manner in which marginal sea overflows are incorporated into circulation models [Legg et al., 2006, 2009]. One of the most effective is the marginal sea boundary condition approach [Price and Yang, 1998], which is largely based on a previous analytical approach to entrainment within major overflow currents [Price and O'Neill-Baringer, 1994]. The analytical approach assumes that entrainment of ambient water occurs as a single event around $100 \mathrm{~km}$ downstream of the Camarinal Sill and that it involves a single type of Mediterranean water and a single type of ambient water to produce a single type of product water (PO94). It is consequently suitable only for a two-layer formulation of the exchange and provides only a single product water density, and it thus does not account for differential mixing due to Ekman veering. Nevertheless, PO94 provides a useful insight into the mean isopycnal on which the AMW will settle. Essentially, PO94 provides a parameterization for the mixing coefficient $\Phi$ :

$$
\Phi=1-\frac{B_{\mathrm{ggo}}^{1 / 3}}{U_{\mathrm{geo}}}
$$

where $B_{\text {geo }}$ is the geostrophic buoyancy flux of the AMW plume and $U_{\text {geo }}$ is the geostrophic velocity. These parameters can be estimated in turn via

$$
\begin{gathered}
\mathrm{U}_{\mathrm{geo}}=\frac{\mathrm{g}_{\mathrm{x}}^{\prime} \alpha}{\mathrm{f}} \\
\mathrm{B}_{\mathrm{geo}}=\frac{\mathrm{H}_{\mathrm{MO}} \mathrm{U}_{\mathrm{MO}} \mathrm{g}^{\prime}}{\left(1+2 \mathrm{~K}_{\mathrm{geo}}{ }^{\left.\mathrm{x} / \mathrm{W}_{\mathrm{MO}}\right)}\right.}
\end{gathered}
$$

where $\alpha$ is the gradient of the continental slope, $f$ is the Coriolis parameter, $x$ is the distance downstream from Gibraltar, $g_{x}^{\prime}$ is the reduced gravity at $x$, and $K_{\text {geo }}$ is the geostrophic Ekman number which generally is equal to or lower than 0.2 (PO94). $H_{\mathrm{MO}}, W_{\mathrm{MO}}$ and $U_{\mathrm{MO}}$ are the height, width and velocity of the Mediterranean Outflow plume. Today, $\Phi=0.58$, meaning that AMW product water comprises $42 \%$ Mediterranean water (PO94), which is slightly higher than, but of similar order as, estimates from direct measurement ( 33\%) [O'Neill-Baringer and Price, 1999].
The difference between the observed and modeled values for entrainment results in the AMW plume in the model having density enhanced by $\sim 1.27 \times 10^{-4} \mathrm{~kg} \mathrm{~m}^{-3}$, which is $\sim 7.5 \%$ of the initial density anomaly of pure MOW and therefore negligible.

[28] The major consequence of the control on the mixing of AMW that PO94 parameterizes is that $\Phi$ will rise with rising $g^{\prime}$. Consequently, the densest source waters will produce the least dense product water, which will then settle at the shallowest depth. PO94 provide examples of this behavior from the modern ocean, demonstrating that Mediterranean Outflow's initial density $\left(\rho_{\text {src }}=28.48 \mathrm{~kg} \mathrm{~m}^{-3}\right)$ generates less dense product waters than three other systems with lower source-water density, namely Faroe Bank Channel Overflow $\left(\rho_{\text {src }}=28.07 \mathrm{~kg} \mathrm{~m}^{-3}\right)$, Denmark Strait Overflow $\left(\rho_{\text {src }}=\right.$ $\left.28.03 \mathrm{~kg} \mathrm{~m}^{-3}\right)$ and Filchner Ice Sheet Overflow $\left(\rho_{\mathrm{src}}=\right.$ $27.92 \mathrm{~kg} \mathrm{~m}^{-3}$ ). The product water produced by the MOW has a density of $27.67 \mathrm{~kg} \mathrm{~m}^{-3}$, whereas the three other overflow product waters have densities of 27.91, 27.96 and $27.90 \mathrm{~kg} \mathrm{~m}^{-3}$, respectively. This has major implications, because it means that increasing the density of $\mathrm{MO}$ water should not necessarily be expected to increase the settling depth of the AMW plume.

\subsubsection{Impact of the Gibraltar Exchange on Eastern North Atlantic Surface Circulation}

[29] In addition to the $\sim 0.7 \mathrm{~Sv}$ of surface water that is directly lost from the Gulf of Cadiz surface water because of the Atlantic Inflow into the Mediterranean, the near-surface layers in the Gulf of Cadiz lose another $\sim 1.7 \mathrm{~Sv}$ because of entrainment into the subsurface AMW plume. The total $\sim 2.4 \mathrm{~Sv}$ of export is compensated for by the Azores Current (Figure 1), a branch of the subtropical gyre that splits from the Gulf Stream / North Atlantic Drift system at the Newfoundland Grand Banks to flow zonally eastward between $30^{\circ} \mathrm{N}$ and $40^{\circ} \mathrm{N}$, to the south of the Azores Islands [Gould, 1985; Jia, 2000]. Close to the Azores Islands, the Azores Current marks a strong change in water temperature $\left(\sim 4^{\circ} \mathrm{C}\right)$ and also a divide in terms of water mass structure [Fasham et al., 1985] and plankton ecology, with the Deep Chlorophyll Maximum lying at greater depth to the north [Angel, 1989; Fasham et al., 1985; Fernández and Pingree, 1996; Schiebel et al., 2002b]. This transitional zone is characterized by intense upwelling [Alves and DeVerdiere, 1999; Rudnick, 1996], and is termed the Azores Front. The $A C / A F$ is strongest in the spring [Alves and DeVerdière, 1999], slightly postdating the season of strongest MO flow (January), and shows random variability in strength and position throughout the year as a result of meandering [Alves et al., 2002].

[30] Toward the East Atlantic margin, the structure of the Azores Current / Azores Front system degenerates into two components, one remaining zonal and flowing to the Gulf of Cadiz to replace surface water lost as a consequence of water mass transformations due to the Gibraltar exchange [Özgökmen et al., 2001], and one turning south to form an Eastern Boundary Current along the African margin [Käse et al., 1985]. Only the southern component coincides with a significant change in water temperature [Johnson and 
Stevens, 2000]. It is unclear why the northern part of the Azores Current is not associated with a frontal structure but, given that the Azores Front to the west penetrates to around $1000 \mathrm{~m}$ depth [Alves et al., 2002], it would seem likely that this absence of a frontal structure reflects interference by the AMW plume in the northeasterly sector of the Gulf of Cadiz, as the top of AMW here lies at around $300 \mathrm{~m}$.

\section{BEHAVIOR OF THE GIBRALTAR EXCHANGE BEFORE $100 \mathrm{KA}$}

\subsection{Late Tertiary Changes}

[31] In the sense discussed above, the exchange of water between the Mediterranean and Atlantic is dependent on the presence of a single, open channel at Gibraltar. Consequently, prior to the Miocene, when water was exchanged through multiple channels connecting the basins of the western Paratethys via the Betic and Rif Corridors [Krijgsman et al., 1999, 2001; Sierro et al., 1993], the Atlantic-Mediterranean exchange pattern that is discussed herein did not occur. Throughout the so-called "Messinian Salinity Crisis" (5.96 to 5.33 Ma [Hilgen et al., 2000]), when salinity in the Mediterranean locally exceeded the saturation limits of gypsum $(S \sim 140)$ and halite ( $S \sim 350$ ) [Rohling et al., 2008b], there is no known evidence of flow across the sills at Gibraltar [Blanc, 2002, 2006] or on the Iberian margin [Khélifi et al., 2009; Rodero et al., 1999], and the response of the internal circulation of the Mediterranean was significantly altered [Alhammoud et al., 2010]. Modern-like exchange between the Atlantic and Mediterranean must begin at some time subsequently, after the Gibraltar Strait opened, either due to tectonic changes or by erosion of an overtopping "stream" of Atlantic water flowing into the Mediterranean [Blanc, 2006]. Several geomorphological modeling studies have attested to the plausibility of the latter concept [Blanc, 2002, 2006; García-Castellanos et al., 2009; Loget et al., 2005; Loget and Van Den Driessche, 2006], and some limited core data have been presented supporting it [GarciaCastellanos et al., 2009]. The timing of this "breakthrough" event is considered to have been at the onset of the Zanclean (5.33 Ma), based on the return of normal marine conditions within the Mediterranean following the "Lago Mare" brackish phase [Blanc, 2006; García-Castellanos et al., 2009]. This is also thought to be the age of the earliest contourites within the Gulf of Cadiz, which have been identified on the basis of seismic data [Rodero et al., 1999]. However, there is no direct dating evidence for the establishment of an MO system at this time.

[32] The earliest independently dated evidence of an active MO is derived from DSDP Site 548 from the northern Bay of Biscay, which indicates synchronous changes in $\varepsilon_{\mathrm{Nd}}$, $\mathrm{Mg} / \mathrm{Ca}$ and $\delta^{18} \mathrm{O}_{\text {calcite }}$ in benthic foraminifera at $3.5 \mathrm{Ma}$ (Figure 7), interpreted as a significant intensification of $\mathrm{MO}$ flow [Khélifi et al., 2009]. This site is at a modern water depth of $1250 \mathrm{~m}$, and consequently corresponds to the lower part of the modern MO plume (within the northward extension of the descending limb). Similar Middle Pliocene dates have been proposed for a major unconformity within the sedimentary fill of the Strait of Gibraltar [Esteras et al.,
2000] and within the Faro Drift [Llave et al., 2001]. There is an additional significant discontinuity within the drift sediments in the northern Gulf of Cadiz in the Upper Pliocene, at $2.4 \mathrm{Ma}$ and/or 2.6 Ma [Llave et al., 2001, 2007; Raddatz et al., 2011], implying a period of enhanced flow at that time. Although slightly earlier, an intensification of AMW supply to the Porcupine Seabight is also implied by the initiation of "Challenger Mound" development at 2.6 Ma [Raddatz et al., 2011]. Given the combined dating uncertainty of the two studies, these two sources of evidence may reflect the same change and AMW activity. A flow pathway comparable to that of today seems to have been established at the beginning of the Pleistocene (1.8 Ma, based on nannofossil stratigraphy) [García et al., 2009; Llave et al., 2007], with the formation of the linear shalediapir ridges, comprising of compacted Miocene "blue marls" [Rodero et al., 1999], that dominate the bathymetry of the modern slope and thus are indirectly responsible for the distribution of AMW on the slope. This diapirism arises from the regional tectonic stress of the collision of the African and Iberian plates and is an ongoing process [Rodero et al., 1999]. Flow deflection by diapiric ridges first impacted on the MO flow during the Early Pleistocene and continued to further influence the flow into the Middle Pleistocene [García et al., 2009].

[33] The lag of nearly $2 \mathrm{Ma}$ between the opening of the Strait of Gibraltar $(5.33 \mathrm{Ma})$ and the establishment of a recognizable MO (3.5 Ma) suggests that throughout this period the density of Mediterranean water may have been similar to that of eastern Atlantic water (Figure 8). In part, this may reflect a rather more warm and humid climate in the northern Mediterranean at this time [Fauquette et al., 1999; Suc, 1984] which would have substantially reduced the buoyancy loss from the Mediterranean basin. However, once the Strait of Gibraltar achieved its modern configuration $(\sim 5.3 \mathrm{Ma})$, the lack of a recognizable $\mathrm{MO}$ must also reflect the higher sea levels during the Late Tertiary, caused by warmer global climate and lower continental ice volume [Raymo et al., 2006]. As the Gibraltar exchange is only just maximal today, exchange of water through the strait during times with substantially higher sea level would not have been hydraulically controlled, limiting the Mediterranean basin's capacity to enhance density relative to the Atlantic (see section 2.1). This scenario is consistent with the abrupt appearance of a distinctive AMW against a background of relatively smooth and largely cyclic global climate changes [Khélifi et al., 2009] and is also reflected in a significant reorganization within the Gulf of Cadiz drifts [Llave et al., 2001, 2007] and a major increase in the density of subsurface water within the Mediterranean [Khélifi et al., 2009].

\subsection{Early to Middle Pleistocene Changes}

[34] The Pleistocene deposits of the Gulf of Cadiz are divided into two deposition sequences, named $Q I$ and $Q I I$ [Llave et al., 2001, 2007]. The former represents the Early Pleistocene and the latter the Late Pleistocene, with the erosive surface between assigned to the "Mid-Pleistocene Revolution" at about $900 \mathrm{ka}$ on the basis of cyclostratigraphy 
Northeast Atlantic Site 548

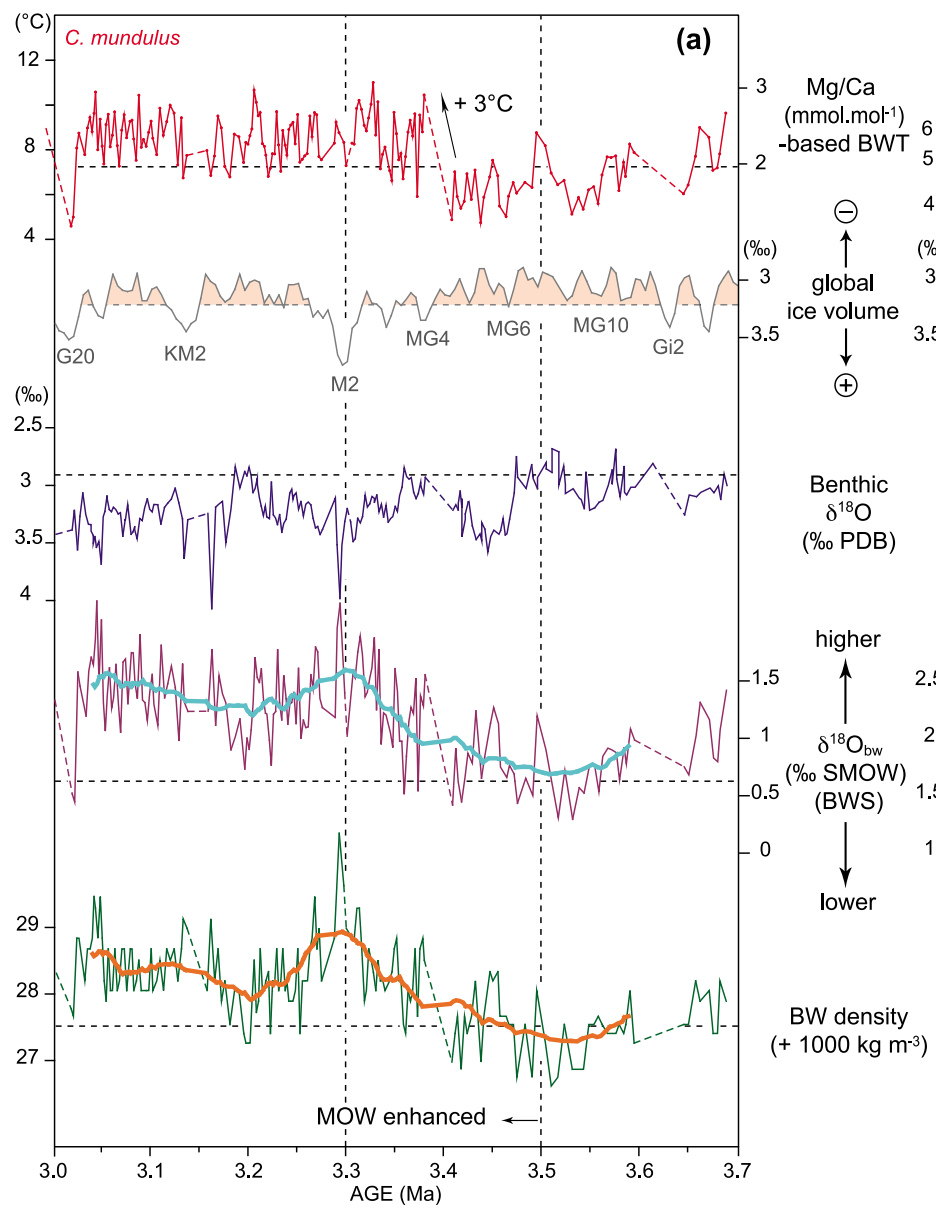

Westernmost Mediterranean Site 978

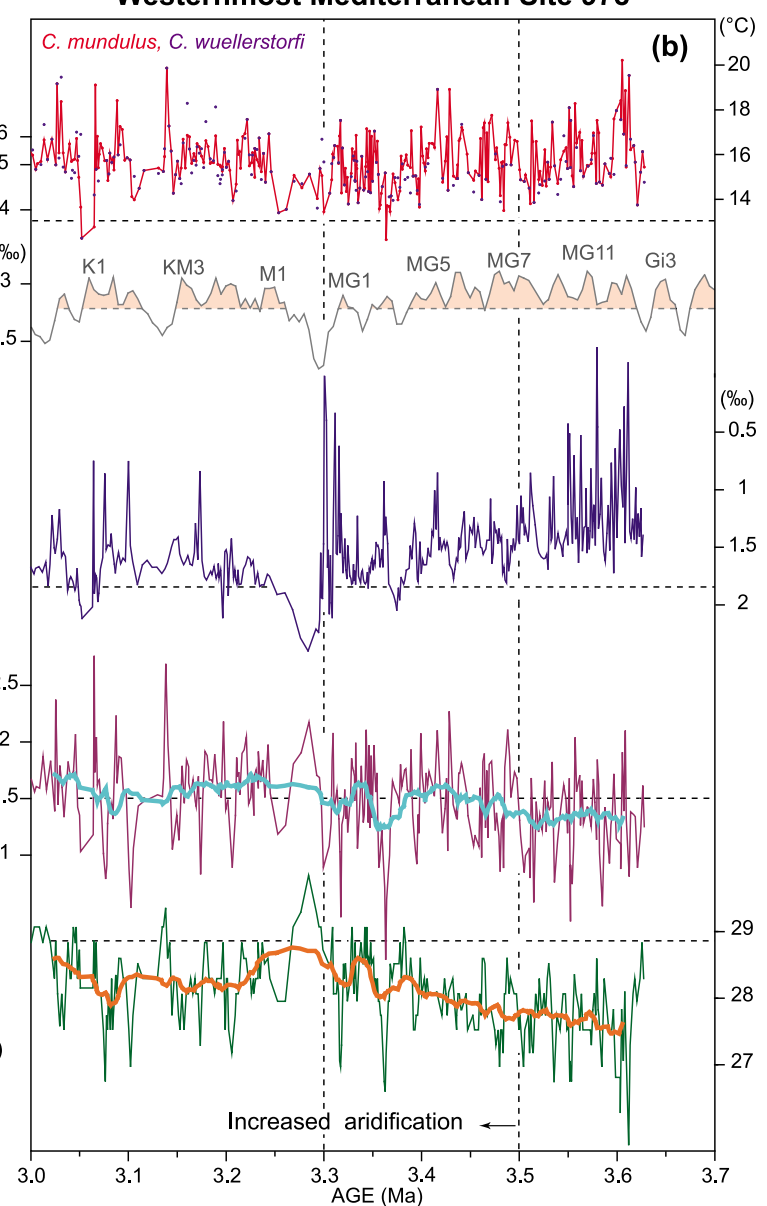

Figure 7. Pliocene changes in properties of (a) Mediterranean Outflow Water (MOW) at Deep Sea Drilling Project (DSDP) Site 548 and (b) Western Mediterranean Deep Water (WMDW) at Ocean Drilling Program (ODP) Site 978. Epibenthic ${ }^{18} \mathrm{O}$ is measured on Cibicidoides spp. at Site 548, on C. wuellerstorfi at Site 978, and compared with the stacked ${ }^{18} \mathrm{O}$ LR04 [Lisiecki and Raymo, 2005]. Mg/Ca-based bottom water temperature (BWT) was obtained from C. mundulus at Site 548 and from C. mundulus and C. wuellerstorfi at Site 978. Trend lines connect averages of paired measurements. Approximately $40 \mathrm{ka}$ running means (thick lines) highlight long-term trends. Dashed horizontal lines show modern levels. Dashed trend lines at Site 548 present potential sediment loss at core breaks. BW, bottom water; BWS, bottom water salinity; SMOW, standard mean ocean water; PDB, Peedee belemnite. Reproduced from Khélifi et al. [2009] with permission.

(E. Llave, personal communication, 2010). This transition reflects the shift from obliquity-dominated climate with a dominant period of $41 \mathrm{kyr}$ to an eccentricity-dominated climate with a dominant period of $100 \mathrm{kyr}$ [Park and Maasch, 1993], and an additional growth of Northern Hemisphere ice [de Boer et al., 2010; Raymo et al., 2006]. It is important that the QII sequence has elevated sedimentation rates, which drive a progradational rather than aggradational character, and is positioned higher on the slope than QI, which suggests a faster and shallower MO capable of transporting increased sediment fluxes [Llave et al., 2001, 2007]. As explained in section 3.2, this is consistent with the formation of higherdensity waters in the Mediterranean during deposition of the QII sequence than the QI sequence. The observation of the MO becoming sequentially shallower on the slope through the Pleistocene is compatible with the expectation that the density contrast between Atlantic and Mediterranean water was increasing through this period; that is, the Pleistocene shoaling of the $\mathrm{MO}$ is an indirect indicator of the synchronous increases in global ice volume and Mediterranean aridity.

[35] Both the QI and QII packages contain four internal seismic reflectors which bound individual depositional sequences, despite the fact that QI is relatively acoustically transparent [Llave et al., 2001, 2007]. The three Late Pleistocene erosive surfaces have been tentatively related to the Marine Isotope Stages (MIS) 16, 12 and 6 on the basis of calcareous nannofossil and cyclostratigraphy [Llave et al., 2001, 2007]. A more recent erosive surface has been comprehensively demonstrated to be associated with Termination 1 (see section 6.3), which suggests that the older acoustic reflectors actually correspond to the glacial Terminations rather than the 


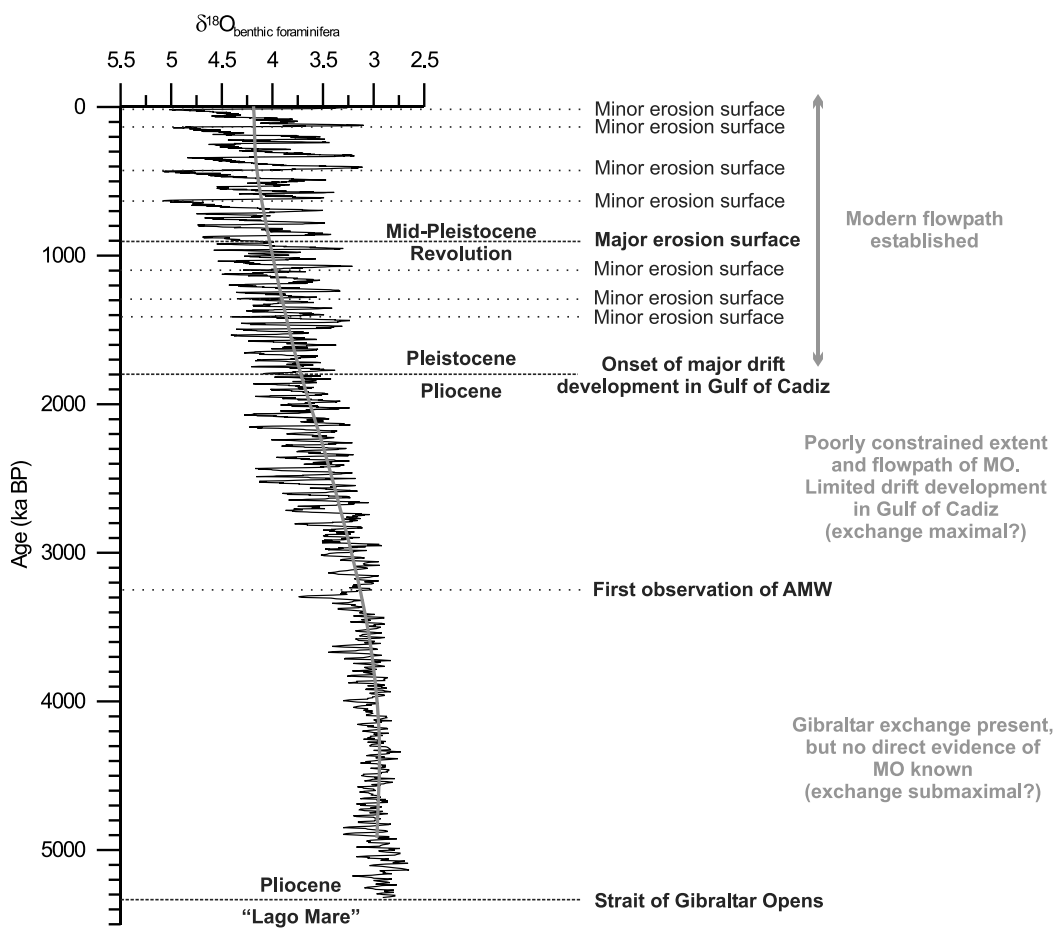

Figure 8. Plio-Pleistocene evolution of the Mediterranean Outflow (MO). Benthic foraminiferal $\delta^{18} \mathrm{O}$ LR04 stack [Lisiecki and Raymo, 2005] compared to changes in Atlantic Mediterranean Water (AMW) activity from geochemical [Khélifi et al., 2009] and seismic data [Llave et al., 2001, 2007; Rodero et al., 1999].

lowstands themselves. Indeed, as can be seen in Figure 8, the four known Late Quaternary erosive phases correspond to the four highest-amplitude changes in $\delta^{18} \mathrm{O}_{\text {benthic foraminifera }}$ since the Mid-Pleistocene transition. This attests to an acute sensitivity of the Gibraltar exchange to periods of rapid North Atlantic freshening [Rogerson et al., 2006a, 2010] and therefore to rapid and large-scale shrinkage of global ice sheets. We propose that the four Early Pleistocene erosive surfaces reflect similarly fast/large-scale shrinkages of Early Pleistocene ice sheets.

\section{CHANGES IN THE EXCHANGE DURING THE LAST 100 KA}

\subsection{Changes to the West of the Strait}

[36] The Gulf of Cadiz slope exhibits either relatively high sedimentation rates on the sediment drifts (Figure 2a), which generally aggrade at $\sim 30 \mathrm{~cm} \mathrm{kyr}^{-1}$ [Rogerson et al., 2004, 2005; Toucanne et al., 2007; Voelker et al., 2006], or else major hiatuses and unconformities within the channel and sand drift regions [Nelson et al., 1993, 1999; Rogerson et al., 2006a] (Figure 2a). As a consequence, continuous sedimentary records that extend back beyond $30 \mathrm{ka}$ are rare [Toucanne et al., 2007; Voelker et al., 2006]. In contrast, the response of the Mediterranean Outflow system to the last glacial-interglacial transition (Termination 1) is well recorded in numerous records both within the Gulf of Cadiz [Rogerson et al., 2006a] and beyond [Schönfeld and Zahn, 2000]. A compilation of the evidence from the Gulf of Cadiz is presented in Figure 9.
[37] The sediments deposited on the upper and lower slopes of the Gulf of Cadiz (corresponding to the geostrophic and descending limbs of the MO) show opposite fluctuations in flow activity between the Last Glacial Maximum and the present day. Only core MD99-2341 shows high flow during both the glacial and Late Holocene, reflecting the proximity of this core to the Strait of Gibraltar, upstream of the major division into two limbs. The cores from the upper slope (Kc8227, N-1, M39008-3, N-2, and N-3) show high flow in the Late Holocene and evidence for much reduced flow during the last glaciation. In contrast, cores from the lower slope (D13898, D13900, MD99-2339, and D13892) show evidence for higher flow during the last glaciation than during the Holocene. Through the Termination, the focus of major flow activity shifts from a dominantly descending plume to a dominantly geostrophic one [Rogerson et al., 2005]. This is supported by evidence from sedimentological, isotopic and benthic ecological change on the Portuguese margin [Löwemark et al., 2004; Schönfeld and Zahn, 2000], suggesting that the bottom of the plume shoaled from at least $2000 \mathrm{~m}$ depth to its modern position of $1500 \mathrm{~m}$ at this time. During the abrupt warming and sea level rise of Termination 1a, large areas of the slope were subjected to erosion [Nelson et al., 1993, 1999] and high fluxes of sediment were suspended within the MO plume [Rogerson et al., 2006b], emphasizing the large-scale rearrangement of flow within the plume. It is because of these observations that we suggested that maximum flow reflecting major glacial terminations accounted also for the older erosive periods in the Quaternary (see section 4.2 and Figure 8). 


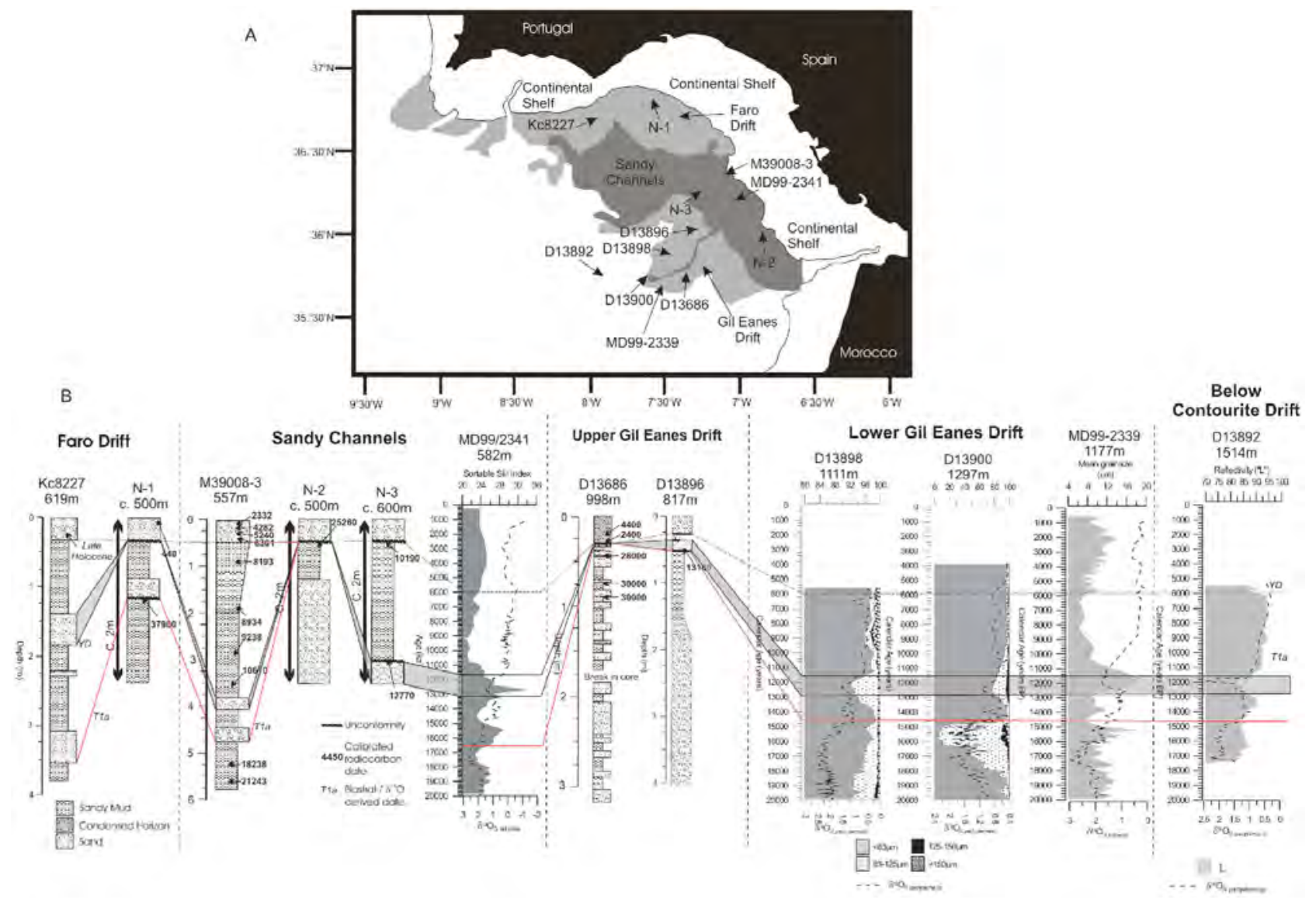

Figure 9. Compilation of sedimentary evidence of changes in the Mediterranean Outflow from the Gulf of Cadiz since the Last Glacial Maximum. (a) Location of cores. (b) Grain-size and planktonic $\delta^{18} \mathrm{O}$ data for MD99-2339 [Voelker et al., 2006], MD99-2341 [Toucanne et al., 2007], D13898 and D13900 [Rogerson et al., 2005], sediment reflectance and planktonic $\delta^{18} \mathrm{O}$ data for $\mathrm{D} 13892$ [Rogerson et al., 2006b], grain-size and calibrated radiocarbon datings for M39008-3 [Schönfeld, 2002], cores from the compilation of Nelson et al. [1999], D13686 and D13896 [Rogerson et al., 2006a], and grain-size and biostratigraphic dates for Kc8227 [Stow et al., 1986].

[38] A pattern of flow similar to that of Termination 1a has also been reconstructed for the Younger Dryas (Figure 9) and for Heinrich events [Llave et al., 2006; Voelker et al., 2006]. Unconformities dating to these periods are not so extensive or so deeply incising as those of Termination 1a, implying a somewhat less intensified plume of MO. However, high flow speeds are indicated by extensive sandy contourite formation on both the upper and lower slope [Llave et al., 2006; Rogerson et al., 2006a]. The $>10-\mathrm{cm}-$ thick sand-rich layers of Younger Dryas age reported on both the Gil Eanes Drift (D13898, D13900, and MD99-2339) and the Faro Drift (Kc8227) are exceptionally well expressed due to the fine-grained nature of sedimentation throughout the Gulf of Cadiz during the preceding Bølling-Allerød and succeeding Early Holocene intervals, which present as regional minima in contourite deposition.

[39] Previous papers emphasize that core records available for MIS3 (20 to $50 \mathrm{ka}$ B.P.) reveal a coherent relationship between temperature in Greenland and grain size on the GoC drifts [Toucanne et al., 2007; Voelker et al., 2006]. Millennial-scale cold periods (i.e., Dansgaard-Oeschger stadials) correspond to periods of relatively high energy, and the warmer interstadials correspond to periods of relatively low energy, both proximal to the Strait of Gibraltar (MD99-2341) and in the descending limb (MD99-2339) [Toucanne et al., 2007; Voelker et al., 2006]. Although the record is discontinuous, this behavior is also thought to be indicated by changes in grain size dated to MIS3 within sandy channels in Sedimentary Sector 3 [Mulder et al., 2002]. If the temporal correlation is correct, then this behavior during MIS3 must arise from interaction of terms controlling the Mediterranean buoyancy budget. This makes it a good target for the quantitative analysis we perform in section 6 .

\subsection{Changes to the East of the Strait}

[40] Although less constrained than for the eastern Mediterranean [Rohling, 1994; Rohling et al., 2004], it is known that substantial variations have occurred in the deep western Mediterranean [Cacho et al., 2000]. The indirect coupling of WMDW generation [Frigola et al., 2008], deepwater ventilation in the western Mediterranean and export of water through the Strait of Gibraltar (section 3.1) means that 
inferred relationships between these three phenomena should be interpreted with caution. However, throughout MIS3 the three systems seem to display similar responses to DansgaardOeschger cyclicity. High production of WMDW and wellventilated bottom water in the western Mediterranean basin during Dansgaard-Oeschger (D-O) stadials [Cacho et al., 2000; Frigola et al., 2008] coincide with high velocities within the MO (see previous section). The systems therefore do seem to have been coupled on these timescales, and responded to the same underlying climatic forcing. However, this coupling appears to break down during Heinrich events, with very high flow in MO (see previous section) and strong ventilation in the deep western Mediterranean [Cacho et al., 2000] in apparent contrast to an interpreted reduction in WMDW activity [Frigola et al., 2008]. We must conclude that during D-O stadials, generation of both MIW and MDW was enhanced, whereas during Heinrich events, MIW generation was enhanced while MDW formation was impeded [Rogerson et al., 2008, 2010]. Similar decoupling is evident during Termination 1a, when deep waters within the western Mediterranean became stagnant [Rogerson et al., 2008], whereas ventilation in the eastern Mediterranean remained strong [Abu-Zied et al., 2008; Casford et al., 2003].

\subsection{Zonal Surface Water Gradients Across the Strait of Gibraltar}

[41] The gradients in $\delta^{18} \mathrm{O}_{G \text {. bulloides }}$ and sea surface temperature (SST) across the Strait of Gibraltar have been previously shown to be diagnostic of the Atlantic Inflow flux [Rogerson et al., 2010]. Steep gradients indicate significantly different water masses on either side of the Strait [Rogerson et al., 2010] and therefore insufficient inflow flux to prevent advection of cold northern waters sourced from the Gulf of Lion down the eastern margin of Iberia [Hayes et al., 2005]. Both $\delta^{18} \mathrm{O}_{G \text {. bulloides }}$ and SST gradients have been highly variable during the last $30 \mathrm{ka}$, with periods of low gradients (high exchange flux) during the Late Holocene and Heinrich events strongly contrasting with periods of high gradient (low exchange flux) such as during the Last Glacial Maximum (LGM) [Rogerson et al., 2010]. These data are reproduced in Table 3, which also provides new data for the Bølling-Allerød, Younger Dryas and Early Holocene as compiled from the same records and using the same approach taken in our previous study [Rogerson et al., 2010]. Generally, the changes in surface water gradients compare well with evidence of changes in the MO activity. Heinrich event 1 shows the highest Atlantic Inflow flux followed by the Younger Dryas and Core Top reconstructions, and the LGM shows lowest flux. For these times, evidence from proxies of surface and bottom flux is coherent. However, the Early Holocene surface water gradients are comparable to those of the Younger Dryas or HS1 in terms of $\delta^{18} \mathrm{O}_{G \text {. bulloides }}$ and temperature (Table 3), despite this being a time of no sandy contourite deposition in the Gulf of Cadiz (Figure 9). We highlight the persistent warming experienced by surface water as it passed through the strait at this time (Table 3), which implies that unlike today [Folkard et al., 1997] there was little vertical mixing (see independent evidence for this 


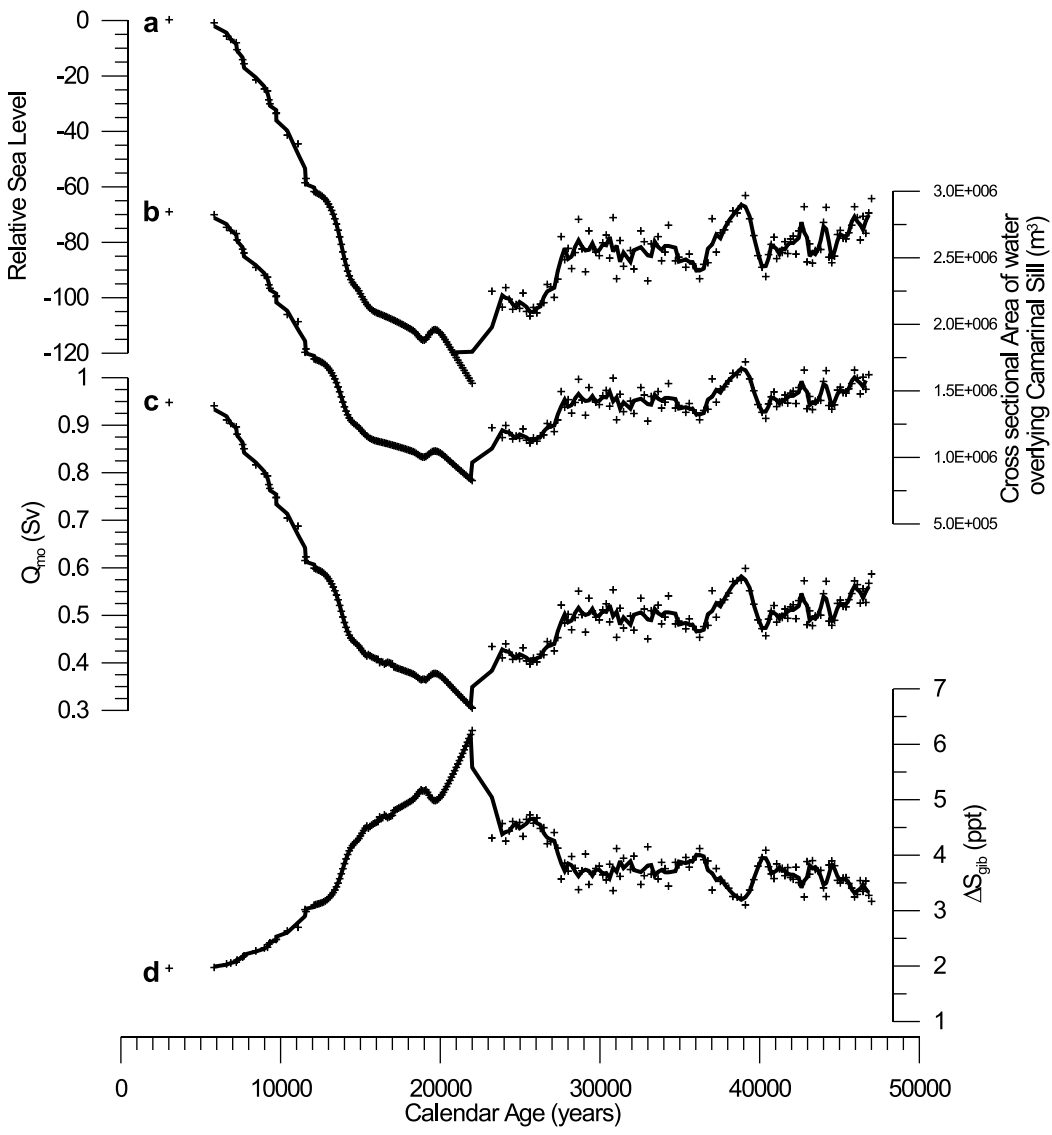

Figure 10. Impact of sea level changes over the last $50 \mathrm{ka}$ on the output of the Gibraltar exchange model (two-layer formulation). (a) Eustatic sea level; for deglacial (22-0 ka B.P.) the data set used is a Monte Carlo assessment of Sunda Shelf and Barbados data [Stanford et al., 2012]. MIS3 is taken from Red Sea isotope-derived data sets [Rohling et al., 2008a; Siddall et al., 2003]. Note that the apparent jump at $\sim 22 \mathrm{ka} \mathrm{B.P.} \mathrm{is} \mathrm{caused} \mathrm{by} \mathrm{the} \mathrm{different} \mathrm{sampling} \mathrm{resolutions} \mathrm{of} \mathrm{the} \mathrm{source} \mathrm{data} \mathrm{sets,} \mathrm{and} \mathrm{this} \mathrm{effect} \mathrm{is}$ too small to be significant when propagated through the later calculations. (b) Cross-sectional area of the Camarinal Sill, assuming a triangular cross section. (c) Flux of Mediterranean water at the Camarinal Sill $\left(Q_{\mathrm{MO}}\right)$. (d) Salinity anomaly of outflowing Mediterranean water $\left(\Delta S_{\text {gib }}\right)$.

in Rohling et al. [1995]), which in turn implies a strongly altered state of the exchange. We will return to this highly anomalous situation in section 6.4.

\section{QUANTITATIVE CONSTRAINT OF THE PAST EXCHANGE}

[42] Sections 4 and 5 lay out in detail some qualitative arguments for how and why the behavior of the Gibraltar exchange, and particularly the Mediterranean Outflow, has changed in the past. In this section, we aim to test these arguments quantitatively using a simple, one-dimensional model for the exchange based on the physical understanding of the system laid out in section 3. We present this as a series of numerical experiments considering the impact of changing eustatic sea level, changes in the mixing during the conversion of MOW to AMW, changes in the Mediterranean total buoyancy budget and surface water freshening both west and east of Gibraltar in turn in order to develop a mechanical understanding of the known paleoceanographic changes. Finally, we provide a first quantitative reconstruction of flow exchange at Gibraltar spanning the last $50 \mathrm{ka}$, built on the understanding developed during the numerical experiments.

\subsection{Control From Eustatic Sea Level}

[43] Previous studies have shown that sea level provides a major control on the salinity and flux of the water exported from the Mediterranean through the Strait of Gibraltar as a consequence of changing the cross-sectional area of water overlying the Camarinal Sill [Rogerson et al., 2005; Rohling and Bryden, 1994]. Consequently, first-order changes in the behavior of the Gibraltar exchange are indirectly controlled by continental ice volume. Figure 10a shows a compilation of global sea level data (taken from a new probabilistic synthesis for the last deglaciation [Stanford et al., 2012] and the Red Sea record for MIS3 [Rohling et al., 2008a; Siddall et al., 2003]), and Figure 9b shows the reconstructed crosssectional area of the Strait of Gibraltar assuming a simple triangular geometry [Bryden and Kinder, 1991]. Figures 10c and 10d, respectively, show MO flux and $\Delta S_{\text {gib }}$ estimated from equations (1)-(3), assuming no change in other relevant parameters. Under that assumption, sea level control 
can be analyzed as a purely two-layer solution without changes in the buoyancy loss from the Mediterranean [Bryden and Kinder, 1991].

[44] Figure 10 shows that the observed reorganization of the MO during Termination 1a, with a switch from a descending-limb-dominated flow to a geostrophic-limbdominated flow (see section 3.2), coincided with a nearly $4 \mathrm{~S}_{\mathrm{p}}$ change in model-output $\Delta S_{\text {gib }}$ and a more than $50 \%$ increase in modeled $Q_{\mathrm{MO}}$, which can be ascribed entirely to relaxation of the restriction on the exchange at Gibraltar due to sea level rise [Rogerson et al., 2005]. Consequently, it appears that relatively high density contrasts at Gibraltar are reflected in relatively high flow on the lower slope of the Gulf of Cadiz (GoC) and relatively low flow on the upper slope (Figure 9). It would follow that higher sea levels during MIS3 relative to the LGM [Siddall et al., 2003] may underlie the repeated observation of relatively strong flow on the upper slope of the Gulf of Cadiz [Toucanne et al., 2007] and a return to true sandy contourite deposition in many areas (N-2, D13686, and D13896). However, such a simple view of the system not only overlooks the impact of mixing (see section 3.2.2) but also fails to explain the observed millennial-scale variability during MIS3 in MD992339 [Voelker et al., 2006] and MD99-2341 [Toucanne et al., 2007], as sea level varies on an "Antarctic-style" rhythm [Rohling et al., 2008a; Siddall et al., 2003, 2008] (i.e., a temporal pattern similar to the Antarctic ice core records) whereas grain-size changes appear to occur on a "Greenland-style" rhythm (i.e., a temporal pattern similar to Greenland ice core records) (Figure 8). Similarly, sea level control alone cannot explain the periods of maximum flow during T1a and the Younger Dryas (Figure 9). Consequently, a significant amount of the variability within this system must reflect changes other than the impact of sea level on the Gibraltar exchange.

\subsection{The Role and Implications of Changes in Mixing}

[45] The rapid reduction of density within fast moving plumes highlighted in the PO94 model (section 1.3.2) represents a major problem for the simple view that highdensity MOW source water would result in a deeper-settling plume. The repeated reconstruction of AMW at $>1500 \mathrm{~m}$ depth during the last glacial on the basis of sedimentary, isotopic and ecological impacts [Löwemark et al., 2004; Schönfeld and Zahn, 2000; Skinner and Elderfield, 2007] indicates an approximate doubling of the settling depth of the plume, and although the observation of minor amounts of AMW mixing into bottom water at $2637 \mathrm{~m}$ depth during Heinrich stadials is less established [Skinner and Elderfield, 2007], this further indicates that the AMW is highly vertically mobile. However, increased $g^{\prime}$ values as we reconstruct for the late glacial (Figure 10) would result in a fast moving plume which would entrain more ambient water and thus should be expected to settle at similar or even shallower depths than today (section 3.2.2).

[46] To simulate this, we follow Rogerson et al. [2012] and use the $g^{\prime}$ and velocity of the outflowing MO water to produce estimates of settling depth using the PO94 model (equations (6)-(9)). A constant offset of $4.5^{\circ} \mathrm{C}$ from the SST values for MD99-2339 is used as a baseline temperature of Atlantic Ambient Water at the depth of the Camarinal Sill. We use this value for the offset as it produces values similar to today $\left(12^{\circ} \mathrm{C}\right)$ for time $t=0$. The only other parameter introduced into this model is the vertical density gradient of the eastern North Atlantic, which we estimate at $9 \times 10^{-7} \mathrm{~kg} \mathrm{~m}^{-4}$ following the original PO94 study [Price and O'NeillBaringer, 1994]. The maximum increase in calculated settling depth compared to contemporary sea level estimated by this model is $\sim 82 \mathrm{~m}$, and even accounting for the additional increase in apparent settling depth induced by the change in contemporary sea level from modern values, only $\sim 160 \mathrm{~m}$ of increased settling seems possible. This is inadequate to explain the empirical observations, and sensitivity analysis of the model suggests that altering hydrographic terms (temperature and salinity offsets) is highly unlikely to alter this picture [Rogerson et al., 2012].

[47] The simplest and most coherent answer to the problem is that the North Atlantic vertical density gradient $(\partial \rho / \partial z$ in equation (7)) has not been constant, but varies according to North Atlantic meridional overturning intensity [Gherardi et al., 2005; Hall et al., 2006; Lynch-Stieglitz et al., 2007; McManus et al., 2004; Peltier et al., 2006; Stanford et al., 2006]. There is strong physical justification for this argument, as a lack of deep convection in the northern North Atlantic should be reflected in a glacial North Atlantic Intermediate Water which is less dissimilar to surface water than is the case today. Indeed, important glacial-interglacial changes in $\partial \rho / \partial z$ have previously been suggested from benthic foraminiferal isotope data [Lynch-Stieglitz et al., 2007]. The response of $h^{\prime}$ to changes in $\partial \rho / \partial z$ is nonlinear (Figure 11 ), and a change in $\partial \rho / \partial z$ of $\sim 50 \%$ would be sufficient to bring the base of the AMW plume down to the $2000 \mathrm{~m}$ depth suggested by Schönfeld and Zahn [2000] and Rogerson et al. [2012]. Given that mixing small quantities of AMW down to $\sim 2600 \mathrm{~m}$ depth is argued to have occurred during Heinrich stadials on the basis of foraminiferal data from the Portuguese margin [Skinner and Elderfield, 2007], it seems likely that $\partial \rho / \partial z$ was even lower during periods of total collapse of NADW formation [Rogerson et al., 2012].

[48] This analysis results in the highly counterintuitive conclusion that variations in the settling depth of the AMW were not controlled by changes in the buoyancy loss in the Mediterranean, but instead by changes in the internal structure of the Atlantic [Rogerson et al., 2012]. This places paleoceanographic studies of the AMW plume within a completely new context, linking changes in the AMW plume's settling depth more closely to the freshwater cycle in the high-latitude North Atlantic than to that in the easternmost Mediterranean region.

\subsection{MIS3 Variability: What Mechanism Underlies Changes in Mediterranean Buoyancy Loss?}

[49] An important control on buoyancy loss from the Mediterranean basin is the cooling experienced by surface water, and there is extensive and coherent evidence for spatial and temporal changes in the degree of cooling within 


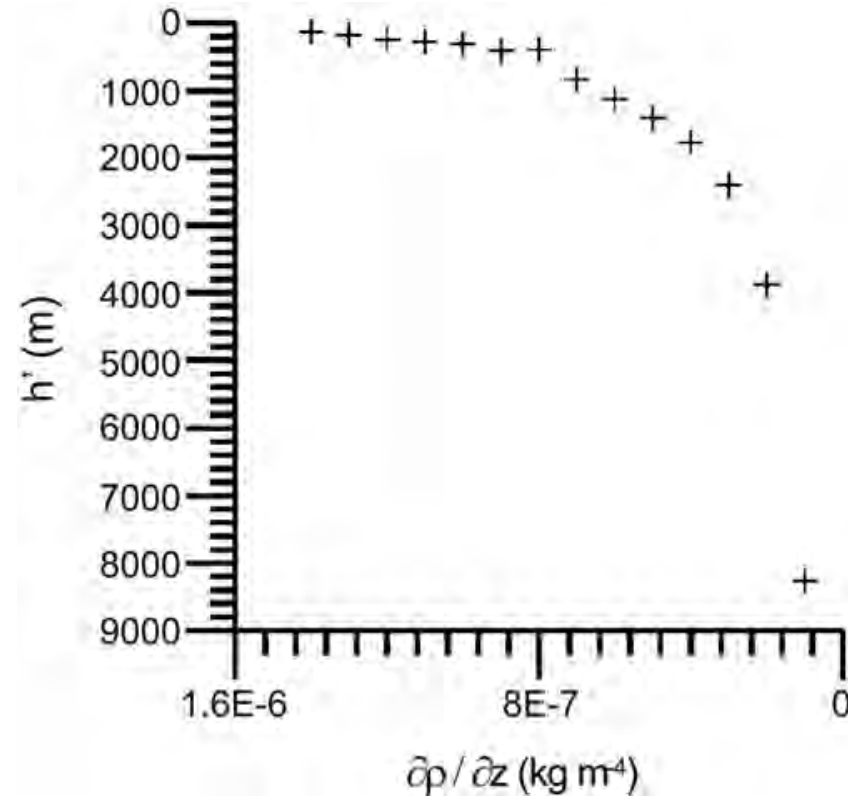

Figure 11. Control on AMW settling depth $\left(h^{\prime}\right)$ from variable Atlantic vertical density gradient $(\partial \rho / \partial z)$. Note the nonlinear control and strong impact at gradient lower than those today $\left(9 \times 10^{-7}\right)$.

the Mediterranean [Hayes et al., 2005; Kuhlemann et al., 2008] relative to such cooling outside that region [MARGO Project Members, 2009]. A critical observation from those studies is that, although SST changes were in phase between the midlatitude East Atlantic and the northwestern Mediterranean and easternmost Mediterranean, the LGMmodern changes in the Gulf of Lion are roughly double those of other areas. It is therefore feasible that some changes in exchange at Gibraltar will arise from changes in the Mediterranean heat budget, and this mechanism has repeatedly been considered as a major control on water mass dynamics both west and east of Gibraltar, especially on the Dansgaard-Oeschger timescale [Cacho et al., 2000, 2002; Toucanne et al., 2007; Voelker et al., 2006].

[50] To achieve the simplest solution to the question of SST impact on Gibraltar exchange activity, we use a single record of SST, derived from winter season Artificial Neural Network (ANN) analysis of planktonic foraminiferal assemblages in MD99-2339 (Figure 12a). We assume that the temperature difference between the Winter Atlantic Water and MIW was constant through time (i.e., a constant of $3^{\circ} \mathrm{C}$ cooling). This assumption is justified on the basis that the difference in winter SST in the easternmost Mediterranean (where the majority of MIW is generated) and Gulf of Cadiz was the same during the $\operatorname{LGM}\left(\sim 1^{\circ} \mathrm{C}\right)$ as it is today [Hayes et al., 2005]. Mediterranean Dense Water exported at Gibraltar then is assumed to be $0.5^{\circ} \mathrm{C}$ colder than the overlying Mediterranean Intermediate Water. To simulate the amplification of SST experienced in the Gulf of Lion (where the coldest dense water, WMDW, is generated) during cold phases (i.e., winter SST in MD99-2339 $<13^{\circ} \mathrm{C}$ ), we increase the cooling imposed on the exported dense water layer by $3^{\circ} \mathrm{C}$, based on the observed excess cooling in this sector in Hayes et al. [2005]. The resulting record of Mediterranean Dense Water (MDW) temperature is shown in Figure 12b. To calculate MO properties, we assume a constant 2:1 mixture of intermediate and dense waters, based on observations of the modern exchange (see section 2.1). A secondary impact of Mediterranean heat loss on MOW dynamics could theoretically arise from changes in the proportion of MOW being derived from the dense water layer, which would further cool the outflowing water mass [Millot, 2008]. However, even in the most extreme case, in which the entire $3^{\circ} \mathrm{C}$ cooling of Gulf of Lion surface water is transmitted to the dense water and the entire MOW is assumed to consist of this very cold water, we find virtually no impact on either $Q_{\mathrm{MO}}$ or $g^{\prime}$ within our model. Although SST control is an appealing intuitive explanation for the observation that bottom current velocity in the Gulf of Cadiz seems to vary on a "Greenland-style" rhythm [Toucanne et al., 2007; Voelker et al., 2006], it appears that thermal forcing is not physically capable of driving the changes observed, even during the strong SST variability of MIS3.

[51] Additional buoyancy loss during D-O stadials can be derived from increasing $X_{\text {med }}$, by either increasing the amount of evaporation from surface water and/or by decreasing the flux of fresh water returned to surface water via precipitation or continental runoff. Consequently, we have to explore whether it might be possible to drive Mediterranean Outflow variability by means of alterations to the Mediterranean freshwater cycle. Unfortunately, the Mediterranean net evaporation $\left(X_{\mathrm{med}}\right)$ is an exceptionally difficult parameter to derive from existing paleodata, as $X_{\text {med }}$ is not truly constrained by records of continental aridity. Pollen reconstructions indicate that in the continental areas adjacent to the Mediterranean, colder conditions may have coincided with increases in the arid plant groups [Tzedakis, 2007]. Lake level and isotopic compilations generally show similar trends toward arid conditions during colder periods [Roberts et al., 2008], although locally they may show the opposite [Haase-Schramm et al., 2004]. However, these data likely reflect reduced evaporation from the surface of the Mediterranean, which likely is associated with reduced freshwater export from the marine basin (see, for example, coupled model simulations that estimate reductions in $X_{\text {med }}$ of up to $50 \%$ relative to the present despite the apparent evidence of higher continental aridity [Bigg, 1995; Mikolajewicz, 2011]).

[52] Following Mikolajewicz [2011], we estimate the impact of variable $X_{\text {med }}$ as we did previously with temperature, using the modern value $(0.05 \mathrm{~Sv})$ for periods of similar SST to today and a reduced value $(0.03 \mathrm{~Sv})$ for periods when SST is more than $3^{\circ} \mathrm{C}$ lower than today. The combined result of both temperature and $X_{\text {med }}$ forcing are shown in Figures 12e and 12f; Figure 12 also shows three grain-size records from the Gulf of Cadiz (MD99-2339, D13891, and MD99-2341). There is virtually no modeled variability in $Q_{\text {MO }}$ arising from changes in temperature, with sea level maintaining a dominant control, but variable $X_{\text {med }}$ does seem 


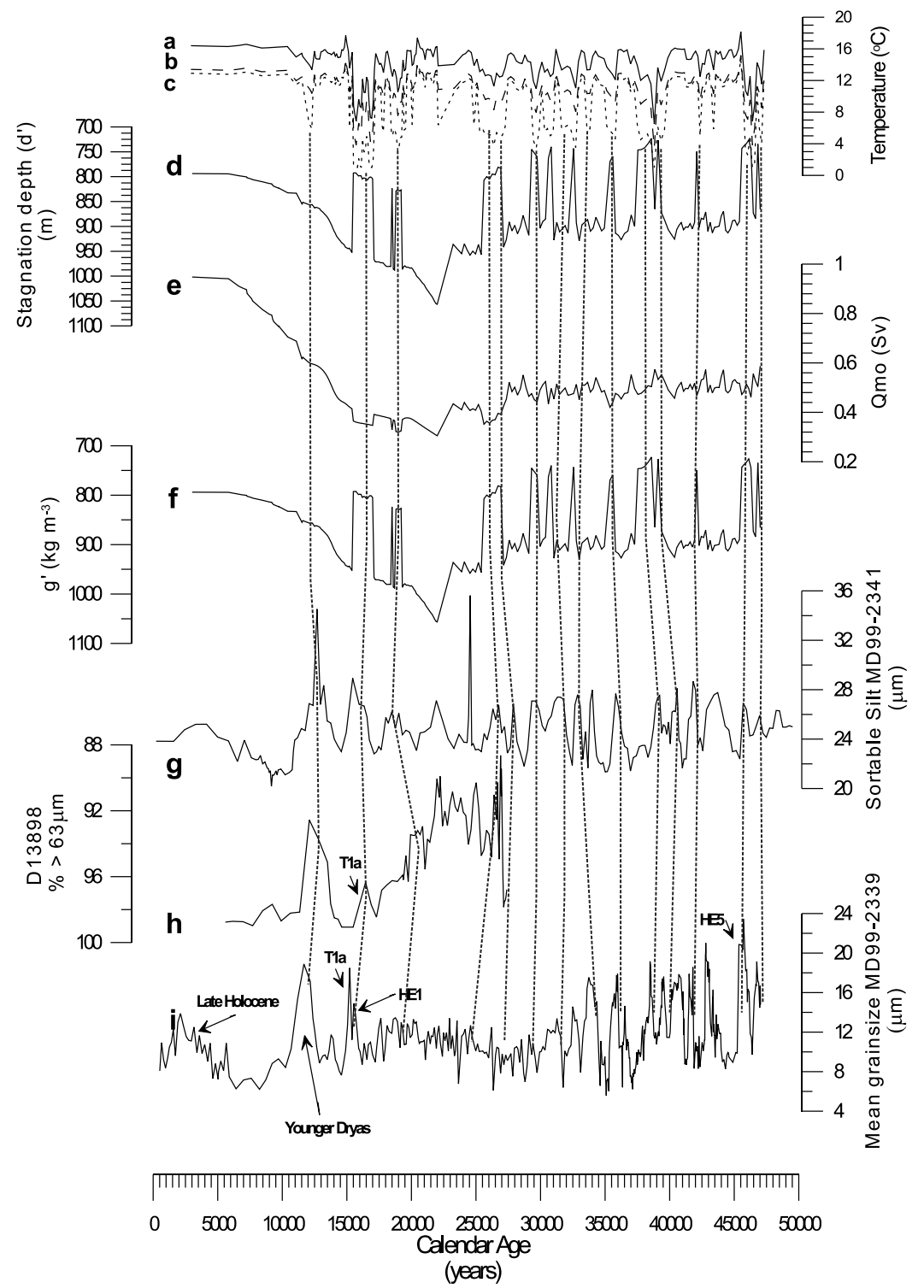

Figure 12. Impact of buoyancy forcing over the last $50 \mathrm{ka}$ on the Gibraltar exchange. (a) ANN winter sea surface temperature for MD99-2339 [Rogerson et al., 2010]. (b) Estimated temperature of Mediterranean Intermediate Water. (c) Estimated temperature of Mediterranean Deep Water. (d) Stagnation depth of Mediterranean Deep Water in the Alboran Sea $\left(d^{\prime}\right)$. (e) Flux of Mediterranean water at the Camarinal Sill $\left(\mathrm{Q}_{\mathrm{MO}}\right)$, showing impact of varying the proportional admixture of Mediterranean Deep Water. (f) Reduced density of outflowing Mediterranean water showing impact of varying the proportional admixture of Mediterranean Deep Water. (g) Grain-size record for MD99-2341 [Toucanne et al., 2007]. (h) Grain-size record for D13898 [Rogerson et al., 2005]. (i) Grain-size record for MD99-2339 [Voelker et al., 2006].

to be capable of driving variability in $g^{\prime}$ of similar relative magnitude and timing to changes in grain size in MD992341. However, periods of low $g^{\prime}$ correspond to coarse deposition at MD99-2341, suggesting that the geostrophic limb is more active at these times. This counterintuitive result is a likely consequence of minor $(\sim 100 \mathrm{~m})$ shoaling of the AMW plume due to changes in the initial density of MOW. Changes in settling depth of the magnitude of $100 \mathrm{~m}$ are plausibly driven by changes to the initial density of MOW even after the nonlinear impact of mixing is taken into account (see previous section). An alternative explanation for the changes in settling depth implied by the MD99-
2341 record would be that $\partial \rho / \partial z$ is varying in response to changes in $A M O C$ occurring on the Dansgaard-Oeschger rhythm, in a similar manner to our explanation for glacialinterglacial changes. As yet, neither our model nor the primary empirical evidence can distinguish the relative importance of these two potential mechanisms.

[53] As with the glacial-interglacial variability, our results strongly suggest that variability in flow activity of AMW during MIS3 primarily reflect changes in the settling depth of AMW within the Gulf of Cadiz. Variability in parameters such as velocity at a single site will therefore reflect the combined effects of initial density, settling depth and the 


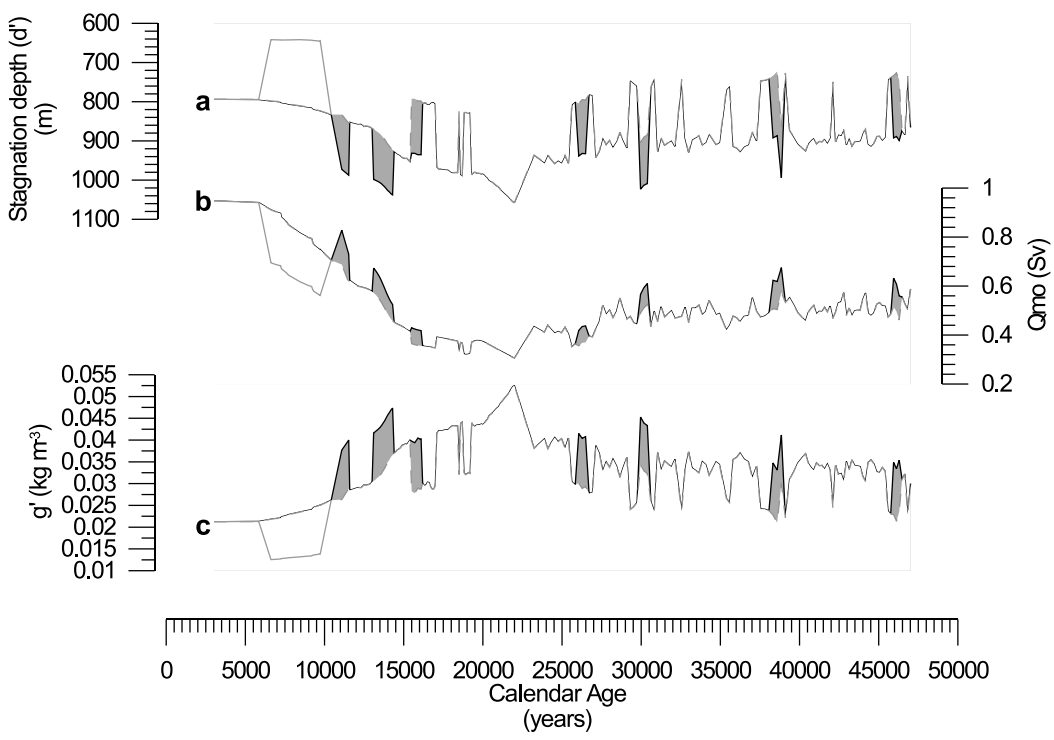

Figure 13. Estimates of changes in the past exchange considering the impact of Atlantic freshening. (a) Mediterranean Deep Water stagnation depth $\left(d^{\prime}\right)$. (b) Flux of Mediterranean water at the Camarinal Sill $\left(Q_{\mathrm{MO}}\right)$. (c) Reduced density of outflowing Mediterranean water $\left(g^{\prime}\right)$.

size of the MOW plume itself, and this means that inferences of MOW properties from single-location grain-size data will be extremely error-prone. The proximal position of MD992341 minimizes the potential impact of plume size and settling behavior, but even if the potentially dominant role of $\partial \rho / \partial z$ is overlooked in this case, significant differences between the modeled and empirical data remain, notably concerning the prominent peaks in grain size during Heinrich events 1 and 5, Termination 1a and the Late Holocene. With the exception of the Late Holocene, these periods share the characteristic that they are thought to be times of significant freshening in the North Atlantic [Bard et al., 1996; Hemming, 2004; Stanford et al., 2006].

\subsection{Impacts of Atlantic Freshening}

[54] Our modeled reconstruction of the exchange (shown in Figure 12) suggests that $Q_{\mathrm{MO}}$ and $g^{\prime}$ would be lower during the deglacial period, including the interval spanning Meltwater Pulse 1a (MWP1a) and Heinrich event 1, than the preceding interval of the LGM. This reflects the fact that sea level was already rising even during the earliest phases of the deglaciation. However, Rogerson et al. [2010] show that water mass exchange through the Strait of Gibraltar during Heinrich event 1 was substantially enhanced and extend previous analyses to show the same was probably true for MWP1a [Rogerson et al., 2006a]. Enhanced exchange is reflected in the development of Alboran Freshening Events $(A F E)$ in the westernmost Mediterranean [Rogerson et al., 2010; Sierro et al., 2005], decreased formation of WMDW relative to other millennial-scale stadial events due to enhanced surface water buoyancy in the Gulf of Lion [Frigola et al., 2008] despite intensive cooling [Rohling et al., 1998], enhanced sand deposition on the lower slope of the Gulf of Cadiz [Voelker et al., 2006], and erosion on the upper slope of the Gulf of Cadiz [Llave et al., 2006]. In combination, the evidence suggests substantially enhanced flow within the MIW system both during Heinrich events and Meltwater Pulses (both in terms of $Q_{\mathrm{MO}}$ and $g^{\prime}$ ), which was confirmed with general circulation modeling experiments concerning the Gibraltar exchange response to freshwater "hosing" in the North Atlantic [Rogerson et al., 2010]. It is likely that the enhanced flow reconstructions during earlier glacial terminations (see section 5.1) reflect a similar process, implying that meltwater pulses also affected the exchange during those terminations.

[55] Quantitatively, the impact of Atlantic freshening can be modeled as a period of decreased $S_{\text {atl }}$ and increase in $\Delta S_{\text {gib }}$, where the specific amount of change relates to the amount of meltwater mixed into North Atlantic surface waters. Calculations presented in Rogerson et al. [2010] suggest that $\Delta_{\mathrm{t}} Q_{\text {otal }} \propto 0.13 \Delta S_{\text {atl }}-4.7 \times 10^{-3} \Delta S_{\text {atl }}^{2}$. As the magnitude and temporal structure of freshwater admixture into inflowing Atlantic water during AFE cannot be sufficiently constrained with existing proxy methods [Rohling, 2007], and evidence from the Gulf of Cadiz suggests very different expression of the two most recent Heinrich events [Penaud et al., 2010; Rogerson et al., 2004, 2010], here we investigate the potential impact of an Atlantic-derived freshwater pulse using a hypothetical scenario. Figure 13 shows the impact of freshening on the parameters shown in Figure 12 under the assumption that an equal freshening of $2 \mathrm{~S}_{\mathrm{p}}$ occurred in the inflowing Atlantic water during all Heinrich events, during MWP1a and during the Younger Dryas ("Heinrich event 0"). The differences to the estimates of Figure 12, which were driven purely by mixing of the exchanged waters, are shown as gray areas. We particularly highlight the significant changes to $g^{\prime}$ that 
occur during Heinrich events and the Younger Dryas, bringing the modeled output into closer agreement with the grainsize data at both the shallow and deep locations (Figure 13). For completeness, we also show the modeled output for stagnation depth in the Alboran Sea, the critical parameter in regulating the export of MDW [Rogerson et al., 2008]. The hydraulic control on this system is a critical component of the regulation of deep ventilation of the western Mediterranean, and should be closely considered when interpreting paleoceanographic changes in this system.

\subsection{Impacts of Mediterranean Freshening}

[56] In addition to freshening in the North Atlantic, west of Gibraltar, it is well established that pulses of fresh water have occurred that were sufficient to disrupt deepwater formation in the eastern Mediterranean during precession minima [Cramp and O'Sullivan, 1999; Rohling, 1994]. During these periods a significant increase in freshwater influx, mainly sourced from North Africa [Osborne et al., 2008; Revel et al., 2010; Rohling et al., 2002; Scrivner et al., 2004], freshened the surface water of the eastern Mediterranean, preventing formation of Eastern Mediterranean Deep Water and altering the formation of LIW. Note that both empirical reconstructions and modeling indicate that some form of LIW formation did still occur, and that circulation at intermediate depth continued even throughout the most extreme surface freshening phases [Casford et al., 2002, 2003; De Lange et al., 2008; Myers et al., 1998]. This remnant overturning circulation is thought to have been mainly thermally driven at these times [Myers, 2002].

[57] Only one period of major freshening occurred during the $\sim 50$ kyr period covered by the records presented here, namely the "S1" sapropel period between about 10 and 6 ka. This freshening period is likely to have been characterized by disrupted exchange through the Strait of Gibraltar. Under present-day sea level conditions, even a decrease in $X_{\text {med }}$ of $\sim 5 \%$ would be sufficient to suppress supercritical flow over the Camarinal Sill, so that the exchange would no longer be hydraulically controlled. The result of this change would be that the Gibraltar exchange would no longer be physically comparable with the modern exchange, as was previously discussed for the Pliocene (section 4.1). Indeed, much reduced outflow of Mediterranean water during the times of S1 deposition is strongly implied by the complete absence of sandy contourites from the Gulf of Cadiz slope. Importantly, a submaximal exchange would generate a completely different pattern of surface water circulation adjacent to the Strait, which is consistent with the unexpectedly low zonal gradients of surface water properties during the deposition of S1 (Table 3 and section 5.3).

[58] Quantitative analysis of the exchanges response to Mediterranean freshening phases can only be illustrative, but we are able to demonstrate the relative impact compared to a basin with present-day-like evaporative conditions. The postglacial model output shown in Figure 13 contrasts conditions with no freshening in the Mediterranean (black line, same data as shown in Figure 12) and with freshening during the interval 10 to $6 \mathrm{ka}$ (red line). During this interval, the MIW layer has the same salinity as the inflowing Atlantic water, which we have achieved by reducing the $X_{\text {med }}$ to the value for the modern western Mediterranean $(0.015 \mathrm{~Sv})$. In this scenario, the eastern Mediterranean is therefore considered to be overturning only due to thermal forcing, as proposed by Myers [2002]. We acknowledge that this is an extreme scenario when compared with less reduced $X_{\text {med }}$ reconstructions from proxy data [Rohling, 1999] and models [Myers et al., 1998; Myers, 2002]. The extreme assumed forcing has a small impact on $Q_{\mathrm{MO}}$, but results in a prominent minimum in $g^{\prime}$ that would agree with minima in grain size in MD99-2339 and MD99-2431. We conclude that the period of inactivity between peak contourites II and III in the Gulf of Cadiz is consistent with being a local expression of enhanced runoff occurring in the eastern Mediterranean. More precise future analysis of this "Holocene contourite gap," especially investigation of possible muddy contourites positioned high on the slope that may be expected to have formed at this time, may reveal a considerable amount regarding basin-averaged buoyancy loss for the Mediterranean during the Early Holocene. This constraint would address keys issues regarding the intensity of the MIW and WMDW circulations at the time of the African Humid Period [deMenocal et al., 2000], capturing the basin-averaged magnitude of response to this low-latitude climate forcing.

\subsection{Final Output of Model Including Effects of SST, $X_{\text {med }}$ and Freshening}

[59] Figure 14 shows the final output of the model described above including all the discussed forcings. It is evident that none of the three grain-size records available are responding to one parameter in isolation. We do find, however, that the relative magnitudes, timing and rhythm of changes in MD992341 show close resemblance to the inferred total variability in $g^{\prime}$. The periods of inactivity and activity during the Holocene closely match changes in $g^{\prime}$, as is also the case during MIS3. However, the sign of the response is reversed, with high $g^{\prime}$ leading to high contour current activity during the Holocene but low activity during the glacial. This will reflect the position of the MD99-2341 location relative to the core of AMW on the slope at different time; during interglacials, MD99-2341 lies close to the core of the flow, and consequently, local velocity directly responds to changes in $g^{\prime}$, whereas during glacials, MD99-2341 lies above the core of the flow, and consequently, local velocity responds more to vertical changes in the plume, apparently bringing the core locations toward/away from the depth of maximum velocity. Again, this behavior highlights the dangers of inferring past changes in the MOW system from single location records.

[60] The inability of the model to simulate the $>1000 \mathrm{~m}$ variability in the vertical position of AMW without variable eastern North Atlantic $\partial \rho / \partial z$ is highlighted by the very small variability in settling depth simulated throughout the last $50 \mathrm{ka}$ (Figure 14). To take the analysis presented here to its logical conclusion, we require further information 


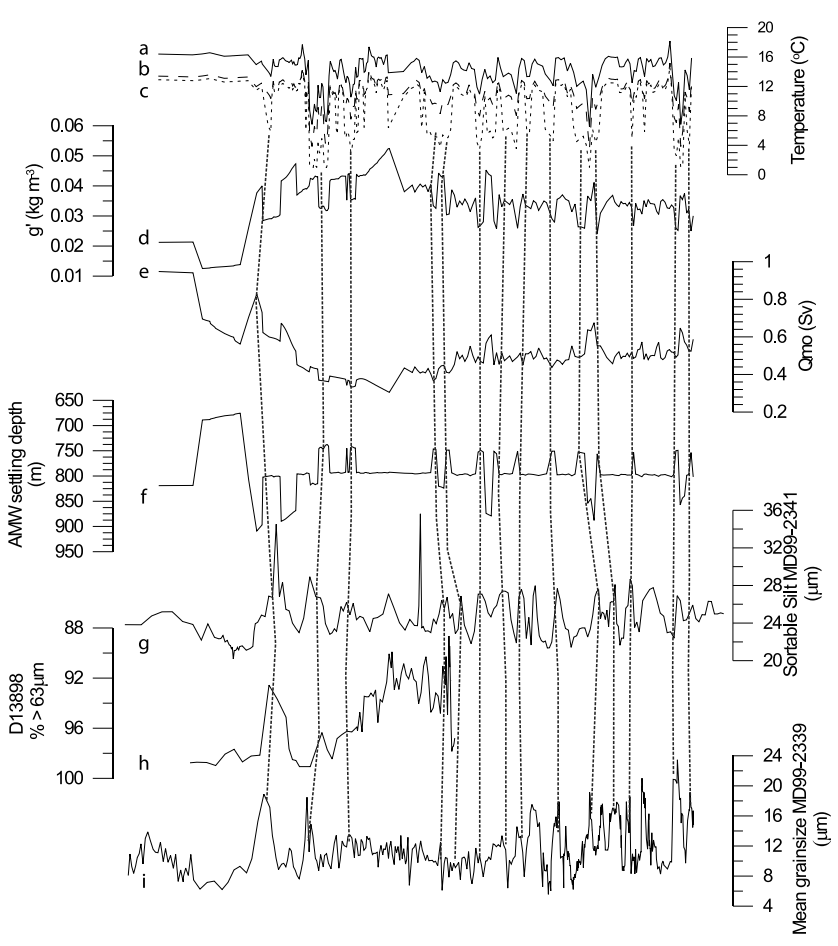

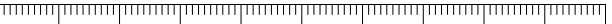

$\begin{array}{lllllllllll}0 & 5000 & 10000 & 15000 & 20000 & 25000 & 30000 & 35000 & 40000 & 45000 & 50000\end{array}$ Calendar Age
(years)

Figure 14. Final output of combined model including all effects: (a, d) $g^{\prime}$; (b, e) $Q_{\text {MOW }}$; (c, f) the settling depth of Atlantic Mediterranean Water assuming invariable $\partial \rho / \partial z$; (g) the grain-size record for MD99-2341 [Toucanne et al., 2007]; (h) the grain-size record for MD99-2339 [Voelker et al., 2006]; (i) the grain-size record for D13898 [Rogerson et al., 2005].

about the temporal changes in the vertical position of the plume (i.e., regarding $\partial \rho / \partial z$ ) before we could proceed to estimations of the AMW contributions at the depth levels of individual cores.

\section{OUTSTANDING PROBLEMS WITH CHARACTERIZING THE GIBRALTAR EXCHANGE SYSTEM}

\subsection{Quantitative Constraint of the Relationship Between Hydrography and Sedimentary Parameters}

[61] Although there are established qualitative links between sedimentary parameters such as grain size [HernándezMolina et al., 2003; Kenyon and Belderson, 1973], benthic foraminiferal assemblages [Schönfeld, 2002] and benthic foraminiferal stable isotopes [Rogerson et al., 2011], proper quantitative analysis of past MOW distribution remains beyond our reach [Rogerson et al., 2011]. This primarily reflects a lack of coherence between single-location proxies of MOW presence and the "real" physical hydrography (i.e., the difficulty of linking individual sediment core records to specific changes in MOW parameterization). The major priority for further studies of this and similar systems must be to solve this problem and establish at least paired if not multiple sedimentological or geochemical data from which the more than three water mass end-members active within the Gulf of Cadiz can be distinguished. We highlight that it is not necessary to calibrate these data to "standard" hydrographic parameters (e.g., velocity, in situ temperature, and salinity), overcoming some of the shortcomings of paired foraminiferal $\mathrm{Mg} / \mathrm{Ca}$ and $\delta^{18} \mathrm{O}_{\text {calcite }}$ analyses. Instead, these parameters can more simply be used in a direct manner to "unmix" the contribution of the three source waters in the same manner as temperature and salinity data in standard physical oceanography practice [Rogerson et al., 2011]. A very promising avenue in multiproxy studies concerns sediment-derived radioisotope measurements of isotopes of neodymium and lead [Stumpf et al., 2010]. Because those methods essentially resolve water provenance, they are able to differentiate Mediterranean-sourced waters from Atlanticsourced waters, which is a major advantage over proxy systems based on foraminiferal carriers such as $\delta^{18} \mathrm{O}_{\text {calcite }}$ which will typically struggle to differentiate pure MOW from linear mixes of Atlantic deep and intermediate waters [Rogerson et al., 2011].

\subsection{The Gibraltar Exchange as a Negative Feedback Mechanism to Atlantic Meridional Overturning}

[62] The occurrence of peaks in $Q_{\mathrm{MO}}$ and $g^{\prime}$ during the last deglaciation (Figure 14) has previously been proposed to play a role in restarting Atlantic meridional overturning (AMOC) subsequent to periods of "shutdown" [Rogerson et al., 2006a]. We are able to quantify this effect by converting the density offset and flux of water at Gibraltar calculated above to an estimate of density flux. Figure 15 shows this estimate for our final model (Figure 14) compared to the ${ }^{231} \mathrm{~Pa} /{ }^{230} \mathrm{Th}$ record from OCE326-GGC5 from the Bermuda Rise, which is considered an indicator of AMOC [McManus et al., 2004]. Due to the balancing effects of changing $\Delta S_{\text {gib }}$ and $Q_{\text {MOW }}$ there is less than $25 \%$ difference between modern and "background" glacial density flux from the Mediterranean despite a $>50 \%$ change in $Q_{\text {MOw }}$. Given that evaporative loss from the northern North Atlantic generally was lower during the LGM [Weber et al., 2007], this supports the concept that the Mediterranean represented a larger proportion of the buoyancy loss from the North Atlantic as a whole, increasing its importance for sustaining AMOC. Moreover, we find that periods of high AMOC intensity during the deglacial, especially the Bølling-Allerød interstadial, corresponded to significant increases in the Mediterranean buoyancy forcing. Further inspection shows that there are increases in Mediterranean buoyancy flux prior to both the AMOC recoveries shown by the McManus et al. [2004] record (see arrows in Figure 15). This supports previous suggestions that the Mediterranean responds to changes in Atlantic deep circulation inversely [Rogerson et al., 2010] and may have been responsible for reinitiating AMOC after periods of shutdown [Rogerson et al., 2006a], at least in part [Knorr and Lohmann, 2007; Stanford et al., 2011; Thornalley et al., 2010]. In section 4.3 we showed that this inverse relationship extends into the last glacial, at least during Heinrich stadial periods, when again maxima in $Q_{\mathrm{MO}}$ and $g^{\prime}$ at Gibraltar corresponded to an AMOC "shutdown" phase (section 6.4). 


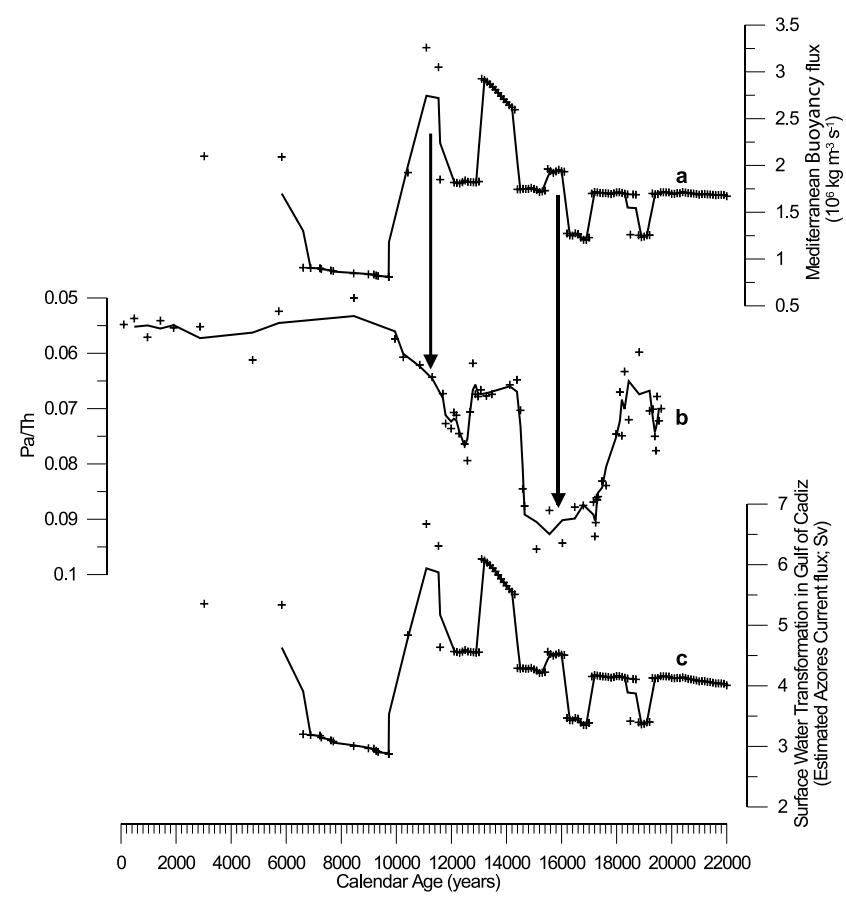

Figure 15. Comparison of Mediterranean buoyancy flux with the $\mathrm{Pa} / \mathrm{Th}$ Atlantic meridional overturning strength proxy [McManus et al., 2004]. (a) Mediterranean buoyancy flux estimated from the density difference between inflowing Atlantic and outflowing Mediterranean water at Gibraltar and the flux of Mediterranean water $\left(Q_{\mathrm{MO}}\right)$. The data are shown with a 3-point running average. (b) $\mathrm{The} \mathrm{Pa} / \mathrm{Th}$ Atlantic overturning record of McManus et al. [2004] with a 5-point running average. (c) The flux of the Azores Current, with a 3-point running average.

[63] The linkage between AMW formation and the generation of the Azores Front and Current system (see section 1.3.3) means that the presence and relative strength of the Azores Current can be estimated from the flux and mixing of the MO plume in the GoC [Özgökmen et al., 2001]. Figure $15 \mathrm{c}$ presents an estimate of water export from the Gulf of Cadiz, calculated from the flux of MO at Gibraltar $\left(Q_{\mathrm{MO}}\right)$ and the proportional admixture of ambient water during the formation of AMW, plus the inflow of Atlantic water to the Mediterranean at Gibraltar $\left(Q_{\mathrm{AI}}\right)$. Although this estimate indicates that the Azores Current system should always have been present, which compares well with the empirical evidence [Rogerson et al., 2004; Schiebel et al., 2002a] and theoretical expectations [Jia, 2000; Kida et al., 2008], and also that it is highly variable and strongly tied to the Mediterranean buoyancy flux (Figure 15a). The permanence of this hydrographic barrier explains the repeated observation of steep gradients in surface water properties in the midlatitude North Atlantic during cooling periods [Chapman and Maslin, 1999; Eynaud et al., 2009; Penaud et al., 2010; Rogerson et al., 2010; Watkins et al., 2007], and strong, eastward flow during Heinrich stadials also explains anomalies in the biogeochemistry of surface waters off northwest Africa [Plewa et al., 2006]. Moreover, it may be critical in forming a barrier to southward transport of icebergs beyond the latitude of $\sim 35^{\circ} \mathrm{N}$ [Bigg et al., 2010]. The front's midlatitude impediment to the expansion of ocean-surface cooling and freshening signals would have strongly influenced atmospheric responses at these latitudes during Heinrich stadials. Combined with the strong feedback from North Atlantic buoyancy, it is evident that the coupled behavior of the Mediterranean and Atlantic provides an important complicating factor in regulating the global response to abrupt events derived from the North Atlantic.

\subsection{Defining the Mediterranean Buoyancy Budget}

[64] Although the calculations presented here represent the - to date-most comprehensive and quantitatively coherent estimates of change in the Gibraltar exchange over the last glacial cycle, they still only crudely resolve changes in the Mediterranean buoyancy budget. Essentially, these changes are represented by arbitrary increases in thermal and freshwater forcing during cold periods and an increase in runoff during the Early Holocene. The lack of a clear way to resolve these critical parameters highlights a general lack of specific, quantifiable knowledge about (1) the past net evaporative export flux from the Mediterranean (and we emphasize again that this is not the same as continental aridity; see section 6.2), (2) the temperature of waters within the interior of the western Mediterranean and (3) the depth of the MIW/MDW interface within the western Mediterranean $\left(d^{\prime}\right.$ in equation (5)) from which the proportional admixture of MDW at Gibraltar could be investigated. Determining the past state of Mediterranean net evaporative flux will require spatially resolved data on sea surface temperature and salinity, magnitude fluxes at major loci of freshwater supply (Black Sea, Nile and other eastern North African paleorivers, Rhone, Ebro and Po) and hydrographic status of adjacent continents for particular time slices being used to groundtruth general circulation modeling experiments. Establishing past changes in interior temperature and $d^{\prime}$ is largely dependent on having effective benthic paleothermometers, most likely foraminiferal $\mathrm{Mg} / \mathrm{Ca}$, the calibration of which remains a matter of active research for the Mediterranean [Ferguson et al., 2008; Hoogakker et al., 2009].

[65] Defining these three parameters will be challenging, but should be considered an essential aim for Mediterranean paleoclimatologists. It would allow-for the first time - a truly detailed, empirically derived picture of changes in circulation within the entire Mediterranean. Moreover, it would shed light on the interaction between Mediterranean and Atlantic circulation in the past, especially the potentially crucial negative feedback to AMOC.

\section{CONCLUSIONS}

[66] The Gibraltar exchange is a critical feature in regulating the hydrography of both the Mediterranean Sea and the eastern North Atlantic Ocean. It is implicated in maintaining Atlantic meridional overturning in the modern ocean, but may be much more important in restarting overturning subsequent to collapses.

[67] Exchange at Gibraltar responds to a number of external forcing mechanisms. First-order changes are driven 
by changes in eustatic sea level, and although the direct impact of cooling seems to be too small to resolve, we do find subordinate influences from thermally induced changes to Mediterranean net evaporation, as well as from freshening of surface water both west and east of the strait. Freshening on the Atlantic side results in enhanced exchange with increased deposition of sandy contourites in the Gulf of Cadiz, while freshening in the eastern Mediterranean has the opposite impact.

[68] Flow velocity of the Mediterranean water in the Gulf of Cadiz reflects a composite impact of plume size, settling depth and initial density. However, $g^{\prime}$ shows some degree of coherence with the most proximal long grain-size record available (MD99-2341). On glacial to interglacial timescales, low $g^{\prime}$ is reflected in enhanced flow velocity on the upper slope, until the condition of maximal flow at Gibraltar is no longer satisfied, under which conditions contourites fail to form. The best example of this is the period of Mediterranean sapropel, S1, during which time a prominent "Holocene contourite gap" occurs in the Gulf of Cadiz record. Increasing long-term mean $g^{\prime}$ through the Late Neogene also provides an adequate explanation for changes in AMW distribution on timescales $>100 \mathrm{ka}$. The first, abrupt appearance of evidence of AMW activity on the slope at around $3.22 \mathrm{Ma}$ is strongly delayed relative to the opening of the Strait of Gibraltar (5.33 Ma). It reflects the combined influence of changing sea level and Mediterranean buoyancy loss reaching maximal conditions for the first time around 3.22 Ma B.P. Continued increases in externally forced $g^{\prime}$ resulted in an increase in the velocity of AMW and its gradual shoaling, due to increased admixture of ambient water into the plume.

[69] We also find that a significant proportion of the variability of contourite formation in the Gulf of Cadiz is controlled by the structure and properties of the North Atlantic. Due to the negative feedback influences of the admixture of ambient Atlantic water into the outflow plume, the position of contourites on the slope is found to be insensitive to changes in $g^{\prime}$ on glacial to interglacial timescales. Sediment entrainment also is insufficient to explain differences in AMW settling depth. We conclude that observed changes in AMW settling depth on timescales shorter than 100 ka must reflect changes in the Atlantic vertical density gradient. The same behavior could also be controlling grain-size changes in the Gulf of Cadiz on Dansgaard-Oeschger timescales in MIS3, but it is impossible to assess from the data available to what extent this reflects subtle changes in settling depth from the influence of $g^{\prime}$ and/or to what extent Atlantic vertical density gradients are driving these changes.

[70] The close coupling of Gibraltar exchange dynamics and conditions in the high-latitude Atlantic means that the Mediterranean may operate as a "negative feedback" for North Atlantic climate changes. High-latitude cooling reduces Atlantic meridional overturning, but also permits/reflects freshening of Atlantic surface water. The consequence is an increased loss of buoyancy from the Atlantic into the Mediterranean via the Gibraltar exchange, preconditioning a return to a higher meridional overturning state. Conversely, high-latitude warming leads to increased freshwater runoff from North Africa. Consequently, the Mediterranean buoyancy flux decreases, reducing the promotion of Atlantic overturning derived from AMW. This effect, and the coupled impact of intensifying the flow of the Azores Current in the midlatitude North Atlantic, means that the magnitude of impact from the Gibraltar exchange on the behavior of the Atlantic will be highest when the Atlantic overturning is weakest and vice versa. Consequently, the repeated demonstration that the AMW is not a major promoter of $\mathrm{AMOC}$ today (when AMOC is strong) is not necessarily material to the concept that AMW may have been an important promoter of AMOC in the past.

[71] Given the very counterintuitive way in which the Strait of Gibraltar-Mediterranean Outflow system behaves, we strongly recommend that any analysis of the paleoceanography of this system includes a significant quantitative analysis of the kind presented herein. Without this quantitative supporting work, qualitative interpretations of how the system has responded to external forcing are unlikely to be robust.

\section{GLOSSARY}

AC/AF: Azores Current / Azores Front. A zonal flow of water in the midlatitude North Atlantic associated with strong upwelling on its northern side.

AFE: Alboran Freshening Event. A period of significant freshening in surface water within the Alboran Sea arising from melting ice icebergs during Heinrich events.

Al: Atlantic Inflow. The bottom current forming the lower layer of the Gibraltar exchange.

AIW: Atlantic Inflow Water. The water comprising the AI (see Table 1).

AMW: Atlantic Mediterranean Water. A mixture of MOW and ambient Atlantic water produced by entrainment of water into the MO west of the Camarinal Sill (see Table 1).

D-O stadials/interstadials: Dansgaard-Oeschger stadials/interstadials. Danshaard-Oeschger cycles are cyclic variations between cold and warm periods on a typical $\sim 1.5 \mathrm{ka}$ wavelength that are prominent in the Northern Hemisphere during Marine Isotope Stage 3.

GoC: Gulf of Cadiz. The large embayment to the west of the Strait of Gibraltar.

LGM: Last Glacial Maximum. The most recent maximum extent of Northern Hemisphere glaciers (24-20 ka B.P.).

LIW: Levantine Intermediate Water. Cool and very salty water produced in the easternmost Mediterranean and contributing to the Mediterranean Outflow (see Table 1).

MAW: Modified Atlantic Water. A mixture of AIW and MOW produced by upwelling east of the Camarinal Sill (see Table 1).

MDW: Mediterranean Dense Water. Cold and salty water forming a bottom layer at the Camarinal Sill (see Table 1).

MIS: Marine Isotope Stage. A division of time as determined by global variations in marine $\delta^{18} \mathrm{O}$ variability. 
MIW: Mediterranean Intermediate Water. Cool and salty water forming an intermediate depth layer at the Camarinal Sill (see Table 1).

MO: Mediterranean Outflow. The bottom current forming the lower layer of the Gibraltar exchange.

MOC: Meridional Overturning Circulation. The total northward /southward flow in the Atlantic, averaged over latitude and depth.

MOW: Mediterranean Outflow Water. The water comprising the MO (see Table 1).

MWP1a: Meltwater Pulse 1a. The most recent largescale collapse of Northern Hemisphere ice sheets, resulting in a prominent pulse of fresh water entering the North Atlantic.

QI: A sedimentary sequence of contourites identified on the north GoC margin using seismic analysis dating from the Late Quaternary.

QII: A sedimentary sequence of contourites identified on the north $\mathrm{GoC}$ margin using seismic analysis dating from the Early Quaternary.

TDW: Tyrrhenian Dense Water. Cool and salty water produced in the Tyrrhenian Sea and contributing to the Mediterranean Outflow (see Table 1).

WIW: Winter Intermediate Water. Cool water produced on the southern Iberian margin and contributing to the Mediterranean Outflow (see Table 1).

WMDW: Western Mediterranean Deep Water. Cold and saline water produced in the Gulf of Lion and contributing to the Mediterranean Outflow (see Table 1).

[72] ACKNOWLEDGMENTS. We thank Mark Moldwin for his careful editing, and an anonymous reviewer for helping us improve the manuscript for publication. M.R. thanks Nabil Khelifi and Juan Miguel Vargas for permission to reproduce their excellent figures. This study contributes to U.K. Natural Environment Research Council (NERC) projects NE/I009906/1, NE/E01531X/1, NE/D001846/1, and NE/H004424/1.

[73] Mark Moldwin thanks one anonymous reviewer.

\section{REFERENCES}

Abu-Zied, R. H., E. J. Rohling, F. J. Jorissen, C. Fontanier, J. S. L. Casford, and S. Cooke (2008), Benthic foraminiferal response to changes in bottom-water oxygenation and organic carbon flux in the eastern Mediterranean during LGM to Recent times, Mar. Micropaleontol., 67(1-2), 46-68, doi:10.1016/j.marmicro.2007. 08.006.

Aleinik, D. L. (1998), The structure and evolution of a Meddy and Azores Frontal Zone in autumn 1993, Oceanol. Engl. Transl., 38(3), 312-322.

Alhammoud, B., P. T. Meijer, and H. A. Dijkstra (2010), Sensitivity of Mediterranean thermohaline circulation to gateway depth: A model investigation, Paleoceanography, 25, PA2220, doi:10.1029/2009PA001823.

Álvarez, M., F. F. Pérez, D. R. Shoosmith, and H. L. Bryden (2005), Unaccounted role of Mediterranean water in the drawdown of anthropogenic carbon, J. Geophys. Res., 110, C09S03, doi:10.1029/2004JC002633.

Alves, M., F. Gaillard, M. Sparrow, M. Knoll, and S. Giraud (2002), Circulation patterns and transport of the Azores FrontCurrent system, Deep Sea Res., Part II, 49, 3983-4002, doi:10.1016/S0967-0645(02)00138-8.
Alves, M. L. G. R., and A. C. DeVerdière (1999), Instability dynamics of a subtropical jet and applications to the Azores Front current system: Eddy-driven mean flow, J. Phys. Oceanogr., 29, 837-864, doi:10.1175/1520-0485(1999)029<0837:IDOASJ $>2.0$. $\mathrm{CO} ; 2$.

Ambar, I., and M. R. Howe (1979), Observations of the Mediterranean Outflow: II. The deep circulation in the vicinity of the Gulf of Cadiz, Deep Sea Res., Part A, 26, 555-568.

Angel, M. V. (1989), Vertical profiles of pelagic communities in the vicinity of the Azores Front and their implications to deep ocean ecology, Prog. Oceanogr., 22, 1-46, doi:10.1016/00796611(89)90009-8.

Armi, L., and N. A. Bray (1982), A standard analytical curve of potential temperature versus salinity for the western North Atlantic, J. Phys. Oceanogr., 24, 1295-1316.

Armi, L., and D. M. Farmer (1986), Maximal two-layer exchange through a contraction with barotropic flow, J. Fluid Mech., 164, 27-51, doi:10.1017/S0022112086002458.

Armi, L., and D. M. Farmer (1988), The flow of Mediterranean water through the Strait of Gibraltar, Prog. Oceanogr., 21, 1-105, doi:10.1016/0079-6611(88)90055-9.

Bard, E., B. Hamelin, M. Arnold, L. Montaggionis, G. Cabiochll, G. Faurell, and F. Rougerie (1996), Deglacial sea-level record from Tahiti corals and the timing of global meltwater discharge, Nature, 382, 241-244, doi:10.1038/382241a0.

Bethoux, J. P. (1979), Budgets of the Mediterranean Sea. Their dependence on the local climate and on the characteristics of the Atlantic waters, Oceanol. Acta, 2(2), 157-163.

Bethoux, J. P., and B. Gentili (1999), Functioning of the Mediterranean Sea: Past and present changes related to freshwater input and climate changes, J. Mar. Syst., 20(1-4), 33-47, doi:10.1016/S0924-7963(98) 00069-4.

Bigg, G. R. (1995), Aridity of the Mediterranean Sea at the Last Glacial Maximum: A reinterpretation of the $\delta^{18} \mathrm{O}$ record, Paleoceanography, 10, 283-290, doi:10.1029/94PA03165.

Bigg, G. R., T. D. Jickells, P. S. Liss, and T. J. Osborn (2003), The role of the oceans in climate, Int. J. Climatol., 23(10), 1127-1159, doi:10.1002/joc.926.

Bigg, G. R., R. C. Levine, C. D. Clark, S. L. Greenwood, H. Haflidason, A. L. C. Hughes, A. Nygård, and H. P. Sejrup (2010), Last glacial ice-rafted debris off southwestern Europe: The role of the British-Irish Ice Sheet, J. Quat. Sci., 25(5), 689-699, doi:10.1002/jqs.1345.

Blanc, P. L. (2002), The opening of the Plio-Quaternary Gibraltar Strait: Assessing the size of a cataclysm, Geodin. Acta, 15(5-6), 303-317, doi:10.1016/S0985-3111(02)01095-1.

Blanc, P. L. (2006), Improved modelling of the Messinian Salinity Crisis and conceptual implications, Palaeogeogr. Palaeoclimatol. Palaeoecol., 238(1-4), 349-372, doi:10.1016/j.palaeo.2006.03.033.

Borenäs, K. M., A. K. Wåhlin, I. Ambar, and N. Serra (2002), The Mediterranean Outflow splitting: A comparison between theoretical models and CANIGO data, Deep Sea Res., Part II, 49, 4195-4205, doi:10.1016/S0967-0645(02)00150-9.

Broecker, W. (1991), The great ocean conveyor, Oceanography, 4(2), 79-89.

Bryden, H. L. (1993), Sill exchange to and from enclosed seas, in Mediterranean Symposium, edited by N. F. R. D. Croce, pp. 17-41, Inst. Sci. Ambientali Mar., Genoa, Italy.

Bryden, H. L., and T. Kinder (1991), Steady two-layer exchange through the Strait of Gibraltar, Deep Sea Res., Part A, 38, 445-463.

Bryden, H. L., and H. M. Stommel (1982), Origins of the Mediterranean Outflow, J. Mar. Res., 40, suppl., 55-71.

Bryden, H. L., and H. M. Stommel (1984), Limiting processes that determine basic features of the circulation in the Mediterranean Sea, Oceanol. Acta, 7(3), 289-296.

Bryden, H. L., E. C. Brady, and R. D. Pillsbury (1988), Flow through the strait of Gibraltar, in Seminario sobre la Oceanografia fisica del Estrecho de Gibraltar, edited by J. L. Almazan et al., pp. 166-194, SECEG, Madrid. 
Bryden, H. L., J. Candela, and T. H. Kinder (1994), Exchange through the Strait of Gibraltar, Prog. Oceanogr., 33, 201-248, doi:10.1016/0079-6611(94)90028-0.

Cacho, I., J. O. Grimalt, C. Pelejero, M. Canals, F. J. Sierro, J. A. Flores, and N. Shackleton (1999), Dansgaard-Oesschger and Heinrich event imprints in Alboran Sea palaeotemperatures, Paleoceanography, 14(6), 698-705, doi:10.1029/1999PA900044.

Cacho, I., J. O. Grimalt, F. J. Sierro, N. Shackleton, and M. Canals (2000), Evidence for enhanced Mediterranean thermohaline circulation during rapid climatic coolings, Earth Planet. Sci. Lett., 183, 417-429, doi:10.1016/S0012-821X(00)00296-X.

Cacho, I., N. Shackleton, H. Elderfield, F. J. Sierro, and J. O. Grimalt (2002), Response of the western Mediterranean Sea to the rapid climatic variability that occurred during the last 50,000 years. A molecular biomarker approach, J. Mar. Syst., 33-34, 253-272, doi:10.1016/S0924-7963(02)00061-1.

Casford, J. S. L., E. J. Rohling, R. Abu-Zied, S. Cooke, C. Fontanier, M. Leng, and V. Lykousis (2002), Circulation changes and nutrient concentrations in the Late Quaternary Aegean Sea: A nonsteady state concept for sapropel formation, Paleoceanography, 17(2), 1024, doi:10.1029/2000PA000601.

Casford, J. S. L., E. J. Rohling, R. H. Abu-Zied, C. Fontanier, F. J. Jorissen, M. J. Leng, G. Schmiedl, and J. Thomson (2003), A dynamic concept for eastern Mediterranean circulation and oxygenation during sapropel formation, Palaeogeogr. Palaeoclimatol. Palaeoecol., 190, 103-119, doi:10.1016/S0031-0182(02) 00601-6.

Chapman, M. R., and M. A. Maslin (1999), Low-latitude forcing of meridional temperature and salinity gradients in the subpolar North Atlantic and the growth of glacial ice sheets, Geology, 27, 875-878, doi:10.1130/0091-7613(1999)027<0875:LLFOMT>2.3.CO;2.

Cramp, A., and G. O'Sullivan (1999), Neogene sapropels in the Mediterranean: A review, Mar. Geol., 153(1-4), 11-28, doi:10.1016/S0025-3227(98)00092-9.

Daniault, N., J. P. Mazé, and M. Arhan (1994), Circulation and mixing of Mediterranean water west of the Iberian Peninsula, Deep Sea Res., Part I, 41, 1685-1714, doi:10.1016/0967-0637(94) 90068-X.

de Boer, B., R. S. W. van de Wal, R. Bintanja, L. J. Lourens, and E. Tuenter (2010), Cenozoic global ice-volume and temperature simulations with 1-D ice-sheet models forced by benthic $\delta^{18} \mathrm{O}$ records, Ann. Glaciol., 51, 23-33, doi:10.3189/ 172756410791392736

De Lange, G. J., J. Thomson, A. Reitz, C. P. Slomp, M. Speranza Principato, E. Erba, and C. Corselli (2008), Synchronous basinwide formation and redox-controlled preservation of a Mediterranean sapropel, Nat. Geosci., 1(9), 606-610, doi:10.1038/ngeo283.

deMenocal, P., J. Ortiz, T. Guilderson, J. Adkins, M. Sarnthein, L. Baker, and M. Yarusinsky (2000), Abrupt onset and termination of the African Humid Period: Rapid climate responses to gradual insolation forcing, Quat. Sci. Rev., 19, 347-361, doi:10.1016/S0277-3791(99)00081-5.

Esteras, M., J. Izquierdo, N. G. Sandoval, and A. Bahmad (2000), Evolucion morfologica y estratigrafica plio-cuaternaria del Umbral de Camarinal (Estrecho de Gibraltar) basada en sondeos marinos, Rev. Soc. Geol. Espana, 13(3-4), 539-550.

Eynaud, F., et al. (2009), Position of the Polar Front along the western Iberian margin during key cold episodes of the last $45 \mathrm{ka}$, Geochem. Geophys. Geosyst., 10, Q07U05, doi:10.1029/ 2009GC002398.

Farmer, D. M., and L. Armi (1986), Maximal two-layer exchange over a sill and contraction with barotropic flow, J. Fluid Mech., 164, 53-76, doi:10.1017/S002211208600246X.

Farmer, D. M., and L. Armi (1988), The flow of Atlantic water through the Strait of Gibraltar, Prog. Oceanogr., 21, 1-105, doi:10.1016/0079-6611(88)90055-9.

Fasham, M. J. R., T. Platt, B. Irwin, and K. Jones (1985), Factors affecting the spatial pattern of the Deep Chrolophyll Maximum in the region of the Azores Front, in Essays on Oceanography:
A Tribute to John Swallow, edited by J. Crease et al., pp. 129166, Pergamon Press, Oxford, U. K.

Fauquette, S., J.-P. Suc, J. Guiot, F. Diniz, N. Feddi, Z. Zheng, E. Bessais, and A. Drivaliari (1999), Climate and biomes in the west Mediterranean area during the Pliocene, Palaeogeogr. Palaeoclimatol. Palaeoecol., 152(1-2), 15-36, doi:10.1016/S00310182(99)00031-0.

Ferguson, J. E., G. M. Henderson, M. Kucera, and R. E. M. Rickaby (2008), Systematic change of foraminiferal $\mathrm{Mg} / \mathrm{Ca}$ ratios across a strong salinity gradient, Earth Planet. Sci. Lett., 265(1-2), 153-166, doi:10.1016/j.epsl.2007.10.011.

Fernández, W., and R. D. Pingree (1996), Coupling between physical and biological fields in the North Atlantic subtropical front southeast of the Azores, Deep Sea Res., Part I, 43(9), 1369-1393, doi:10.1016/S0967-0637(96)00065-9.

Folkard, A. M., P. A. Davies, A. F. G. Fiúza, and I. Ambar (1997), Remotely sensed sea surface thermal patterns in the Gulf of Cadiz and the Strait of Gibraltar: Variability, correlations, and relationships with the surface wind field, J. Geophys. Res., 102(C3), 5669-5683, doi:10.1029/96JC02505.

Frigola, J., A. Moreno, I. Cacho, M. Canals, F. J. Sierro, J. A. Flores, and J. O. Grimalt (2008), Evidence of abrupt changes in Western Mediterranean Deep Water circulation during the last 50 ka: A high-resolution marine record from the Balearic Sea, Quat. Int., 181, 88-104, doi:10.1016/j.quaint.2007.06.016.

Gammelsrød, T. (1975), Instability of Couette flow in a rotating fluid and origin of Langmuir circulations, J. Geophys. Res., 80(36), 5069-5075, doi:10.1029/JC080i036p05069.

García, M., F. J. Hernández-Molina, E. Llave, D. A. V. Stow, R. León, M. C. Fernández-Puga, V. Diaz del Río, and L. Somoza (2009), Contourite erosive features caused by the Mediterranean Outflow Water in the Gulf of Cadiz: Quaternary tectonic and oceanographic implications, Mar. Geol., 257(1-4), 24-40, doi:10.1016/j.margeo.2008.10.009.

García-Castellanos, D., F. Estrada, I. Jiménez-Munt, C. Gorni, M. Fernàndez, J. Vergés, and R. De Vicente (2009), Catastrophic flood of the Mediterranean after the Messinian Salinity Crisis, Nature, 462(7274), 778-781, doi:10.1038/nature08555.

García Lafuente, J., J. Delgado, J. Miguel Vargas, M. Vargas, F. Plaza, and T. Sarhan (2002), Low-frequency variability of the exchanged flows through the Strait of Gibraltar during CANIGO, Deep Sea Res., Part II, 49(19), 4051-4067.

García Lafuente, J., A. Sánchez Román, G. Díaz del Río, G. Sannino, and J. C. Sánchez Garrido (2007), Recent observations of seasonal variability of the Mediterranean Outflow in the Strait of Gibraltar, J. Geophys. Res., 112, C10018, doi:10.1029/2009JC005496.

García Lafuente, J., J. Delgado, A. Sánchez Román, J. Soto, L. Carracedo, and G. Díaz del Río (2009), Interannual variability of the Mediterranean Outflow observed in Espartel Sill, western Strait of Gibraltar, J. Geophys. Res., 114, C10018, doi:10.1029/ 2009JC005496.

Garrett, C., M. Bormans, and K. Thompson (1990), Is the exchange through the Straits of Gibraltar maximal or sub-maximal, in The Physical Oceanography of Sea Straits, edited by L. J. Pratt, pp. 271-294, Kluwer, Boston, Mass.

Gasse, F., and E. van Campo (1994), Abrupt post-glacial climate events in west Asia and North Africa monsoon domains, Earth Planet. Sci. Lett., 126, 435-456, doi:10.1016/0012-821X(94) 90123-6.

Gherardi, J.-M., L. Labeyrie, J. F. McManus, R. Francois, L. C. Skinner, and E. Cortijo (2005), Evidence from the northeastern Atlantic basin for variability in the rate of the Meridional Overturning Circulation through the last deglaciation, Earth Planet. Sci. Lett., 240(3-4), 710-723, doi:10.1016/j.epsl.2005.09.061.

Gomis, D., M. N. Tsimplis, B. Martín-Míguez, A. W. Ratsimandresy, J. García-Lafuente, and S. A. Josey (2006), Mediterranean Sea level and barotropic flow through the Strait of Gibraltar for the 
period 1958-2001 and reconstructed since 1659, J. Geophys. Res., 111, C11005, doi:10.1029/2005JC003186.

Gould, W. J. (1985), Physical oceanography of the Azores Front, in Essays in Oceanography: A Tribute to John Swallow, edited by J. Crease et al., pp. 167-190, Pergamon Press, Oxford, U. K.

Haase-Schramm, A., S. L. Goldstein, and M. Stein (2004), U-Th dating of Lake Lisan (Late Pleistocene Dead Sea) aragonite and implications for glacial east Mediterranean climate change, Geochim. Cosmochim. Acta, 68(5), 985-1005, doi:10.1016/j. gca.2003.07.016.

Hall, I. R., S. B. Moran, R. Zahn, P. C. Knutz, C.-C. Shen, and R. L. Edwards (2006), Accelerated drawdown of meridional overturning in the late-glacial Atlantic triggered by transient pre-H event freshwater perturbation, Geophys. Res. Lett., 33, L16616, doi:10.1029/2006GL026239.

Hayes, A., M. Kucera, N. Kallel, L. Sbaffi, and E. J. Rohling (2005), Glacial Mediterranean sea surface temperatures based on planktonic foraminiferal assemblages, Quat. Sci. Rev., 24(7-9), 999-1016, doi:10.1016/j.quascirev.2004.02.018.

Hemming, S. R. (2004), Heinrich events: Massive Late Pleistocene detritus layers of the North Atlantic and their global climate imprint, Rev. Geophys., 42, RG1005, doi:10.1029/2003RG000128.

Hernández-Molina, J., et al. (2003), Looking for clues to palaeoceanographic imprints: A diagnosis of the Gulf of Cadiz contourite depositional systems, Geology, 31(1), 19-22, doi:10.1130/ 0091-7613(2003)031<0019:LFCTPI >2.0.CO;2.

Hilgen, F. J., L. Bissoli, S. Iaccarino, W. Krijgsman, R. Meijer, A. Negri, and G. Villa (2000), Integrated stratigraphy and astrochronology of the Messinian GSSP at Oued Akrech (Atlantic Morocco), Earth Planet. Sci. Lett., 182, 237-251, doi:10.1016/ S0012-821X(00)00247-8.

Hill, A. E., and E. G. Mitchelson-Jacob (1993), Observations of a poleward-flowing saline core on the continental slope west of Scotland, Deep Sea Res., Part I, 40(7), 1521-1527, doi:10.1016/ 0967-0637(93)90127-O.

Hoogakker, B. A. A., G. P. Klinkhammer, H. Elderfield, E. J. Rohling, and C. Hayward (2009), Mg/Ca paleothermometry in high salinity environments, Earth Planet. Sci. Lett., 284(3-4), 583-589, doi:10.1016/j.epsl.2009.05.027.

Iorga, M. C., and M. S. Lozier (1999), Signatures of the Mediterranean Outflow from a North Atlantic climatology: 1. Salinity and density fields, J. Geophys. Res. 104(C11), 25,985-26,009, doi:10.1029/ 1999JC900115.

Jia, Y. (2000), Formation of an Azores Current due to the Mediterranean Overflow in a modelling study of the North Atlantic, J. Phys. Oceanogr., 30, 2342-2358, doi:10.1175/1520-0485(2000) $030<2342$ :FOAACD $>2.0$. CO; .

Johnson, G. C., T. B. Sanford, and M. O’Neil Baringer (1994a), Stress on the Mediterranean Outflow plume: Part I. Velocity and water property measurements, J. Phys. Oceanogr., 24, 2072-2083, doi:10.1175/1520-0485(1994)024<2072:SOTMOP >2.0.CO;2.

Johnson, G. C., R. G. Lueck, and T. B. Sanford (1994b), Stress on the Mediterranean Outflow plume: Part II. Turbulent dissipation and shear measurements, J. Phys. Oceanogr., 24, 2084-2092, doi:10.1175/1520-0485(1994)024<2084:SOTMOP >2.0.CO;2.

Johnson, J., and I. Stevens (2000), A fine resolution model of the eastern North Atlantic between the Azores, the Canary Islands and the Gibraltar Strait, Deep Sea Res., Part I, 47, 875-899, doi:10.1016/S0967-0637(99)00073-4.

Käse, R. H., W. Zenk, T. B. Sanford, and W. Hiller (1985), Currents, fronts and eddy fluxes in the Canary Basin, Prog. Oceanogr., 14, 231-257, doi:10.1016/0079-6611(85)90013-8.

Kenyon, N. H., and R. H. Belderson (1973), Bed forms of the Mediterranean undercurrent observed with Side-Scan sonar, Sediment. Geol., 9, 77-99, doi:10.1016/0037-0738(73)90027-4.

Khélifi, N., M. Sarnthein, N. Andersen, T. Blanz, M. Frank, D. Garbe-Schönberg, B. A. Haley, R. Stumpf, and M. Weinelt (2009), A major and long-term Pliocene intensification of the Mediterranean Outflow, 3.5-3.3 Ma ago, Geology, 37(9), 811-814, doi:10.1130/G30058A.1.

Kida, S., J. F. Price, and J. Yang (2008), The upper-oceanic response to overflows: A mechanism for the Azores Current, J. Phys. Oceanogr., 38(4), 880-895, doi:10.1175/2007JPO3750.1.

Kinder, T. H., and H. L. Bryden (1990), Aspiration of deep waters through straits, in The Physical Oceanography of Sea Straits, edited by L. J. Pratt, pp. 295-319, Kluwer Acad., Dordrecht, Netherlands.

Kinder, T. H., and G. Parrilla (1987), Yes, some of the Mediterranean Outflow does come from great depth, J. Geophys. Res., 92(C3), 2901-2906, doi:10.1029/JC092iC03p02901.

Kinder, T. H., G. Parrilla, N. A. Bray, and D. A. Burns (1988), The hydrographic structure of the Strait of Gibraltar, in Seminario sobre la oceanografia fisica del Estrecho de Girbraltar, edited by J. L. Almazan et al., pp. 55-67, SECEG, Madrid.

Knorr, G., and G. Lohmann (2007), Rapid transitions in the Atlantic thermohaline circulation triggered by global warming and meltwater during the last deglaciation, Geochem. Geophys. Geosyst., 8, Q12006, doi:10.1029/2007GC001604.

Krijgsman, W., C. G. Langereis, W. J. Zachariasse, M. Boccaletti, G. Moratti, R. Gelati, S. Iaccarino, G. Papani, and G. Villa (1999), Late Neogene evolution of the Taza-Guercif Basin (Rifian Corridor, Morocco) and implications for the Messinian Salinity Crisis, Mar. Geol., 153(1-4), 147-160, doi:10.1016/S0025-3227(98) 00084-X.

Krijgsman, W., A. R. Fortuin, F. J. Hilgen, and F. J. Sierro (2001), Astrochronology for the Messinian Sorbas basin (SE Spain) and orbital (precessional) forcing for evaporite cyclicity, Sediment. Geol., 140(1-2), 43-60, doi:10.1016/S0037-0738(00)00171-8.

Kuhlemann, J., E. J. Rohling, I. Kumrei, P. Kubik, S. Ivy-Ochs, and M. Kucera (2008), Regional synthesis of Mediterranean atmospheric circulation during the Last Glacial Maximum, Science, 321(5894), 1338-1340, doi:10.1126/science.1157638.

Lacombe, H., and C. Richez (1982), The regime of the Strait of Gibraltar, in Hydrodynamics of Semienclosed Seas, edited by J. C. J. Nihoul, pp. 13-73, Elsevier, New York.

Legg, S., R. W. Hallberg, and J. B. Girton (2006), Comparison of entrainment in overflows simulated by $z$-coordinate, isopycnal and non-hydrostatic models, Ocean Modell., 11, 69, doi:10.1016/j.ocemod.2004.11.006.

Legg, S., et al. (2009), Improving oceanic overflow representation in climate models, Bull. Am. Meteorol. Soc., 90(5), 657-670, doi:10.1175/2008BAMS2667.1.

Lisiecki, L. E., and M. E. Raymo (2005), A PliocenePleistocene stack of 57 globally distributed benthic $\delta^{18} \mathrm{O}$ records, Paleoceanography, 20, PA1003, doi:10.1029/2004PA001071.

Llave, E., F. J. Hernández-Molina, L. Somoza, V. Díaz-del-Río, D. A. V. Stow, A. Maestro, and J. M. Alveirinho Dias (2001), Seismic stacking pattern of the Faro-Albufeira contourite system (Gulf of Cadiz): A Quaternary record of paleoceanographic and tectonic influences, Mar. Geophys. Res., 22(5-6), 487-508, doi:10.1023/A:1016355801344.

Llave, E., J. Schönfeld, F. J. Hernández-Molina, T. Mulder, L. Somoza, V. Díaz del Río, and I. Sánchez-Almazo (2006), High-resolution stratigraphy of the Mediterranean Outflow contourite system in the Gulf of Cadiz during the Late Pleistocene: The impact of Heinrich events, Mar. Geol., 227(3-4), 241-262, doi:10.1016/j.margeo.2005.11.015.

Llave, E., F. J. Hernandez-Molina, D. A. V. Stow, M. C. FernandezPuga, M. Garcia, J. T. Vazquez, A. Maestro, L. Somoza, and V. Diaz del Rio (2007), Reconstructions of the Mediterranean Outflow Water during the quaternary based on the study of changes in buried mounded drift stacking pattern in the Gulf of Cadiz, Mar. Geophys. Res., 28(4), 379-394, doi:10.1007/ s11001-007-9040-7.

Loget, N., and J. Van Den Driessche (2006), On the origin of the Strait of Gibraltar, Sediment. Geol., 188, 341-356, doi:10.1016/ j.sedgeo.2006.03.012. 
Loget, N., J. Van Den Driessche, and P. Davy (2005), How did the Messinian Salinity Crisis end?, Terra Nova, 17(5), 414-419, doi:10.1111/j.1365-3121.2005.00627.x.

Löwemark, L., J. Schönfeld, F. Werner, and P. Schäfer (2004), Trace fossils as a paleoceanographic tool: Evidence from Late Quaternary sediments of the southwestern Iberian margin, Mar. Geol., 204(1-2), 27-41, doi:10.1016/S0025-3227(03)00351-7.

Lozier, M. S., and N. M. Stewart (2008), On the temporally varying northward penetration of Mediterranean Overflow Water and eastward penetration of Labrador Sea water, J. Phys. Oceanogr., 38(9), 2097-2103, doi:10.1175/2008JPO3908.1.

Lynch-Stieglitz, J., et al. (2007), Atlantic Meridional Overturning Circulation during the Last Glacial Maximum, Science, 316(5821), 66-69, doi:10.1126/science. 1137127.

MARGO Project Members (2009), Constraints on the magnitude and patterns of ocean cooling at the Last Glacial Maximum, Nat. Geosci., 2, 127-132, doi:10.1038/ngeo411.

Matthiesen, S., and K. Haines (2003), A hydraulic box model study of the Mediterranean response to postglacial sea-level rise, Paleoceanography, 18(4), 1084, doi:10.1029/2003PA000880.

McManus, J. F., R. Francois, J.-M. Gherardi, L. D. Keigwin, and S. Brown-Leger (2004), Collapse and rapid resumption of Atlantic meridional circulation linked to deglacial climate changes, Nature, 428(6985), 834-837, doi:10.1038/nature02494.

MEDAR Group (2002), Medatlas 2002: Mediterranean and Black Sea Database of Temperature, Salinity and Biochemical Parameters-Climatological Atlas, IFREMER, Brest, France.

Mikolajewicz, U. (2011), Modelling Mediterranean ocean climate of the Last Glacial Maximum, Clim. Past, 7, 161-180, doi:10.5194/cp-7-161-2011.

Millot, C. (1999), Circulation in the western Mediterranean Sea, J. Mar. Syst., 20(1-4), 423-442, doi:10.1016/S0924-7963(98) 00078-5.

Millot, C. (2008), Short-term variability of the Mediterranean inand out-flows, Geophys. Res. Lett., 35, L15603, doi:10.1029/ 2008GL033762.

Millot, C. (2009), Another description of the Mediterranean Sea outflow, Prog. Oceanogr., 82(2), 101-124, doi:10.1016/j. pocean.2009.04.016.

Millot, C., J. Candela, J.-L. Fuda, and Y. Tber (2006), Large warming and salinification of the Mediterranean Outflow due to changes in its composition, Deep Sea Res., Part I, 53(4), 656-666, doi:10.1016/j.dsr.2005.12.017.

Mulder, T., et al. (2002), Studying past deep-ocean circulation and the palaeoclimate record in the Gulf of Cadiz, Eos Trans. AGU, 83(43), 481, doi:10.1029/2002EO000337.

Myers, P. G. (2002), Flux-forced simulations of the palaeocirculation of the Mediterranean, Paleoceanography, 17(1), 1009, doi:10.1029/2000PA000613.

Myers, P. G., K. Haines, and E. J. Rohling (1998), Modeling the paleocirculation of the Mediterranean: The Last Glacial Maximum and the Holocene with emphasis on the formation of sapropel $\mathrm{S}_{1}$, Paleoceanography, 13(6), 586-606, doi:10.1029/98PA02736.

Nelson, C. H., J. Baraza, and A. Maldonado (1993), Mediterranean undercurrent sandy contourites, Gulf of Cadiz, Spain, Sediment. Geol., 82, 103-131, doi:10.1016/0037-0738(93)90116-M.

Nelson, C. H., J. Baraza, A. Maldonado, J. Rodero, C. Escutia, and J. H. Barber Jr. (1999), Influence of the Atlantic Inflow and Mediterranean Outflow currents on Late Quaternary sedimentary facies of the Gulf of Cadiz continental margin, Mar. Geol., 155, 99-129, doi:10.1016/S0025-3227(98)00143-1.

New, A. L., S. Barnard, P. Herrmann, and J.-M. Molines (2001), On the origin and pathway of the saline inflow to the Nordic Seas: Insights from models, Prog. Oceanogr., 48(2-3), 255-287, doi:10.1016/S0079-6611(01)00007-6.

O'Neill-Baringer, M., and J. F. Price (1997), Mixing and spreading of the Mediterranean Outflow, J. Phys. Oceanogr., 27, 1654-1677, doi:10.1175/1520-0485(1997)027<1654:MASOTM>2.0.CO;2.
O’Neill-Baringer, M., and J. F. Price (1999), A review of the physical oceanography of the Mediterranean Outflow, Mar. Geol., 155, 63-82, doi:10.1016/S0025-3227(98)00141-8.

Osborne, A. H., D. Vance, E. J. Rohling, N. Barton, M. Rogerson, and N. Fello (2008), A humid corridor across the Sahara for the migration of early modern humans out of Africa 120,000 years ago, Proc. Natl. Acad. Sci. U. S. A., 105, 16,444-16,447, doi:10.1073/pnas.0804472105.

Özgökmen, T. M., E. P. Chassignet, and C. G. H. Rooth (2001), On the connection between the Mediterranean Outflow and the Azores Current, J. Phys. Oceanogr., 31, 461-480, doi:10.1175/ 1520-0485(2001)031<0461:OTCBTM>2.0.CO;2.

Park, J., and K. A. Maasch (1993), Plio-Pleistocene time evolution of the 100-kyr cycle in marine paleoclimate records, J. Geophys. Res., 98(B1), 447-461, doi:10.1029/92JB01815.

Peliz, A., P. Marchesiello, A. M. P. Santos, J. Dubert, A. TelesMachado, M. Marta-Almeida, and B. Le Cann (2007), Surface circulation in the Gulf of Cadiz: Model and mean flow structure, J. Geophys. Res., 112, C11015, doi:10.1029/2007JC004159.

Peltier, W. R., G. Vettoretti, and M. Stastna (2006), Atlantic meridional overturning and climate response to Arctic Ocean freshening, Geophys. Res. Lett., 33, L06713, doi:10.1029/2005GL025251.

Penaud, A., F. Eynaud, J. L. Turon, D. Blamart, L. Rossingol, F. Marret, C. Lopez-Martinez, J. O. Grimalt, B. Malaizé, and K. Charlier (2010), Contrasting paleoceanographic conditions off Morocco during Heinrich events (1 and 2) and the Last Glacial Maximum, Quat. Sci. Rev., 29, 1923-1939, doi:10.1016/ j.quascirev.2010.04.011.

Pettigrew, N. R. (1989), Direct measurements of the flow of Western Mediterranean Deep Water over the Gibraltar Sill, J. Geophys. Res., 94(C12), 18,089-18,093, doi:10.1029/JC094iC12p18089.

Plewa, K., H. Meggers, and S. Kasten (2006), Barium in sediments off northwest Africa: A tracer for paleoproductivity or meltwater events?, Paleoceanography, 21, PA2015, doi:10.1029/ 2005PA001136.

Pollard, R. T., and S. Pu (1985), Structure and circulation of the upper Atlantic Ocean north-east of the Azores, in Essays on Oceanography: A Tribute to John Swallow, edited by J. Crease et al., pp. 443-463, Pergamon Press, Oxford, U. K.

Price, J. F., and M. O'Neill-Baringer (1994), Outflows and deep water production by marginal seas, Prog. Oceanogr., 33, 161-200, doi:10.1016/0079-6611(94)90027-2.

Price, J. F., and J. Y. Yang (1998), Marginal sea overflows for climate simulations, in Ocean Modeling and Parameterization, edited by E. P. Chassignet and J. Verron, pp. 155-170, Springer, Dordrecht, Netherlands.

Raddatz, J., A. Rüggeberg, S. Margreth, W.-C. Dullo, and the IODP Expedition 307 Scientific Party (2011), Paleoenvironmental reconstruction of Challenger Mound initiation in the Porcupine Seabight, NE Atlantic, Mar. Geol., 282(1-2), 79-90, doi:10.1016/j. margeo.2010.10.019.

Rahmstorf, S. (1998), Influence of Mediterranean Outflow on climate, Eos Trans. AGU, 79(24), 281, doi:10.1029/98EO00208.

Raymo, M. E., L. E. Lisiecki, and K. H. Nisancioglu (2006), Plio-Pleistocene ice volume, Antarctic climate, and the global $\delta^{18} \mathrm{O}$ record, Science, 313(5786), 492-495, doi:10.1126/science. 1123296

Reid, J. L. (1979), On the contribution of the Mediterranean Sea outflow to the Norwegian-Greenland Sea, Deep Sea Res., Part A, 26, 1199-1223.

Revel, M., E. Ducassou, F. E. Grousset, S. M. Bernasconi, S. Migeon, S. Revillon, J. Mascle, A. Murat, S. Zaragosi, and D. Bosch (2010), 100,000 years of African monsoon variability recorded in sediments of the Nile margin, Quat. Sci. Rev., 29(11-12), 1342-1362, doi:10.1016/j.quascirev.2010.02.006

Roberts, N., et al. (2008), Stable isotope records of Late Quaternary climate and hydrology from Mediterranean lakes: The ISOMED synthesis, Quat. Sci. Rev., 27(25-26), 2426-2441, doi:10.1016/ j.quascirev.2008.09.005. 
Rodero, J., L. Pallarés, and A. Maldonado (1999), Late Quaternary seismic facies of the Gulf of Cadiz Spanish margin: Depositional processes influenced by sea-level change and tectonic controls, Mar. Geol., 155, 131-156, doi:10.1016/S0025-3227(98)00144-3.

Rogerson, M., E. J. Rohling, P. P. E. Weaver, and J. W. Murray (2004), The Azores Front since the Last Glacial Maximum, Earth Planet. Sci. Lett., 222, 779-789, doi:10.1016/j.eps1.2004.03.039.

Rogerson, M., E. J. Rohling, P. P. E. Weaver, and J. W. Murray (2005), Glacial to interglacial changes in the settling depth of the Mediterranean Outflow plume, Paleoceanography, 20, PA3007, doi:10.1029/2004PA001106.

Rogerson, M., E. J. Rohling, and P. P. E. Weaver (2006a), Promotion of meridional overturning by Mediterranean-derived salt during the last deglaciation, Paleoceanography, 21, PA4101, doi:10.1029/2006PA001306.

Rogerson, M., P. P. E. Weaver, E. J. Rohling, L. J. Lourens, J. W. Murray, and A. Hayes (2006b), Colour logging as a tool in highresolution palaeoceanography, Geol. Soc. Spec. Publ., 267, 99-112, doi:10.1144/GSL.SP.2006.267.01.07.

Rogerson, M., I. Cacho, F. Jimenez-Espejo, M. I. Reguera, F. J. Sierro, F. Martinez-Ruiz, J. Frigola, and M. Canals (2008), A dynamic explanation for the origin of the western Mediterranean organic rich layers, Geochem. Geophys. Geosyst., 9, Q07U01, doi:10.1029/2007GC001936.

Rogerson, M., et al. (2010), Enhanced Mediterranean-Atlantic exchange during Atlantic freshening phases, Geochem. Geophys. Geosyst., 11, Q08013, doi:10.1029/2009GC002931.

Rogerson, M., J. Schönfeld, and M. J. Leng (2011), Qualitative and quantitative approaches in palaeohydrography: A case study from core-top parameters in the Gulf of Cadiz, Mar. Geol., 280, 150-167, doi:10.1016/j.margeo.2010.12.008.

Rogerson, M., et al. (2012), North Atlantic density gradients since the Last Glacial Maximum, Clim. Dyn., doi:10.1007/s0038200011-01148-00384, in press.

Rohling, E. J. (1994), Review and new aspects concerning the formation of eastern Mediterranean sapropels, Mar. Geol., 122(1-2), 1-28, doi:10.1016/0025-3227(94)90202-X

Rohling, E. J. (1999), Environmental control on Mediterranean salinity and $\delta^{18} \mathrm{O}$, Paleoceanography, 14(6), 706-715, doi:10.1029/ 1999PA900042.

Rohling, E. J. (2007), Progress in paleosalinity: Overview and presentation of a new approach, Paleoceanography, 22, PA3215, doi:10.1029/2007PA001437.

Rohling, E. J., and H. L. Bryden (1994), Estimating past changes in the eastern Mediterranean fresh-water budget, using reconstructions of sea level and hydrography, Proc. K. Ned. Akad. van Wetenschappen, Ser. B, 97(2), 201-217.

Rohling, E. J., M. Den Dulk, C. Pujol, and C. Vergnaud-Grazzini (1995), Abrupt hydrographic change in the Alboran Sea (western Mediterranean) around 8000 yrs BP, Deep Sea Res., Part I, 42(9), 1609-1619.

Rohling, E. J., A. Hayes, S. De Rijk, D. Kroon, W. J. Zachariasse, and D. Eisma (1998), Abrupt cold spells in the northwest Mediterranean, Paleoceanography, 13(4), 316-322.

Rohling, E. J., et al. (2002), African monsoon variability during the previous interglacial maximum, Earth Planet. Sci. Lett., 202(1), 61-75, doi:10.1016/S0012-821X(02)00775-6.

Rohling, E. J., et al. (2004), Reconstructing past planktic foraminiferal habitats using stable isotope data: A case history for Mediterranean sapropel S5, Mar. Micropaleontol., 50(1-2), 89-123, doi:10.1016/S0377-8398(03)00068-9.

Rohling, E. J., K. Grant, C. Hemleben, M. Kucera, A. P. Roberts, I. Schmeltzer, H. Schulz, M. Siccha, M. Siddall, and G. Trommer (2008a), New constraints on the timing and amplitude of sea level fluctuations during Marine Isotope Stage 3, Paleoceanography, 23, PA3219, doi:10.1029/ 2008PA001617.

Rohling, E. J., R. Schiebel, and M. Siddall (2008b), Controls on Messinian lower evaporite cycles in the Mediterranean, Earth
Planet. Sci. Lett., 275(1-2), 165-171, doi:10.1016/j.epsl.2008b. 08.022.

Rohling, E. J., K. Grant, M. Bolshaw, A. P. Roberts, M. Siddall, C. Hemleben, and M. Kucera (2009), Antarctic temperature and global sea level closely coupled over the past five glacial cycles, Nat. Geosci., 2(7), 500-504, doi:10.1038/ngeo557.

Rudnick, D. L. (1996), Intensive surveys of the Azores Front: 2. Inferring the geostrophic and vertical velocity fields, J. Geophys. Res., 101(C7), 16,291-16,303, doi:10.1029/96JC01144.

Sannino, G., A. Carillo, and V. Artale (2007), Three-layer view of transports and hydraulics in the Strait of Gibraltar: A three-dimensional model study, J. Geophys. Res., 112, C03010, doi:10.1029/2006JC003717.

Sannino, G., L. Pratt, and A. Carillo (2009), Hydraulic criticality of the exchange flow through the Strait of Gibraltar, J. Phys. Oceanogr., 39(11), 2779-2799, doi:10.1175/2009JPO4075.1.

Schiebel, R., B. Schmuker, M. Alves, and C. Hemleben (2002a), Tracking the Recent and Late Pleistocene Azores Front by the distribution of planktic foraminifers, J. Mar. Syst., 37, 213-227, doi:10.1016/S0924-7963(02)00203-8

Schiebel, R., J. Waniek, A. Zeltner, and M. Alves (2002b), Impact of the Azores Front on the distribution of planktic foraminifers, shelled gastropods and coccolithophorids, Deep Sea Res., Part II, 49, 4035-4050, doi:10.1016/S0967-0645(02) 00141-8.

Schönfeld, J. (2002), A new benthic foraminiferal proxy for nearbottom current velocities in the Gulf of Cadiz, northeastern Atlantic Ocean, Deep Sea Res., Part I, 49(10), 1853-1875, doi:10.1016/S0967-0637(02)00088-2.

Schönfeld, J., and R. Zahn (2000), Late Glacial to Holocene history of the Mediterranean Outflow. Evidence from benthic foraminiferal assemblages and stable isotopes at the Portuguese margin, Palaeogeogr. Palaeoclimatol. Palaeoecol., 159(1-2), 85-111, doi:10.1016/S0031-0182(00)00035-3.

Scrivner, A. E., D. Vance, and E. J. Rohling (2004), New neodymium isotope data quantify Nile involvement in Mediterranean anoxic episodes, Geology, 32(7), 565-568, doi:10.1130/ G20419.1.

Seim, H. E., and M. C. Gregg (1997), The importance of aspiration and channel curvature in producing strong vertical mixing over a sill, J. Geophys. Res., 102(C2), 3451-3472, doi:10.1029/ 96JC03415

Siddall, M., E. J. Rohling, A. Almogi-Labin, C. Hemleben, D. Meischner, I. Schmelzer, and D. A. Smeed (2003), Sea-level fluctuations during the last glacial cycle, Nature, 423(6942), 853-858, doi:10.1038/nature01690.

Siddall, M., E. J. Rohling, W. G. Thompson, and C. Waelbroeck (2008), Marine Isotope Stage 3 sea level fluctuations: Data synthesis and new outlook, Rev. Geophys., 46, RG4003, doi:10.1029/2007RG000226.

Sierro, F. J., et al. (1993), Late Miocene globorotaliid event-stratigraphy and biogeography in the NE Atlantic and Mediterranean, Mar. Micropaleontol., 21, 143-167, doi:10.1016/0377-8398(93) 90013-N

Sierro, F. J., et al. (2005), Impact of iceberg melting on Mediterranean thermohaline circulation during Heinrich events, Paleoceanography, 20, PA2019, doi:10.1029/2004PA001051.

Skinner, L. C., and H. Elderfield (2007), Rapid fluctuations in the deep North Atlantic heat budget during the last glacial period, Paleoceanography, 22, PA1205, doi:10.1029/2006PA001338.

Stanford, J. D., E. J. Rohling, S. E. Hunter, A. P. Roberts, S. O. Rasmussen, E. Bard, J. McManus, and R. G. Fairbanks (2006), Timing of Meltwater Pulse 1a and climate responses to meltwater injections, Paleoceanography, 21, PA4103, doi:10.1029/ 2006PA001340.

Stanford, J. D., et al. (2011), A new concept for the paleoceanographic evolution of Heinrich event 1 in the North Atlantic, Quat. Sci. Rev., 30(9-10), 1047-1066, doi:10.1016/j.quascirev. 2011.02.003. 
Stanford, J. D., R. Hemingway, E. J. Rohling, P. G. Challenor, M. Medina-Elizalde, and A. J. Lester (2012), Sea-level probability for the last deglaciation: A statistical analysis of far-field records, Global Planet. Change, 79(3-4), 193-203, doi:10.1016/j.gloplacha. 2010.1011.1002.

Stommel, H., H. Bryden, and P. Mangelsdorf (1973), Does some of the Mediterranean Outflow come from great depth?, Pure Appl. Geophys., 105, 879-889, doi:10.1007/BF00875837.

Stow, D. A. V., J.-C. Faugères, and E. Gonthier (1986), Facies distribution and textural variation in Faro Drift contourites: Velocity fluctuation and drift growth, Mar. Geol., 72, 71-100, doi:10.1016/0025-3227(86)90100-3.

Stumpf, R., M. Frank, J. Schönfeld, and B. A. Haley (2010), Late Quaternary variability of Mediterranean Outflow Water from radiogenic $\mathrm{Nd}$ and $\mathrm{Pb}$ isotopes, Quat. Sci. Rev., 29(19-20), 2462-2472, doi:10.1016/j.quascirev.2010.06.021.

Suc, J. P. (1984), Origin and evolution of the Mediterranean vegetation and climate in Europe, Nature, 307, 429-432, doi:10.1038/ 307429a0.

Thornalley, D. J. R., I. N. McCave, and H. Elderfield (2010), Freshwater input and abrupt deglacial climate change in the North Atlantic, Paleoceanography, 25, PA1201, doi:10.1029/2009PA001772.

Thorpe, S. A. (1976), Variability of the Mediterranean undercurrent in the Gulf of Cadiz, Deep Sea Res., Part A, 23, 711-727.

Toucanne, S., T. Mulder, J. Schönfeld, V. Hanquiez, E. Gonthier, J. Duprat, M. Cremer, and S. Zaragosi (2007), Contourites of the Gulf of Cadiz: A high-resolution record of the paleocirculation of the Mediterranean Outflow Water during the last 50,000 years, Palaeogeogr. Palaeoclimatol. Palaeoecol., 246(2-4), 354-366, doi:10.1016/j.palaeo.2006.10.007.

Tsimplis, M. N., and H. L. Bryden (2000), Estimation of the transports through the strait of Gibraltar, Deep Sea Res., Part I, 47, 2219-2242, doi:10.1016/S0967-0637(00)00024-8.
Tzedakis, P. C. (2007), Seven ambiguities in the Mediterranean palaeoenvironmental narrative, Quat. Sci. Rev., 26(17-18), 2042-2066, doi:10.1016/j.quascirev.2007.03.014.

Vargas, J. M., J. García-Lafuente, J. Candela, and A. J. Sánchez (2006), Fortnightly and monthly variability of the exchange through the Strait of Gibraltar, Prog. Oceanogr., 70(2-4), 466-485, doi:10.1016/j.pocean.2006.07.001.

Voelker, A. H. L., S. M. Lebreiro, J. Schönfeld, I. Cacho, H. Erlenkeuser, and F. Abrantes (2006), Mediterranean Outflow strengthening during Northern Hemisphere coolings: A salt source for the glacial Atlantic?, Earth Planet. Sci. Lett., 245(1-2), 39-55, doi:10.1016/j.eps1.2006.03.014.

Watkins, S. J., B. A. Maher, and G. R. Bigg (2007), Ocean circulation at the Last Glacial Maximum: A combined modeling and magnetic proxy-based study, Paleoceanography, 22, PA2204, doi:10.1029/ 2006PA001281.

Weber, S. L., S. S. Drijfhout, A. Abe-Ouchi, M. Curcifix, M. Eby, A. Ganopolski, S. Murakami, B. Otto-Bliesner, and W. R. Peltier (2007), The modern and glacial overturning circulation in the Atlantic Ocean in PMIP coupled model simulations, Clim. Past, 3(1), 51-64, doi:10.5194/cp-3-51-2007.

Wu, W., G. Danabasoglu, and W. G. Large (2007), On the effects of parameterized Mediterranean Overflow on North Atlantic ocean circulation and climate, Ocean Modell., 19(1-2), 31-52, doi:10.1016/j.ocemod.2007.06.003.

Zenk, W. (1975), On the origin of the intermediate double-maxima in T/S profile from the North Atlantic, Meteor Forschungsergeb., $16,35-43$.

Zenk, W., and L. Armi (1990), The complex spreading pattern of Mediterranean water off the Portuguese continental slope, Deep Sea Res., Part A, 37(12), 1805-1823, doi:10.1016/0198-0149 (90)90079-B.

Zodiatis, G., and G. P. Gasparini (1996), Thermohaline staircase formations in the Tyrrhenian Sea, Deep Sea Res., Part I, 43(5), 655, doi:10.1016/0967-0637(96)00032-5. 